\title{
THE ROLE OF /OVERLAPS IN INTERCULTURAL WORKPLACE INTERACTION
}

\author{
By \\ Mariana Lazzaro Salazar
}

\begin{abstract}
A Thesis
Submitted to the Victoria University of Wellington in Fulfilment of the Requirements for the Degree of Master in Applied Linguistics
\end{abstract}

School of Linguistics and Applied Language Studies

Victoria University of Wellington

2009 


\begin{abstract}
The field of workplace communication continues to grow, and globalisation has encouraged researchers to focus on the phenomenon of intercultural interaction in multicultural workplaces. Usually, but not exclusively, framed within the constructs of Brown and Levinson's Politeness Theory, intercultural studies have typically concentrated on instances of miscommunication taking a partial, one-sided account of intercultural workplace interaction. Differing social norms for what constitutes politeness have been a major focus of debate into the merits of politeness theory. Overlapping speech, in particular, is one aspect of workplace interaction that has been long neglected in the field of intercultural workplace interaction research. Moving away from the traditional views in the field, the present study takes a positive stance on the study of the interplay of interactional norms of politeness in intercultural face-to-face workplace interaction and investigates how people from different ethnic backgrounds undertake relational work in naturally-occurring workplace exchanges. As the analytic framework, rapport management (developed by Spencer-Oatey) provides a useful reconceptualisation of linguistic politeness with a greater focus on negotiated interaction. The analysis focuses on the role of overlapping speech in this context of interaction guided by two research questions: 1) how does overlapping speech function in workplace interactions in New Zealand? and 2) how are these overlaps intended and 'perceived' by culturally different interactants? To this end, the data for the present study were drawn from two meetings in a large educational institution in New Zealand. In the first phase of data collection, two meetings were video and audio recorded, from which representative extracts containing overlaps were chosen for analysis. In the second phase, individual stimulated recall interviews were held with the participants with the purpose of eliciting participants' intentions and perceptions regarding the use of overlaps. The findings suggest that this group of instructors operate as a Community of Practice (CofP) rather than as ethnic individualities with shared assumptions and expectations regarding the appropriate use of overlaps to cooperatively construct meaning in interaction. This CofP, it was noted, is also strongly oriented towards the maintenance and enhancement of social harmony in their workplace interaction, which influences the use of overlapping speech as a communicative strategy employed to this end. Overall, the study demonstrates that considering intercultural communication from the perspective of rapport management can provide positive insights into how people from different ethnic backgrounds do relational work as they construct meaning in interaction.
\end{abstract}




\section{List of contents}

Pag

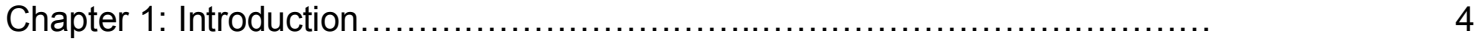

1.1 Introduction.................................................. 4

1.2 The purpose of the study........................................

1.3 Overview of chapters..........................................

Chapter 2: Simultaneous speech............................................ 9

2.1 Introduction to simultaneous speech............................. 9

2.2 Interruptions: functions............................................

2.3 Classifications of interruptions....................................

2.4 Overlaps in workplace context....................................

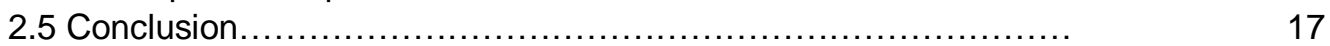

Chapter 3: Theoretical framework: Politeness................................

3.1 Politeness Theory: some considerations............................ 18

3.2 Rapport Management.......................................... 21

3.3 Investigating politeness in the workplace......................... 24

3.4 Interactional context of studies of overlapping speech.............. 26

3.5 Summary...................................................

Chapter 4: Design and analysis of the research study .......................... 29

4.1 Phase 1: collecting meetings' data................................ 30

4.2 Selection of extracts..............................................

4.3 Phase 2: collecting participants' perceptions..................... 33

4.4 Methodological considerations................................

4.5 Ethical considerations.......................................... 36

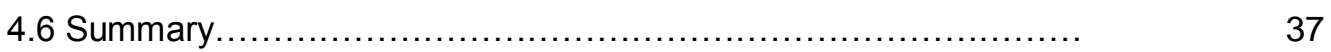

Chapter 5 - Analysis and discussion........................................ 38

5.1 Discussion: analyst's perspective on overlapping speech............ 39

5.2 Discussion....................................................... 54

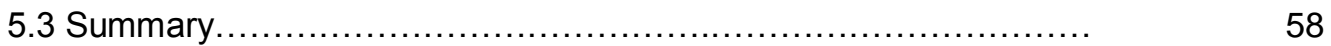

Chapter 6 - An Emic Discussion.............................................. 60

6.1 Introduction...................................................

6.2 Speakers' intentions when using overlapping speech............... 61

6.3 Speakers' perceptions of the use of overlaps....................... 65

6.4 Summary..............................................................

6.5 What constitutes interruptive behaviour...........................

6.6 Conclusion.......................................................

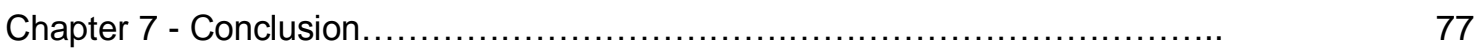

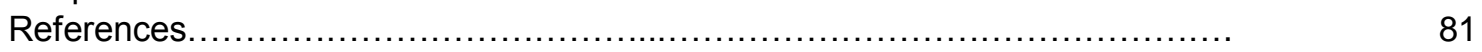

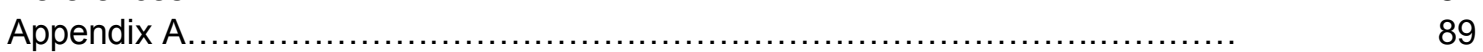

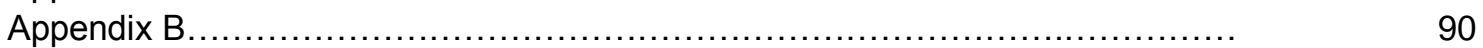

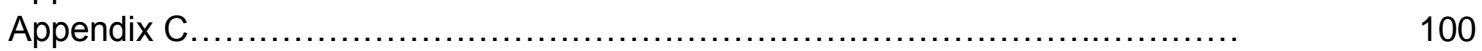

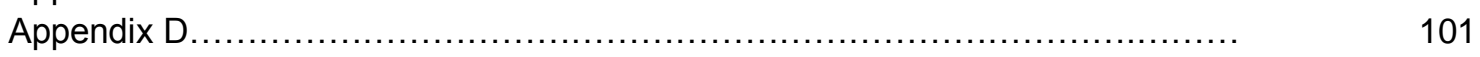

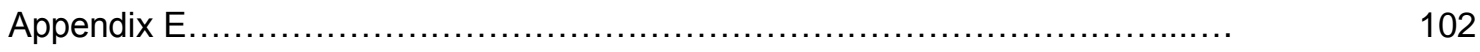




\section{Chapter 1: Introduction}

\subsection{Introduction}

For a country such as New Zealand where every year an increasing number of people from around the world decide to settle and start a new life (www.stats.govt.nz, for statistics), a discussion about how people from different ethnic backgrounds do relational work in face-to-face workplace interaction seems timely. With the aim of providing illuminating insights into this discussion, the present study focuses on the role of overlapping speech in naturally-occurring intercultural workplace interaction.

Traditionally, in the field of sociolinguistics, overlaps have been the centre of attention when investigating turn-taking violations, with overlaps being seen as a means of seizing turns and dominating talk (see Murata, 1994; Ng et al., 1995; Zimmerman and West, 1975). Clyne (1996), for example, examines interruptions within what he terms 'turn appropriating' devices as "the classic case of competition for control of the "floor" (1996: 95) which, as he argues, is prone to cause communication breakdowns. Because many researchers have interpreted interruptions, both inter and intra-culturally, as a sign of asymmetry in conversations, most instances of overlaps have been analysed in terms of conversation dominance, that is to say, power (for a discussion of related studies see Talbot, 1998; Coates, 1993; Li, 2001). For instance, Talbot (1998) explored interruptions in jointly constructed narratives in family interactions in relation to how power is wielded in couples. Studies comparing men and women's use of interruptions made a case for discussing the construction of male-dominant roles, which has also become popular in the literature (Talbot, 1998; Coates, 1993).

Other researchers have put more emphasis on a more balanced view on interruptions focusing of overlaps as they occur in some speech acts ( $\mathrm{Ng}$ et al., 1995; Stubbe, 1991; Coates, 1996). This has given rise to a number of distinctions resulting in the classification of overlaps as disruptive, i.e. when they have "the potential to disrupt the addressee's turn" (Stubbe, 1991: 56), and collaborative or supportive (Li et al., 2005; Li, 2008, Kitzinger, 2008), i.e. when they are intended to contribute to talk (e.g.: minimal responses, agreeing and supporting claims), for instance. This view of overlaps enables 
the researcher to consider the role of overlapping speech within its context of interaction. In doing this, it is possible to regard the interplay of the contextual factors of interaction, such as expectations and interactional setting, with the use of overlapping speech as an interactional strategy to achieve a given communicational goal (Furo, 2001; Liddicoat, 2007).

Of particular interest to this study is the role of overlapping speech in workplace interaction where they have most often been considered interruptions as disruptive. The few studies concerning interruptions in the workplace are gender-related and they focus on their ability to be employed as a strategy to wield power in conversation (see Tannen, 1994). In addition, Heritage (2005) explores the structures governing the turn-taking system in institutional talk and maintains that these structures are fixed and systematic, which discards the role of contextual factors of interaction in overlapping speech. Moreover, even though some researchers have come a long way in exploring the cooperative function of interruptions over the last two decades, these studies do not explore how interruptions are used and perceived when people of different ethnic backgrounds engage in naturally-occurring interaction (see Murata, 1994; Karakowsky et al., 2004; cf. Li, 2001). In other words, studies of overlapping speech have not so far informed workplace research in the field of intercultural communication, which is defined by Gudykunst (in Spencer-Oatey 2000: 314) as the kind of research that "involves examining behaviour when members of two or more cultures interact." In fact, most of the studies in this field have traditionally restricted their examination to intracultural and/or crosscultural interaction. That is to say, the majority of these studies have explored interactional features in monocultural settings or drawn comparisons from interactional features noticed across cultures which have not (usually) interacted face to face (cf. Schnurr et al., 2007; Kerbrat-Orecchioni, 2005).

The recent impact the phenomenon of globalization has had on the construction of institutional relations has prompted a shift in interest favouring the growth of a body of studies in multicultural settings (see Marra and Holmes, 2007). In a world governed by this global orientation, organisations have become the host of an increasing number of immigrants from around the world (Harris et al., 2004). These immigrants bring their 
own 'culture' with them. Spencer-Oatey (2000: 4) defines culture as "a fuzzy set of attitudes, beliefs, behavioural conventions and basic assumptions and values" which will in turn influence other people's behaviour and "interpretations of the 'meaning' of other people's behaviour." These culturally-driven assumptions and expectations are thought to shape the management of the face system, that is to say what people perceive to be polite or impolite behaviour, in business encounters (Scollon and Scollon, 2001). As a consequence, a person's expectations about how a meeting, for instance, should proceed so that it observes the face needs of its participants will presumably vary according to whether that person comes from an Asian or a European background (see Scollon and Scollon, 2001). Although the influence of culture remains relatively underexplored in the field (Bargiela-Chiappini and Nickerson, 2003), understanding how people from different ethnic backgrounds interact in face-to-face encounters becomes paramount, especially if harmonious work relations and interactions are the goal.

For the present study it is of upmost importance to regard intercultural communication from a comprehensive point of view to evaluate the role of overlapping speech in intercultural workplace communication more thoroughly. Unfortunately, to date, most of those researchers who have focused on intercultural communication have been concerned with the role of cultural discrepancies in communication (see Boxer 2002; Günthner, 2007). Most have focused on how cultural differences work when there is a violation of pragmatic norms causing failure in communication, what Boxer (2002) calls "infelicitous interaction". Clyne (1996), for instance, explored the workings of a number of speech acts in intercultural interaction and concentrated his analysis on miscommunication arising from the 'incorrect' use of certain speech acts. In addition, Günthner (2008) studied culturally specific expectations of communication and the effect of different social conventions on the construction and maintenance of rapport (related to social relationships) in German-Chinese university students' conversations. It is only recently that researchers have endeavoured to do justice to cultural differences showing that there could actually be 'felicitous' intercultural interaction (see Hickey and Stewart 2005; Marra and Holmes, 2007). 


\subsection{The purpose of the study}

The aim of this study, therefore, is to discuss politeness as an aspect of communication which has been particularly unfairly regarded within the field of intercultural interaction. Rather than focussing on miscommunication, the goal of this study is to take a positive stance on the interplay of interactional norms of politeness in intercultural face-to-face workplace interaction. Consequently, applying a framework of analysis that could explore the interplay of context and social norms of interaction to the study of overlapping speech in intercultural workplace communication has the potential to advance a more comprehensive understanding of interactional phenomena in workplace interaction. Drawing on research both on politeness theory (Brown and Levinson, 1978, 1987, 1994) and rapport management (Spencer-Oatey, 2000, 2008) makes it possible to analyse overlapping speech in naturally-occurring workplace interaction from a positive perspective in intercultural interactions. These frameworks of analysis provide the tools to consider how relational work is done through the use of overlapping speech. Applying these frameworks, the role of overlapping speech will be analysed in interactions among members of a multicultural workplace in New Zealand. Moreover, adopting the stance that overlapping speech is dialogically constructed and an interpretative category in that the role of overlapping speech depends on the participants' perceptions (Furo, 2001), this study also aims to describe interactants' perceptions of overlapping speech in naturally-occurring workplace interaction.

\subsection{Overview of chapters}

Chapter 2 reviews the history of overlapping speech taking into account its structural and functional definitions and classifications.

Chapter 3 outlines relevant issues of Politeness Theory as a starting point to understand the theoretical frameworks of rapport-management, as proposed by SpencerOatey $(2000,2008)$ and relational work, as proposed by Watts and Locher (2005). These two analytical frameworks will subsequently serve as the lense through which the role of overlapping speech in intercultural face-to-face workplace interaction will be explored. 
To collect data in naturally-occurring workplace interaction two meetings were recorded and individual stimulated recall interviews were held after the meeting to elicit participants' perceptions of the role of overlapping speech, as discussed in chapter 4.

Chapters 5 and 6 explore the role of overlapping speech in intercultural workplace interaction from two perspectives. Chapter 5 presents the researcher's analysis of instances of overlapping speech drawing on interviews held with the participants, chapter 6 discusses participants' intentions when using overlaps and perceptions of the role of overlapping speech in the two meetings recorded.

Finally, chapter 7 offers some concluding remarks regarding the collaborative role of overlapping speech in the construction of rapport and management of face in intercultural workplace interaction. 


\section{Chapter 2: Simultaneous speech}

Overlapping speech is a noticeable feature of communication that participants use to interactionally construct conversation (see Liddicoat, 2007). In order to discuss the role and the perceptions of overlapping speech in intercultural communication, it is necessary to review the definitions encompassed in the phrase overlapping speech, or also simultaneous speech, and to consider how the views on interruptions have evolved over the years. The aim of this chapter then is to address these two points.

\subsection{Introduction to Simultaneous Speech}

To regard the phenomenon of simultaneous speech in detail, an obvious starting place is the prevailing model of conversational interaction which is rooted in Sacks' et al. (1974, in Zimmerman and West, 1975) model of speech exchange. This model outlines the principles of the sequencing of talk, the most salient of which dictates that social interaction is governed by a turn-taking mechanism. In the turn-taking mechanism model, Sacks et al. argue that a turn consists of the temporal duration of an utterance as well as of the right to speak, and it is constructed by a unit-type which could be a word, a phrase, clause or sentence (1975). The nature of the turns varies and so do their size, content and distribution according to the context of interaction. As a consequence, the turn-taking mechanism will be adapted to fit the social context depending on, for instance, whether a child is speaking to their teacher as opposed to when they are speaking to their mother. It follows that the turn-taking mechanism is systematic and it abides by an ordered set of rules that shape the smooth flow of conversation as speakers allocate and are allocated a turn in an orderly way (1975; Heritage, 2005). Thus, the current speaker may select the next speaker by yielding the floor of interaction, or a listener may self-select him/herself as the next speaker.

The 'proper' implementation of the turn-taking rules, however, presupposes that no two speakers speak at the same time (Mills, 1995) and that a speaker will seize a turn only when he/she identifies the right speaker-transition cues in the conversation $(\mathrm{Li}$, 
2001). So, for example, a speaker may take the floor when the previous speaker's pitch goes down signalling he/she has finished his/her turn. As a result, Zimmerman and West (1975: 114) suggest that in this model the appropriate use of the turn-taking rules signals competent listenership whereas the violation of these rules indexes 'incompetent' listenership. In this model, turn-taking irregularities, that is, when two or more speakers speak at the same time, are instances of simultaneous or overlapping speech.

These instances of 'inappropriate' behaviour have been grouped and categorized according to when the disruptive behaviour takes place in the current turn. One such example is minimal responses (such as mhm, uh huh, um hmm, yeah) which are not considered violations of the turn-taking mechanism since, as Coates (1990) explains, they do not constitute a turn as the speaker is not claiming a turn (also Stubbe, 1991; Mott and Petrie, 1995). Minimal responses act as indicators of active listenership and interest in the topic development, and build a sense of co-participation in the interaction that is necessary to provide support work to the current speaker (Coates, 1990; Hannah and Murachver, 1999; Tzanne, 2001). More often than not, the use of minimal responses encourages the current speaker to continue his/her turn developing the topic further (Zimmerman and West, 1975), promoting good rapport among interactants.

In addition, Zimmerman and West (1975) define overlaps as those 'speaker transition errors' in which there is a slight anticipation by the next speaker who starts his/her turn "within the boundaries of the last word" of an utterance of the current speaker but who does not intend to infringe on the speaker's turn (1975: 114; also see Coates, 1990; Furo, 2001). In other words, in spite of being considered a turn-taking irregularity by the very nature of its definition an overlap is not regarded as a violation of the turn-taking mechanism (Murata, 1994). Instead, it is merely seen as accidental interactional behaviour usually caused by mistiming and/or eagerness on the part of the next speaker in an attempt to minimize gaps between turns (Stubbe, 1991; Mills, 1995) and it can be said to work within the boundaries of conversational cooperation (Murata, 1994; Liddicoat, 2007). In this way, a speaker may accidentally overlap the addressee by asking a relevant question to encourage the latter to enlarge on a topic. However, when a speaker starts his/her turn any time before the current speaker utters the last word of his/her turn, the former is said to have infringed on another speaker's legitimate right to 
complete his/her turn and an interruption is said to have occurred (Furo, 2001). Thus, the second speaker starts his/her turn when no transition relevance place has been signalled by the current speaker (Kitzinger, 2008). Due to its seemingly disruptive nature, contesting views have stemmed from the study of the phenomenon of interruptions for which it has received considerable attention when compared with overlaps and minimal responses.

\subsection{Interruptions: functions}

Though structurally speaking most research on simultaneous speech defines interruptions as "incursions initiated more than two syllables away from the initial or terminal boundary of a unit-type" (West and Zimmerman, 1983, in Furo, 2001: 31), discussions of the function(s) of verbal interruptions have revolved around two perspectives. On the one hand, some contend that interruptions disrupt the flow of the conversation and embody power displays ( $\mathrm{Ng}$ et al., 1995), and, on the other hand, there are those who contend that interruptions can serve a collaborative function displaying solidarity and cooperation in conversation $(\mathrm{Li}, 2001)$.

Drawing on the idea that interruptions constitute an intrusive move, researchers have very frequently regarded interruptions as a disruptive violation of the turn-allocating rules (Zimmerman and West, 1975; Stubbe, 1991; Mills, 1995; Tzanne, 2001). In addition, Murata (1994) explains that offering resistance to being interrupted is part of the conversational expectation of the speakers involved. In this light, interruptions have traditionally been regarded as a topic control mechanism, a means to wield power and dominance in an interaction employed by powerful interactants in their attempts to gain the floor (see Brown and Levinson, 1994; Mills, 1995). In other words, interruptions construct asymmetry of power relations in conversation where the most powerful participant is likely to dominate the flow and topic of the conversation (Coates, 1990). Related to this is the notion of the management of rights and obligations in relational work (Spencer-Oatey, 2008) as this kind of interruption is seen as a disaffiliative intervention' for it is believed to constitute an infringement on somebody's right to continue speaking (Furo, 2001). In this way, by not allowing the current speaker to 
complete their turn, the 'interrupter' is not observing the negative face needs of the current speaker by which they would expect "to have [his] actions unimpeded by others" (LaPlante and Ambady, 2003). By not signalling a transitional relevant place, it is assumed that the current speaker intends to continue talking for which an interruptive move in this context is considered disruptive and problematic (Li et al., 2005; Liddicoat, 2007).

Most instances of interruptions have only been analysed in terms of conversation dominance (for a discussion of related studies see Talbot, 1998; Coates, 1993). Clyne, for example, examines interruptions within what he terms 'turn appropriating' devices as "the classic case of competition for control of the "floor"' (1996: 95) which, as he argues, is prone to cause communication breakdowns. Moreover, studies comparing men and women's use of interruptions make a case for discussing the construction of a maledominant role in conversation that has become popular in the literature (Coates, 1993, 1996; Holmes, 1995; Eckert and McConnell-Ginet, 2003). Talbot (1998) explored interruptions in jointly constructed narratives in family interactions in relation to how power is wielded in couples, and Zimmerman and West (1975) analyzed interruptions in relation to gender roles in public places in a university community. From a different analytical perspective, Kennedy and Camden (1983) observed nonverbal behaviour associated with interruptions, such as body lean and facial expressions, in a group of mixed-gender graduate students. Most studies of this nature seem to suggest that women have a tendency to use more discourse strategies that display solidarity and that they interrupt at different rates according to whether they participate in male-female or female-female interaction (Kennedy and Camden, 1983; Hannah and Murachver, 1999).

The second perspective regarding the function of interruptions is put forward as a counterbalance to this traditional view of interruptions. Zimmerman's and West's wellreported argument promoting the disruptive nature of interruptions has evolved to allow for a more open view of interruptions that accommodates the potentially structurally turndisruptive role of interruptions in conversation with both positive (supportive) and negative (non-supportive) speech functions at a referential or content level (Stubbe, 1991). Stubbe (1991), then, distinguishes between the formal and the functional criteria 
for analysing interruptions and claims that there is no direct correlation between the form and the function of an interruption. This view rests on the idea that overlapping talk is an interactional achievement which is evident in the fact that the current and the second (and possible more) speakers negotiate and build meaning through a sequence of turns which may also involve overlapping speech (Liddicoat, 2007). In other words, while the form of an interruption may be disruptive, the function it may be performing at the referential level is one of active listenership (Coates, 1990), support and solidarity, which observes interactants' face needs and dialogically constructs cooperative discourse (Mills, 1995; Eckert and McConnell-Ginet, 2003). Interruptions, then, are not necessarily dysfunctional, and conversational analysts have discussed interruptions as a promoter of collaborative floor and a source of initiation of negotiation that is tinted with the intentions and expectations of the interactants (also see Kennedy and Camden, 1983; Edelsky, 1981; Murray, 1985). In addition, Goldberg (1990) explains that interruptions do not have a unilateral but a multi-purpose function and that camaderie, and deference and distance are both in themselves strong driving forces that shape the nature and form of interruptions. In this way, Goldberg argues that, while it is true that interruptions can violate somebody's want and right to continue talking, they can also observe both the current speaker's positive face by displaying active and continued listenership, and the current speaker's negative face by displaying deference when, for instance, the current speaker wants a second speaker to provide an intelligible utterance that helps complete his/her turn. It follows that interruptions have the potential of being both face-threatening and non-face-threatening acts (Goldberg, 1990). She claims that while an interrupter may make a face-threatening move by interrupting, he/she may intend it to be supportive and his/her listener may perceive it in the same way resulting in a face-enhancement act.

Thus, as a strategy for conversational negotiation of meaning, interruptions should be judged not only by their form but also by their function according to its context of interaction (Tannen, 1993). Taking account of these driving forces makes it possible to "provide a conceptually coherent account of interruptions, one which is not only capable of accounting for 'how' but also for 'why' different types of interruptions occur" (Goldberg, 1990: 887). In addition to this, Ng et al. (1995), Mott and Petrie (1995) and Li (2001) warn us that considering the context of interaction is crucial in drawing the 
distinction between disruptive and facilitative interruptions since the context "allows or discourages others to elaborate their points" (Stubbe, 1991: 106). Furo (2001: 32)

elaborates on the importance of context and argues that interruption is "basically an interpretative category for participants to deal with the currently prevailing rights and obligations" in situated practice. In other words, the function of an interruption in the flow of a conversation is judged according to the interactants' perceptions of this interruption in the context where it occurs (Tannen, 1993).

Studies supporting the collaborative view of interruptions include $\mathrm{Ng}$ et al. (1995) who discuss the negotiation of power in face-to-face interactions and show that interruptions may function as a face-saving mechanism. They claim that a second speaker may overlap the current speaker when, for example, the current speaker runs out of new things to say (cf. Goldberg, 1990 above). By doing this, the second speaker is 'rescuing' the current speaker, saving his/her face (Ng et al., 1995). Moreover, Kerbrat-Orecchioni (2005) looks into the role of positive and negative politeness in interruptions in interactions taking place in French bakeries and she concludes that interruptions are governed, more often than not, by positive politeness norms. In other words, interactants are most frequently oriented towards saving and enhancing each other's positive face. Karakowsky et al. (2004) also investigate how positive interruptions are used as a linguistic strategy to build rapport in mixed-gender work groups.

\subsection{Classifications of Interruptions}

For analytical purposes, sociolinguists have focused on different aspects of the nature of interruptions to offer a number of classifications that facilitate their study. Thus, for instance, Mott and Petrie (1995) classify interruptions as either successful, that is to say, when a speaker seizes the floor and is allowed to maintain the control of conversation, or unsuccessful, that is to say, when the interrupter does not succeed at maintaining the control of the conversation and some other participant takes the floor. Informed by the more context-embracing view of the role of interruptions, Li (2001, 2004, et al. 2005, 2008) and Stubbe (1991), for instance, subcategorize them into intrusive, or disruptive, 
and cooperative, or collaborative ${ }^{1}$. Intrusive interruptions are those instances that have the potential to threat an addressee's face by means of expressing disagreement or making a topic change, for instance. Cooperative interruptions, on the other hand, are intended to "help the speaker by coordinating on the process and/or content of the ongoing conversation" (Li, 2001: 269) which could be achieved by, for example, voicing agreement and providing assistance when the speaker needs a word or phrase to complete an idea. $\mathrm{Ng}$ et al. (1995) group interruptions as proactive, for instance, dissent and rely, or reactive, such as consent or request, speech acts. Karakowsky et al. (2004) distinguish between rapport-oriented, neutral and intrusive or negative interruptions, while other researchers call them simply cooperative and competitive (Murata, 1994; see Li et al., 2004). Generally speaking, though the categorizations that overlaps have received vary in terminology, the conceptual groupings they have received according to their nature in context are similar.

\subsection{Overlaps in workplace context}

As briefly mentioned in the previous chapter, when exploring interruptions in their naturally occurring contexts of interaction, researchers have focused their analysis on different contextual factors such as the roles of the interactants, the speech acts in which the interruptions are embedded, and the place where the interaction occurred. In addition, politeness in the workplace has enjoyed a great deal of close attention (see Mills, 1995 for a survey of studies of women in their workplaces; Karakowsky, 2004 for gender associations to perceived competence, power displays and status in the workplace; and Bargiela-Chiappini and Harris, 2006 for a review of studies). Li et al. (2004) looked at interruptions taking two contextual cues into account, the workplace setting and gender roles. She observed doctor-patient interaction with the aims of establishing associations and tendencies of, on the one hand, the use of successful or unsuccessful interruptions when enacted by patients or by doctors and, on the other hand, male and female use of

\footnotetext{
${ }^{1} \mathrm{Li}$ (2001) also added a third category under 'others' for those interruptions that could not be classified as either cooperative or intrusive.
} 
cooperative and intrusive interruptions. Mills (1995) also discusses similar studies of doctor-patient and defendant-magistrate interaction.

However, two issues arising from most studies reviewed here concerning the role of interruptions remain to be discussed. First, most research done in this area is intracultural, that is to say, interaction among members of the same culture, and little reference is made regarding intercultural interaction (see Li, 2001). Clyne (1996) took a step forward in dealing with intercultural issues in the use of interruptions, but exclusively when looking at ways of coping with communication breakdowns, disregarding instances of successful communication. Thus, the role of overlapping speech in ethnically diverse workplace settings has not been explored yet.

Second, all the studies surveyed so far only offer the insights into the researcher's point of view of the role of interruptions. In other words, to date most researchers have relied on their own judgement of the role of interruptions in interaction for analysis but have overlooked the perceptions of the participants involved. If the role of interruptions, and overlapping speech in general for that matter, is determined by the interactants' perceptions of this behaviour in the context of the actual interaction (see Tannen, 1993 above), then providing insights into these perceptions becomes vital in giving a comprehensive description of overlapping speech in intercultural workplace interaction that this study hopes to provide.

Moreover, since this study will primarily rest on the participants' perceptions of the role of interruptions, classifying interruptions as either cooperative or disruptive, as discussed above, presupposes the tacit judgement of the role of these on the part of the researcher, which would pose the risk of misjudging them. In this regard, Watts (1992) explains that what constitutes politic, that is to say, appropriate, and polite behaviour is socio-culturally determined as well as it depends entirely on the speech community involved. As a consequence, it is thought convenient to identify interruptions merely as overlapping speech and overlaps (see Liddicoat, 2007 for same use of terminology) as a first step towards the exploratory data analysis in order to leave the actual judgement of their functions to the participants involved in this study. 


\subsection{Conclusion}

Karakowsky et al. (2004) call for future research to look at the purpose of verbal interruptions, or overlaps, to contest the commonly accepted view that they mainly constitute a form of power display (also Mills, 1995). The evidence discussed in this chapter opens the door to considering the function of overlapping speech in intercultural communication from a rapport-oriented perspective, which challenges previous views on overlapping speech of this nature but which has until now been understudied. Exploring how politeness norms work in overlapping speech in intercultural workplace settings and, most importantly, how overlapping speech is perceived by participants of different ethnic backgrounds would provide new insights to illuminate the fields of intercultural communication and interactional analysis.

Thus, the two questions that will be addressed in this study are:

a) How does overlapping speech function in workplace interactions in New Zealand?

b) How are these overlaps intended to be and 'perceived' by culturally different interactants?

To answer these two questions, a framework that offers a multidimensional approach to the analysis of intercultural interaction is needed to evaluate the role of overlapping speech in intercultural interaction and to incorporate interactants' perceptions of the use of overlaps in naturally-occurring interaction. To that end, chapter 3 will review Politeness Theory, as proposed by Brown and Levinson (1978, 1987, 1994) and rapport management, as proposed by Spencer-Oatey (2000, 2008). 


\section{Chapter 3: Theoretical framework: Politeness}

As a first step towards the goal of exploring how politeness works in overlapping speech in naturally-occurring interactions in a multicultural workplace setting, this chapter starts by offering an outline of the theories that will serve as the framework of analysis. The chapter reviews those aspects of Politeness Theory relevant to the understanding of the theoretical framework under which the research questions will be operationalised, namely, rapport-management (Spencer-Oatey, 2000, 2008). This is followed by a review of studies on politeness carried out in workplace settings.

\subsection{Politeness Theory: some considerations}

Brown and Levinson's seminal work on politeness theory has prompted "an enormous amount of research mileage" as a solid starting point for politeness research (Locher and Watts, 2005: 9): "Without it we would not be in a position to consider the phenomenon of politeness as a fundamental aspect of human socio-communicative verbal interaction in quite the depth and variety that is now available to us." Politeness theory (Brown and Levinson, 1978, 1987) relies on the assumption that "the mutual knowledge of members' public self-image or face, and the social necessity to orient oneself to it in interaction are universal" (Brown and Levinson, 1994: 62). In this regard, it has been shown that the underlying notions driving interactions, such as interactants' face needs, bear a significant resemblance cross-culturally speaking (Brown and Levinson, 1987: 1315 for a discussion of related studies). Brown and Levinson's definition of 'face' as "the public self-image that every member wants to claim for himself' (1994: 61) derives from Goffman's notion of face (1967, in Brown and Levinson, 1994: 61; Goffman, 2006). But Brown and Levinson add two dimensions to this notion claiming that all interactants have a negative face, i.e. interactants" "freedom of action and freedom from imposition" (1994: 61), and a positive face, i.e. interactants' desire to be approved of (1994: 59-64).

Some acts threaten interactants' negative and positive face. These acts are called 'face-threatening acts' (FTAs) and they have the potential to cause interactants to lose face when failing to observe interactants' face needs and wants (Brown and Levinson, 
1994: 59-60, 65-84). Furthermore, following their definition of FTAs, Brown and Levinson have classified speech acts and interactional strategies as being either facethreatening or non-face-threatening acts (1994). It follows that certain acts such as overlaps, whether they fulfil a cooperative or disruptive function (1994), are intrinsically face-threatening acts (1987) since, according to this framework, overlaps constitute a “turn-taking violation” (1994: 232). All interactants' instances of linguistic behaviour in interaction, i.e. speech acts, fall into one of these rigid categories.

Due to this view of FTAs, this theory has come under extensive scrutiny and has been criticised as a theory of face-work rather than politeness (Meier, 1995a \& b; Watts, 2003; Locher and Watts, 2005; Haugh, 2007). The perspective under which certain speech acts are intrinsically face-threatening dashes away the possibility of applying a more flexible context-oriented interpretation of the role of overlapping speech in an interaction. In this regard, Eelen (2001) warns that the categorization of speech acts that Brown and Levinson propose has been made without any empirical examination and it consequently lacks proof of evidence for how social norms of linguistic (and nonlinguistic) behaviour interact with a given social context. Guided by the belief that "politeness [...] arises in interaction between persons" (Arundale, 2006: 194), both Eelen (2001) and Haugh (2007) acknowledge the need to move away from the utterance-level analysis proposed by Brown and Levinson, and to base face-work analysis on how politeness is dialectically negotiated and interactionally achieved. This reconceptualisation of face-work as a dialectical phenomenon of interaction provides an alternative conceptualization of the threatening and non-threatening nature of speech acts making it possible to argue that certain speech acts can be face-threatening in a given context but may not be so in another context. Locher and Watts (2005) also adhere to the belief that politeness is a discursive construct that should not be equated with facethreatening-act (FTA) mitigation. Instead they argue that we should consider the study of politeness as going beyond FTA mitigation in order to explain the norms that govern polite behaviour in communication. In support of this claim, Stubbe (1991) shows how interruptions, originally thought to be a face-threatening act, are used as a supportive 
strategy that signals involvement in the interaction and active listenership among primary school children in New Zealand.

With the view that politeness is dialogically constructed, it seems logical to conclude that if interactants, regardless of their ethnic background, share the same basic face needs, the realization of social norms attending to those needs needs not always be problematic. In other words, although different cultures differ dramatically in the realization of social norms of interaction, these differences should not always interfere with their communication if interactants observe the same basic face needs. It follows that if the main driving force of interactions is the observation of these needs with the aim of achieving specific interactional goals, a group of interactants, regardless of their ethnic background, may be able to negotiate their expectations and maybe even negotiate the realisation of social norms so that they observe interactants' face needs (cf. Hannah et al., 1999). Spencer-Oatey (2008: 6) emphasises this point when she explains that these differences can actually be "a major source of comity and enrichment". Building on Eelen's (2001) discussion on the critique of politeness theories, Spencer-Oatey highlights the normative nature of politeness and urges researchers to study interactions in terms of the social norms surrounding these interactions. In addition to this, she also urges researchers to look at politeness in terms of the evaluations of behaviour interactants make as to what constitutes polite, politic (Watts, 2003), that is to say behaviour that can be judged as appropriate or 'politic' but still not polite (Locher and Watts, 2005), or impolite linguistic behaviour, what Eelen calls 'evaluative activity' (2001, see also Ruhi and Işik-Güler, 2007).

To sum up, while interactants have a positive and a negative face to attend to which could be threatened by certain linguistic features, it is also true to say that those same features may not always be interpreted as threats. And whether interactants perceive certain moves to be face-threatening or non-face-threatening depends on the interactional context in which they are embedded where they negotiate aspects relevant to their communication. In this way, the traditional view of simultaneous speech as constituting an intrinsically face-threatening act is challenged and a new door is open to a more 
context-oriented interpretation of the role of overlapping speech in intercultural communication. In order to do justice to the study of intercultural interaction, BargielaChiappini and Harris (2006) suggest a multidimensional approach to the analysis of cultural interaction. Thus, a context-embracing framework that derives from the politeness constructs of face is most beneficial in order to provide an evaluation of the use of overlaps and consider interactants' perceptions of these overlaps in workplace interaction.

\subsection{Rapport Management}

Rapport management, as proposed by Spencer-Oatey (2000), is a framework that enables researchers to interpret the role of politeness within its interactional context, and in this case the role of politeness in overlapping speech. Guided by Brown and Levinson's focus on FTAs, politeness research has mainly been concerned with the illocutionary domain of interaction, that is, with the aspect of communication that deals with the face-threatening or face-enhancing implications of speech acts (Spencer Oatey, 2000, 2008). Noticing that politeness research has, for some time, been restricted to this area of study has led researchers to search for a descriptive rather than a prescriptive model (Hickey and Stewart, 2005) which could offer a broader framework of facework (see Tracy, 1991 and Penman, 1990 as cited in Spencer-Oatey, 2008: 3) to incorporate new concepts such as 'perceived intention' and 'intentionality' (see Spencer-Oatey, 2008 above; Schnurr, Marra and Holmes, 2007), which play an important role in the analysis of face-to-face interaction. Thus, this need for a context-embracing framework that could bridge the gaps of politeness theory, as outlined above, has prompted the development of the foundations of relational management or, as it was later also referred to, relational work (Spencer-Oatey and Xing, 2003; Spencer-Oatey, 2000, 2008) and impression management research (Bilbow, 1997a, 1997b as cited in Bargiela-Chiappini and Harris, 2006; Spencer-Oatey, 2000, 2008).

To explain relational management, Spencer-Oatey (2008: 1) argues that when people interact they are managing interpersonal rapport, that is to say, communication among people "involves the management of social relations." This idea was later captured by 
Locher and Watts (2005: 9) who label "the work individuals invest in negotiating relationships with others" as relational work. As a framework for analysis of politeness in interaction, Spencer-Oatey suggests the term rapport management to refer to "the use of language [people make] to promote, maintain or threaten harmonious [=positive] social relations [-rapport]" (2008: 3). She bases the foundations of rapport management on the idea that interactants "dynamically co-construct their discourse" (2008:6).

Her model retains the core idea underlying politeness theory, i.e. that politeness is a universal concept that governs interactions as interactants have face needs to attend to. However, as argued in the previous section, she revises some of the assumptions made by Brown and Levinson and, in so doing, she claims that no utterance is in itself, inherently polite or impolite and that politeness is a "social judgement" (2000: 3; cf. Eelen, 2001 above) also referred to as "contextual judgement" (see Fraser and Nolan, 1981 in Spencer-Oatey, 2008:2). Interactants then judge whether an utterance is polite in relation to the context in which it occurs. Thus, this framework incorporates a broader view of politeness that reflects concerns not only of the self but also of the other as they coconstruct situated discourse in interaction.

Within this framework, Spencer-Oatey asserts that "the concerns they [Brown and Levinson] identify as negative face issues are not necessarily face concerns at all" (2008: 13, emphasis added) since an utterance can be considered polite and 'appropriate' (see 2008: 2; see 'politic' in Watts, 2003 above) in one situation but rude and inappropriate in another. In advancing this argument she explains that rapport management is made up of two components. The first component is the management of face defined as "the positive social value a person effectively claims for himself [sic] by the line others assume he has taken during a particular contact" (2000: 14). This component is subdivided into quality face (cf. Brown and Levinson's positive face) and identity face (people's need of acknowledgement and maintenance of social roles). The second component is the management of sociality rights and obligations, that is, the personal and social entitlements a person claims for himself/herself in a given interaction and the management of social expectancies, which is subdivided into equity rights (cf. Brown and Levinson's negative face) and association rights (the belief people have of being entitled to maintain the type of relationship they have with other people) (2000). Consequently, 
according to this model, threatening behaviour can occur in two different ways: facethreatening behaviour and rights-threatening behaviour. Having a two-dimensional view of the phenomenon of interactional politeness means that, as argued by Spencer-Oatey (2008), some behaviour can violate, for example, sociality rights while not causing interactants to lose face.

The distinction between the two components of this model is essential because, while it still accounts for personal aspects of interaction (quality face and equity rights), this framework incorporates a social aspect of interaction (identity face and association rights). Therefore, the personal component of this framework allows the analyst to suggest interpretations of speakers' intentions and, on the other hand, the social component allows the analyst to include and consider hearers' perceptions. In the context of this study this framework enables the researcher to make possible interpretations of the interactional role of overlapping speech in intercultural interaction while at the same time it enables the researcher to consider participants' perceptions of the interactional value of these overlaps. In this regard, Holtgraves (2005) explains how interactants' perceptions of the context of interaction influence the levels of politeness perceived and enacted in interaction. Moreover, Spencer-Oatey claims that while some acts can be interpreted as threatening face or infringing on sociality rights (depending on the context of interaction), the opposite is also true. In this way, this revision of the definition and subdivisions of positive and negative face makes it possible to claim that speech acts and other interactional strategies are not inherently face-threatening. In other words, speech acts could be face-threatening but need not always be so, and interactants' intentions and perceptions of them depend upon the context of interaction, their social (behavioural) expectations and their rapport orientation, i.e. how interactants orient themselves in interaction (for example, challengingly or positively) (Spencer-Oatey, 2005). Furthermore, this framework allows researchers to account for differences in the realizations of speech acts across cultures (Christie, 2007) and how these function in intercultural communication. It then also allows for overlapping speech to be regarded as enhancing of face or supporting of sociality rights, which breaks the rigid 'violation' mould in which they have usually been framed. 


\subsection{Investigating politeness in the workplace}

In order to explore how politeness works in overlapping speech in intercultural workplace communication, a review of relevant workplace research in the field is appropriate. Within the field of intercultural communication, politeness in workplace interaction has attracted considerable attention (Bargiela-Chiappini and Harris, 2006). Politeness theory as proposed by Brown and Levinson (1987) opened the door to a research tradition that has allowed researchers to consider politeness as a salient aspect of 'socio-communicative verbal interaction' (Locher and Watts, 2005). When considering intercultural communication in this context, Brown and Levinson (1987) advise that politeness universals should be considered within the (cultural) context in which they are realized and that research needs to address interethnic concerns of communication, such as implicatures and social distance. But unfortunately, they also emphasize the need to study 'systematic violations' or, in other words, FTAs, in order to uncover culturallybound social norms. Not surprisingly, politeness research on intercultural communication has traditionally focused on instances of miscommunication that can be traced back to the assumption that some speech acts are intrinsically face-threatening moves ${ }^{2}$ (Brown and Levinson 1987, Clyne 1996). Following these assumptions, Tanaka et al. (2008) carried out a cross-cultural study to explore the differences in Japanese and English apologies relating to context and ways of apologising, and warns researchers of the dangers of using stereotypical cultural conventions as constructs for analysis. In addition, SpencerOatey and Xing (2008) provide empirical evidence on how understanding cultural conventions (for example, differing power distance norms) in British and Chinese business interactions plays an important role in maintaining face in order to achieve positive business outcomes. These studies, however, focus on instances of miscommunication and fail to acknowledge the use of politeness strategies in successful intercultural interaction.

As a consequence, research on intercultural workplace interaction has been said to have inherent flaws. These have been summarised by Boxer (2002) as well as Hickey and

\footnotetext{
${ }^{2}$ See Brown and Levinson, 1987: 13-15, 25-27, 33-35 for an overview of cross-cultural studies.
} 
Stewart (2005) who argue that most studies have not used spontaneous face-to-face data in their analysis, that the majority of these studies have concentrated on a very limited number of cultures, such as North American and Japanese. Moreover, little research has been conducted concerning the actual 'exercise' of politeness norms (Hickey and Stewart, 2005) or 'felicitous interaction' (Boxer, 2002) particularly among "members of different ethnic groups interacting with each other on their own terms and in their own workplaces" (as argued by Schnurr, Marra and Holmes 2007: 713).

Fortunately, this rapidly changing field of socio-pragmatic research has also most recently explored politeness in naturally-occurring interactions across cultures in a variety of discursive workplace contexts (Spencer-Oatey, 2008; Holmes and Stubbe, 2003; Holmes, Marra and Schnurr, 2008; Bargiela-Chiappini and Harris, 2006; Holmes and Schnurr, 2005). Some researchers have been concerned with the dangers of, for instance, applying concepts as defined by Western sociology and psychology, and/or categories that have been developed within culturally-distant domains to the study of politeness in intercultural communication (see Bargiela-Chiappini and Harris 2006 for a summary of studies). These concepts and categories, it has been argued, may hinder a comprehensive understanding of culture-specific interactional phenomena of workplace interaction. In addition, the "evaluative judgement" of what constitutes (im)polite behaviour also differs from culture to culture, as it possibly does in different contexts of interactions, since it relies on people's cultural beliefs, values and expectations (Ruhi and Işik-Güler, 2007). In this regard, recent research has resulted in fruitful developments as researchers' primary focus on context and culture-specific norms of interaction has provided a richer, though far from comprehensive, understanding of the role and workings of politeness in intercultural workplace interaction (see Boxer 2002: 52-72 for an overview). As an example of this, Holmes et al. (2008) takes a step further in the study of politeness and intercultural communication offering a discussion on the workings of power and politeness in meetings in Māori-Pākehā workplace contexts in New Zealand. Following Holmes' line of research, Schnurr et al. (2007) have carried out case studies to explore effective ways of doing leadership and politeness in intercultural workplaces in New Zealand as part of the Language in the Workplace (LWP) project. This study 
highlights the importance of common norms developed in 'ethnicised' communities of practice (Schnurr et al., 2007). Contributing to this body of research, Marra (2008) focuses on how to adapt research methodology to work with specific cultures taking into account social norms and expectations of behaviour. Thus, the current direction of politeness research is characterised by a move away from the outdated view that intercultural communication was almost by default unsuccessful and by a move forward towards a more context-embracing view in which politeness norms are negotiated among the members of a group in actual interaction.

\subsection{Interactional context of studies of overlapping speech}

As has been illustrated, the context in which an interaction takes place has become one of the most salient features in the interpretation of interactional politeness in intercultural communication. However, the role of overlapping speech in communication has been largely investigated in monocultural settings and in cross-cultural comparisons of its use. For example, Heritage $(2005)^{3}$ reviews literature on the system of turn-taking rules in a variety of monocultural discursive contexts (such as press conferences, interviews, meetings, interactions in classrooms and courtrooms) as part of his discussion of the dimensions of institutional talk. He explains that in spite of the fact that the turntaking procedures differ according to the nature of the discursive context, the turn-taking practices, even in more informal settings (such as a therapeutic session) are expected to be systematic, explicit and predictable. Yet, when considering the attempts that have been made in order to study overlapping speech in intercultural communication, the studies of Murata (1994) and Li (2001, also see Li et al., 2005), for instance, take a contrastive perspective. In their studies they have endeavoured to describe the cooperative and intrusive function of interruptions involving people from different cultural backgrounds. Thus, while Murata (1994) aimed at exploring both quantitative and qualitative comparisons of the use of overlapping speech among native speakers of English and native speakers of Japanese, Li (2001) aimed at establishing similar comparisons with

\footnotetext{
${ }^{3}$ For more examples of monocultural studies also see $\mathrm{Ng}$ et al., 1995; Kennedy and Camden, 1983; Karakowsky et al., 2004.
} 
native speakers of English and native speakers of Chinese. Though these studies have successfully demonstrated a number of possible functions of overlapping speech, both these studies employed laboratory methods as their data collection approach. Thus, participants were either arbitrarily asked to engage in conversation with people they did not know (such as in the case of Murata, 1994) or they were given a role to play (such as in the case of $\mathrm{Li}, 2001$ ). The research outlined here presents the challenge of studying the role of overlapping speech as a strategy for doing politeness in naturally-occurring workplace interactions.

\subsection{Summary}

Researchers in the field of politeness and (inter)cultural interaction have been concerned with adapting, combining and reformulating frameworks of analysis that can provide a broad and comprehensible scope of research to describe (inter)cultural communication (Christie, 2007; Spencer-Oatey, 2005). In this regard, recent studies on politeness have advanced the importance of the role of context towards a comprehensive interpretation of the workings of politeness in actual interaction, breaking free from old stigmatisations of the intrinsic face-threatening nature of overlapping speech (see Tannen, 1994). In the case of workplace interaction, researchers' efforts can prove fruitful as workplaces in countries such as New Zealand are characterised by the presence of a mosaic of cultures (Harris et al., 2004) and call for a more comprehensible view of this interactional phenomena to explore the complexities of face-to-face workplace interactions.

Thus, as a first step towards providing a comprehensive analysis of the role of overlapping speech in intercultural interaction in a workplace setting in New Zealand, some of the basic principles of politeness theory as proposed by Brown and Levinson have been discussed in this chapter. This discussion was followed by a discussion of the model of rapport management as proposed by Spencer-Oatey $(2000,2008)$ enriched by views of relational work which, together, serve as the analytic framework to explore how interactional politeness is realised in the use of overlapping speech. From the discussion 
on politeness theory and the discussion on rapport management, it was concluded that since all interactants, regardless of their ethnic backgrounds, have face needs that require attention in interaction, cultural differences do not necessarily have to lead to miscommunication problems (Spencer-Oatey, 2008). In addition, applying rapport management criteria enables the researcher to observe context-specific data and use less rigid categorizations of overlapping speech in the analysis of politeness. Most importantly, this analysis provides the grounds for gaining a deeper understanding of the role of overlapping speech as it can account for both interactants' intentions and perceptions of the use of overlaps.

Then, the current study looks at overlaps in an intercultural setting from a more comprehensive rapport-oriented standpoint, aiming at dashing away the assumption that overlapping speech, especially interruptions, bring about miscommunication problems in intercultural communication. To achieve this, rapport management criteria will be applied when analysing how politeness norms work in overlapping speech in intercultural workplace settings. This, in turn, can account for variation in contextual assessment norms, i.e. how interactants judge overlapping speech in naturally-occurring workplace interaction.

The following chapter outlines in detail the methodology employed in this study in order to explore the role of overlaps in an intercultural workplace setting. 


\section{Chapter 4: Design and analysis of the research study}

This chapter discusses the methodology used in the data collection process which, in order to explore the role of overlapping speech in depth, involved two phases. In phase one, two meetings were audio and video recorded in a large educational workplace in New Zealand. In the second phase, individual interviews were held with the meeting participants to elicit their perceptions of instances overlapping speech.

Investigation of the role of politeness in intercultural communication has been critiqued for relying mainly on data collected in laboratories, which Mott and Petrie (1995) call 'ecologically artificial settings', where individuals were given role-play tasks to fulfill in order to analyze the data drawn from the resulting interaction among the participants (see Bargiela-Chiappini and Harris, 2006 for a comprehensive review of studies). However, the past decades have been witness to a development in this field of sociolinguistics as a large body of work uses naturally-occurring data for the analysis of politeness norms in workplace interaction (Tannen, 1994; Holmes and Schnurr, 2005; Schnurr, 2007; Spencer-Oatey, 2008). Bargiela-Chiappini and Nickerson (2003) emphasise the importance of the study of workplace practices in describing how individuals do relational work in the workplace. As a consequence, to examine the possible functions of overlapping speech in an intercultural workplace setting, in addition to participants' perceptions of these overlaps, it is important to understand the situational and institutional norms and practices that shape intercultural interaction in a given workplace setting. For that reason, the data for the present study were drawn from the video and audio recordings of two naturally-occurring meetings which took place in a large educational workplace in New Zealand and researcher's fieldnotes of those meetings. Follow-up individual interviews with participants were conducted to gain insights into their perceptions of the role of overlapping speech in these meetings. The rationale behind using a variety of data collection methods is that one method can compensate for the weakness of another method (Paterson and Graham, 2000). Moreover, these methods provided added depth and, at the same time, served to triangulate and 
validate the data analysis. For practical purposes, the data collection process was divided into two phases: 1) recording naturally-occurring conversations in meetings, and 2) collecting participants' perceptions.

\subsection{Phase 1: collecting meetings' data}

As the starting point of the data gathering process, two work meetings of 45 minutes and 1 hour and 20 minutes each were video recorded. The two meetings were also audio taped as a backup resource in case of any malfunctioning issues with the video camera. The first meeting was held at the end of April 2009 while the second meeting took place in mid-May 2009. Both meetings were held in a meeting room in the afternoon, outside working hours, and participants sat around a rectangular table. The first meeting involved the manager of the institution and five language instructors. For that meeting instructors had prepared a document outlining what they had requested in terms of job advancement for the following year, which was to be presented to the authorities of the institution. The aim of that meeting, then, was to discuss this document and the imminent job adjustments to take place the following year. Since this meeting was presided over by the manager of the institution, Paul ${ }^{4}$, the nature of the meeting was quite formal and instances of overlapping speech were rare (see Holmes and Stubbe, 2003).

The second meeting recorded was a follow-up to a similar meeting previously held with the manager, an HR person and some instructors, who talked about job prospects for the following year. In this second meeting seven instructors were present. The aim of this meeting was to debrief the contents of the previous meeting with the manager and HR staff to those instructors who could not attend that meeting and to decide future actions to be taken by the group. These instructors have worked together for an average of 8.5 years (see Appendix A) and are very familiar and comfortable with each other. This meeting then was rather more informal in style. The incidence of overlaps was significantly higher than in meeting one as the rates of participation were also much higher, having every participant collaborate in the flow of the interaction. The participants who mostly held the floor in this meeting were Delia, who had taken down notes in the previous meeting and

\footnotetext{
${ }^{4}$ Note: all names used are pseudonyms.
} 
seemed to be in charge of debriefing its content, and Greta, who usually participates very actively in these meetings.

In both meetings, the audio recording equipment was placed in the centre of the table and the camera was set up so all the participants faced it (see Holmes and Stubbe, 2003). Both meetings were similar in nature as they were internally run, that is to say, not within the schedule of planned meetings for the year, and they were organised by the instructors out of a need to discuss current job issues, such as contract and role description changes. The two meetings recorded were chosen so as to collect data from two different types of meetings this team has on a regular basis.

Table 1 provides details of the two meetings recorded.

\begin{tabular}{|c|c|c|}
\hline & Meeting 1 & Meeting 2 \\
\hline Date & End of April 2009 & Mid-May 2009 \\
\hline Type of meeting & Discussion and informative & Informative and decision-making \\
\hline Style & Formal & Informal \\
\hline Participants & $\begin{array}{l}\text { Manager of the institution and } \\
\text { five language instructors }\end{array}$ & Seven language instructors \\
\hline Goal & $\begin{array}{l}\text { To discuss a document } \\
\text { written by the instructors } \\
\text { regarding work conditions of } \\
\text { future work contracts and the } \\
\text { imminent job adjustments to } \\
\text { take place the following year. }\end{array}$ & $\begin{array}{l}\text { To debrief contents of a previous } \\
\text { meeting held with the manager and } \\
\text { HR staff for those instructors not } \\
\text { present in that meeting and to } \\
\text { decide on a common course of } \\
\text { action following managerial } \\
\text { announcements of work } \\
\text { opportunities and conditions for the } \\
\text { following year. }\end{array}$ \\
\hline
\end{tabular}

Table 1 - Details of meetings 
The participants in these meetings were seven female language instructors and one male manager of a large educational workplace in New Zealand. The choice of the workplace and participants was based on their willingness to take part in further workplace research following a previous small-scale research project carried out by the researcher as part of a course requirement for a Masters degree.

These participants came from varied national backgrounds, including Germany, Spain, Argentina, New Zealand, France and China (see Appendix A). On average the instructors have been working in this workplace for eleven years. The instructors consider they have been part of this work team for an average of 8.5 years, while the manager has been a staff member and part of this work team for two and a half years. The ages of the participants range from 30 to 54 years old. All six instructors use English as a lingua franca and they rated their English proficiency level as fluent.

The researcher has been an active member of this team for four years and was required by the institution to be present in both meetings. The researcher is not usually very active in this kind of work meeting so she provided minimum input during these meetings to display normal behaviour and to be as unobtrusive as possible. Furthermore, a few fieldnotes were made during the meetings and more detailed comments were written immediately after the meetings while reviewing the videotapes.

The researcher's presence as a participant observer did not seem to have any effect on the dynamics of the meeting as participants' performance and participation was considered typical of this team's work meetings by the participants when asked in the follow-up interviews. On the contrary, this data collection method allowed the researcher to make fieldnotes of naturally-occurring interaction regarding, for example, contextual cues and paralinguistic features relevant to identifying the use and function of overlapping speech in these meetings (cf. Boxer, 2002). These notes were also used later to support the interpretation of the data and to inform the choice of extracts for analysis.

\subsection{Selection of extracts}

After the meetings, the researcher listened to the tapes and watched the video-tapes to identify useful extracts of overlapping speech to analyse. Eighteen extracts were selected 
from a wider corpus of instances of overlapping speech found in the two meetings recorded for their ability to illustrate common linguistic behaviour observed in interaction by this group of instructors. The choice of extracts was based on ethnographic observations made in the field notes involving participants' observable reactions to instances of overlapping speech. Some of these reactions included linguistic behaviour, such as rising pitch and intonation, as well as paralinguistic behaviour, such as body language and gaze (cf. Tannen, 1994). These extracts were transcribed (see Appendix B) and they served two purposes. First, the researcher analysed the chosen instances of overlapping speech using rapport management as the analytic framework. Examples of these extracts are explored in the analysis section and have been numerically arranged into chapter and example number, followed by the number of the original extract from which the example was taken and the lines that will be considered for discussion (for example: Example 5.1 [12: 9-22]). Also the instances of overlapping speech that are used for discussion have been highlighted in each example. Second, the extracts selected were used in the second phase of the data collection process in which participants were interviewed to elicit their perceptions on the role of overlapping speech.

\subsection{Phase 2: collecting participants' perceptions}

In order to gain an insight into participants' perceptions of overlapping speech, an introspective method of data collection known as stimulated recall was used to conduct individual interviews (cf. 'prompted interview' in Henderson et al., 2006) with the participants (Mackey and Gass, 2005). Gass and Mackey (2000: 17) explain that stimulated recall methodology is employed "to prompt participants to recall thoughts they had while [...] participating in an event". Interviewees are then presented with retrieval stimuli, usually in the form of video recordings (Lyle, 2003), that have the aim of eliciting retrospective reports of participants' thoughts at the time when the interaction took place.

Videotaping is a very widely used technique in studies that aim to describe participants' beliefs and perceptions of, for instance, communicative events or mental processes (Steel, 2003; Morgan, 2007). In the present study the video is used with two 
purposes. On the one hand, the video functions as a retrieval cue or aid in the interviews to elicit participants' intentions and perceptions of the use of overlapping speech (Paterson and Graham, 2000; Henderson and Tallman, 2006). On the other hand, the video provides valuable evidence for the analysis of paralinguistic features, such as gaze, which may play a role in the functionality of overlapping speech. In addition, this methodological tool is often used to triangulate and validate the researcher's analysis (Edwards-Leis, 2006).

\subsubsection{Interview procedures}

Using those extracts chosen for the analysis, the researcher identified four instructors that were actively involved in the instances of overlapping speech and arranged to have individual interviews with them. The interviews took place two weeks after the second meeting had taken place, which coincided with the school break, as most participants told the researcher they had inflexible timetables during the teaching period.

At the start of the interviews an information sheet (see Appendix C) was given to the interviewees asking them to focus on any overlapping speech instances they identified in the extracts they were about to see $^{5}$. Participants were also asked to report what they recalled in terms of intentions and perceptions of these overlaps. With the aim of being as unobstrusive as possible so as not to bias participants' responses (see Henderson et al., 2006), two questions constituted the interviewing schedule: 1) How did you feel/think about this instance when you were overlapped? and 2) Do you remember why you overlapped?

Henderson and Tallman (2006) contend that the fresher the event, the more likely participants are to recall their thoughts more accurately. Thus, in order to maximise the stimulated recall process, participants first watched selected extracts of the video of the second meeting for its immediacy to the interview and then watched extracts of the first meeting. Participants watched an average of ten extracts for both meetings that ranged from 1 to $1 \frac{1}{2}$ minutes of duration.

\footnotetext{
${ }^{5}$ See Edwards-Leis, 2006 for importance of instructions prior to video watching session.
} 
Furthermore, Tannen (1993) explains that a linguistic form cannot be regarded but within the context in which it occurs. For that reason, participants watched extracts containing instances of overlapping speech with sufficient preceding and succeeding dialogue which also helped activate the recall process. Some participants, however, needed to watch longer footage to have a broader situational context to be able to recall what they thought at a given moment. Participants were indeed encouraged to play the recording at their own pace, allowing time for rewinding and watching longer stretches of interaction, commenting on and stopping the recording when they thought it appropriate. Researcher and participant-initiated pauses were used to maximise the opportunities for the 'exteriorisation' of their perceptions (Edwards-Leis, 2006). The duration of the meetings varied depending on how much input the participants provided and number of times they watched the extracts.

\subsection{Methodological considerations}

Regarding the video-stimulated recall interviews, Bloom (1954, in Gass and Mackey, 2000: 18) has argued that recall is $95 \%$ accurate within 48 hours and declines to $65 \%$ by two weeks after the event has occurred. This dictates one of the protocols of stimulated recall interviews by which, in order to maximise participants' short-term memory, it is vital that interviews take place within a few days after the event took place (Lyle, 2003). In this study, however, the interviews had to be accommodated to suit participants' availability and they were held two weeks after the second meeting. This, however, did not seem to have a negative impact on the recall process for two possible reasons. Firstly, to overcome this drawback, the first extract the participants watched was a dummy, that is to say, the first extract was not used for analysis but rather it was used with the aim of familiarizing participants with the recalling technique. In addition, the extract contained vital information about the core discussion of the meeting which acted as a first trigger of the recall process. Most participants had to watch this extract no more than three times until they said they remembered 'exactly' what was going on in that meeting. From there on participants watched the extracts no more than two times and could anticipate the exact words that either preceded or followed the extract they watched. They could 
verbalise what they were thinking and feeling at the time of the interaction even before the finished watching the extracts without difficulties.

Secondly, the nature of the meetings may have played an important role in the recall process. These meetings were held to deal with instructors' concerns about the future job adjustments. The two meetings recorded were part of a series of meetings held to discuss the institutions' job prospects for the following year and the instructors' proposed course of action. It follows that because the topic of the meetings was of considerable importance for the instructors, they were more likely to recall the events that had taken place in the meetings vividly. For all these reasons, participants' verbal reports can be said to be as accurate and reliable as one could hope.

\subsection{Ethical considerations}

In order to audio and video record those two meetings the researcher observed the guidelines dictated by the Human Ethics Committee. In accordance with these guidelines, an external researcher was used to contact participants to obtain consent as the researcher is an active member of that workplace team. Thus, a month before the meetings took place, participants were initially contacted by the researcher via email to anticipate that an external researcher would contact them regarding this research project. They were also emailed an information sheet (see Appendix D) with relevant details about the current research project and the procedures involving their participation. In this way participants had time to read about the project and think about their participation in the study before the external researcher approached them. The external researcher then contacted the participants and arranged meetings with them to give, where necessary, further explanation and clarification of the project and to obtain genuine informed consent of all participants. Consent was asked of participants to a) video and audio record the two forthcoming meetings and b) audio record the interviews. In addition, all participants were asked to fill in a background information sheet (Appendix E), which were either collected by the external researcher or posted to the researcher. Some participants also felt more comfortable emailing the researcher herself to ask questions about the project and the forms, which were answered via email. 
The video and audio recording of the meetings was initially to be undertaken by the external researcher for ethical reasons. However, one of the participants expressed some concern about having a 'stranger' in those meetings and instead another participant volunteered to undertake the task of setting up and handling the video and audio-taping equipment. This decision was unanimously approved by participants.

Participation in this project was voluntary and participants could withdraw from the project at any point during the study. Moreover, to protect participants' identities, all names used in this study are pseudonyms. Finally, the researcher brought afternoon tea to the second meeting as a token of appreciation for their participation.

\subsection{Summary}

Three complementary methods of data collection were employed to investigate the function of overlapping speech in intercultural workplace interaction and to elicit participants' 'original' perceptions of the instances of overlapping speech, that is, the perceptions they had regarding overlaps at the time of the interaction. The video and tape recording of two work meetings, together with researcher's fieldnotes and follow-up video-stimulated recall interviews with participants were used to explore the role of overlapping speech in two meetings in a large educational institution in New Zealand.

The following chapter outlines the analytic considerations that were taken into account for the exploration of the selected instances of overlapping speech. This is followed by the researcher's analysis of those instances that illustrate the most common uses of overlaps observed in the two meetings recorded. 


\section{Chapter 5 - Analysis and Discussion}

As discussed in the methodology chapter, the examples discussed in the analysis were chosen for their ability to illustrate common linguistic behaviour observed in interaction by this group of instructors. The discussion of these examples is divided into the analyst's account of the findings and the participants' account of the findings for their potential to address the two research questions posed in this study.

Finding its roots in anthropological studies, Locher and Langlotz (2008) explain that politeness research has been approached from two different angles, namely, from an emic and an etic perspective (consider Ruhi and Işik-Güler, 2007). In politeness research, this distinction goes back to the work of Watts et al. (2005) who differentiate between firstorder and second-order politeness. First-order politeness corresponds to investigations that are emic in nature, that is to say, studies that look into "the various ways in which polite behaviour is perceived and talked about by members of socio-cultural groups" (2005: 3, emphasis added). An emic perspective then offers insights into insiders' interpretations of linguistic behaviour and descriptions of those "schemes and categories regarded as meaningful and appropriate by native members of a culture" (Lett, 1990: 130; also see Tannen, 1994; Haugh, 2007). Second-order politeness, on the other hand, corresponds to investigations that are etic in nature. Research of this kind is characterized by researcher's interpretations of linguistic behaviour that rely on extrinsic concepts and categories deriving from theories of social behaviour and language usage (Watts et al., 2005; Lett, 1990).

Based on this framework for the discussion of the findings, the analysis of the overlapping instances considered in this study will be presented in a similar way to the etic and emic perspective used in politeness research. In this way, the following section of this chapter offers the researcher's interpretations, similar to, although not strictly, an etic analysis, of the overlapping instances studied. In this section, then, the analysis revolves around the researcher's interpretations of the possible functions of overlapping speech in the context of the two meetings recorded. The aim of this section is to answer the first research question posed in this study, namely, the role overlapping speech plays in this particular context of interaction. In addition, the last section of this chapter offers a 
discussion of the linguistic norms of behaviour regarding the use of overlapping speech, which suggests that this group of instructors operate as a Community of Practice rather than as ethnic individualities.

Chapter 6, on the other hand, will offer participants' perceptions, similar to an emic analysis, of the role of overlapping speech in naturally-occurring workplace interaction. The aim of this chapter is to address the second research question posed in this study, namely, how interactants intend to use and perceive overlapping speech.

In both chapters, the several points of analysis identified will be explored as the discussion of these examples unfolds.

\subsection{Discussion: analyst's perspective on overlapping speech}

Drawing on the data gathered in the two meetings, this section will provide an interpretative account of the functions of overlapping speech in intercultural interaction using the interrelated framework of rapport management as basis for analysis.

\subsubsection{Using overlaps to do relational work}

To consider the functions of overlapping speech in the context of workplace communication, it should be emphasized that at the heart of relational work is the idea that interactants negotiate relationships in social encounters through the use of language (Locher, 2006; cf. Spencer-Oatey, 2008). As explored in chapter 3, this negotiation process entails the management of face, sociality rights and obligations, and interactional goals, all of which interact to make up the dynamics of interpersonal interaction (Spencer-Oatey, 2005, 2008).

Within face management, Scollon and Scollon (1995: 36 as cited in Spencer-Oatey: 2005: 101) discuss the concept of involvement face as a person's right to "be considered a normal, contributing, or supporting member (...)." In this regard, doing relational work involves "attending to workplace relationships" (Holmes and Marra, 2004: 378) by making people feel valued, recognising people's expertise and respecting their autonomy, for instance. Supporting each other as a member of a team in this way strengthens the 
bond between them and builds rapport. In close connection with the management of face, sociality rights and obligations encompass behavioural assumptions and expectations for self and other that include behavioural norms of conduct related to the type of job, entitlement to personal consideration and social involvement with other team members (Spencer-Oatey, 2005, 2008). Then, when interacting in the workplace, people commonly bring 'previously acquired' assumptions and expectations of each other's role within the interaction and the kind of behaviour that is appropriate in a given situation (Locher, 2006).

Participants' observation of sociality rights and obligations are in direct relation to the achievement of interactional goals. Relational work in workplace meetings is oriented to the fulfilment of transactional, or instrumental, and/or affective, or relational goals (Holmes and Stubbe, 2003; Holmes and Marra, 2004). Transactional goals are those for which people interact with the aim of achieving a specific task, whereas relational goals are those that aim at 'effective relationship management' (Spencer-Oatey, 2005). These goals are strongly interconnected as the achievement of one may depend on the achievement of the other. For example, the success of a business transaction may depend upon the effective management of relational goals, such as recognising interactants' face needs and acting accordingly. Thus, complying with the group's norms of appropriate social and linguistic behaviour as well as recognising and acting on the face needs of interactants can facilitate the achievement of both transactional and affective goals in workplace interaction.

Consequently, the relationship between the three factors is so fluid that it becomes hard to discuss them in isolation (cf. Holmes and Marra, 2004). For that reason the following examples taken from data gathered for this study will illustrate the interrelation of these factors as manifested in the role of overlaps in terms of sensitivity to interactants' face needs, observation of sociality rights and obligations, and fulfilment of interactional goals. 


\subsubsection{Achieving transactional and affective goals}

To illustrate the interrelation of the factors outlined above, example 5.1 shows how participants use overlaps to achieve both transactional and affective goals in interaction. In this example, Greta, Frida and Delia are discussing how they design their classes in their programmes. The discussion on this matter becomes quite controversial and potentially face-threatening as Greta and Delia do not agree on what the institution implies by 'course design' and 'teaching'. While Greta maintains that their job as instructors entails 'course design' because they look for their own material and teach the classes, Delia and Frida explain that the institution sees that as part of the 'teaching' duties and would not see it as 'course design'.

Example 5.1 [16: 9-22]

Context: the instructors are discussing class design.

People involved: Greta, Frida and Delia

\begin{tabular}{|c|c|}
\hline$\# 9: G>$ & $\begin{array}{l}=\text { finds her own materials and puts it in a certain way } \\
\text { /to do it }{ }^{\circ \circ} \text { and i do the same }{ }^{\circ \circ} \text { I }\end{array}$ \\
\hline$\langle \# 10:\rangle$ & \\
\hline$\langle \# 11: D\rangle$ & /but you see they're they're quite happy to do that \\
\hline$\langle \# 12:\rangle$ & and they /would not have called it asl \\
\hline$\langle \# 13:\rangle$ & $/ /[$ course $]$ design $\|=$ \\
\hline$\langle \# 14: G\rangle$ & /that's the ${ }^{\circ}$ thing $^{\circ \circ} \mathrm{mm}^{\circ}{ }^{\circ}$ yeah ${ }^{\circ}$ \\
\hline$\langle \# 15: F\rangle$ & $/ /{ }^{\circ}$ no that's not course design that's part of \\
\hline 〈\#16:> & the teaching ${ }^{\circ} \|$ \\
\hline$\langle \# 17: D\rangle$ & $=$ they would call it as $/())$ you know?= \\
\hline 〈\#18:G> & ${ }^{\circ \circ}$ that why ${ }^{\circ \circ}{ }^{\circ}$ yeah $^{\circ}$ \\
\hline 〈\#19:> & $=$ that when you've got /a [position] a fourth $\backslash$ year \\
\hline <\#20:> & student uhh in /in uhh!. \\
\hline$\langle \# 21: F\rangle$ & ${ }^{1}$ that's preparing your class ${ }^{\circ} \backslash /$ well that \\
\hline 〈\#22:> & what they call it \[gazing at Martina] \\
\hline
\end{tabular}

There are several overlaps serving various purposes in this example. In line 11 Delia provides immediate feedback that has the purpose of putting forward a new perspective on the matter under consideration; Delia overlaps Greta where no transitional relevance place has been indicated and so Greta claims her right to finish her turn by raising her pitch which she maintains until she finishes her idea (line 10; Liddicoat, 2007; Kitzinger, 2008). However, Delia successfully takes the floor only to be overlapped by Greta in lines 14 and 18. In both cases, the second speaker's overlaps display agreement with what 
Delia is saying for which they have a supportive function in the interaction (Murata, 1994). As opposed to Delia's, Greta's overlaps do not seem to be intended as a turntaking claim but just as a backchanelling response to show agreement $\left(1^{\circ}{ }^{\circ}\right.$ that why ${ }^{\circ 0}$ ${ }^{\circ}$ yeah ${ }^{\circ}$ line 18). Similarly, Frida collaborates (lines 15 and 21) rephrasing what Delia has said to express more referentially supportive comments about what Delia is saying. Also her utterances' low pitch and volume seem to indicate she does not intend it to be a floortaking move. Actually she may intend it to be an affiliative move that confirms what Delia is saying but which is not directed to Delia. Thus, far from attempting to interrupt Delia, Frida may be sharing her views, in line with those of Delia, with another participant (Martina). By expressing agreement and support with what initially can be thought to be a controversial point of discussion, Greta and Frida engage in doing relational work by expressing solidarity which saves Delia's face and mitigates a potentially face-threatening act.

In addition to expressing solidarity, overlaps have been observed to be frequently used as a linguistic strategy to do face repair work. Example 5.2 illustrates this point.

The exchange in example 5.2 is initiated by Martina's comment about how all the current work changes may affect people who have seniority in the institution. In response to this, Michelle explains that it may be time to move on and start a new job. Delia then adds that they (the instructors) have had "ample opportunity" to move to a higher position if they had wanted to (line 8).

\section{Example 5.2 [13: 8-35]}

Context: the instructors are discussing future job options. People involved: Michelle, Greta, Delia, Rebecca

\begin{tabular}{|c|c|}
\hline$\langle \# 8: D\rangle$ & $\mathrm{se}^{\circ \circ}$ that yes i mean in a in a way when you \\
\hline$\langle \# 9:\rangle$ & are in this position you have ample opportunity to \\
\hline$\langle \# 10:\rangle$ & move /up if you wanted to but you haven't \\
\hline <\#11:> & because there ${ }^{\circ}$ is $^{\circ}=$ \\
\hline$\langle \# 12: G\rangle$ & $/ \mathrm{hmmml}$ \\
\hline$\langle \# 13: M\rangle$ & $=/^{\circ \circ}$ or maybe because ${ }^{\circ 0} \backslash /$ or because $l=$ \\
\hline$\langle \# 14: D\rangle$ & ${ }^{10}$ if there were i mean i'm i'm $\mathbf{m}^{\circ} \backslash\{$ in a very high \\
\hline$\langle \# 15:\rangle$ & pitch, leaning back $\}$ \\
\hline $\begin{array}{l}\langle \# 16: M> \\
\langle \# 17:\rangle\end{array}$ & $\begin{array}{l}=\text { we our our character we're no ambitious people in } \\
\text { the sense of ambitious to climb //a ladder } / \text { \{ Martina }\end{array}$ \\
\hline
\end{tabular}




\begin{tabular}{|c|c|}
\hline <\#18:> & laughs nervously\} \\
\hline$<\# 19: G>$ & $/ /{ }^{\circ}$ but the thing is that we're $\uparrow$ doing what we like \\
\hline <\#20:> & doing $^{\circ} \|=$ \\
\hline$\langle \# 21: \mathrm{D}\rangle$ & $/ /$ no no but i want to teach yeah $\backslash\{$ whispering $\}$ \\
\hline$\langle \# 22:>$ & that's right $\mathrm{i}$ want teaching positions \\
\hline <\#23:> & i don't want a research \\
\hline$\langle \# 24:>$ & position $\{$ smiling, her palms up pointing at Greta $\}$ \\
\hline$\langle \# 25: M>$ & ${ }^{\circ}$ that's right ${ }^{\circ}$ \\
\hline$\langle \# 26: G>$ & $=/^{\circ \circ}$ exactly ${ }^{\circ \circ} \backslash$ i mean i can do a phd but i don't \\
\hline$\langle \# 27:>$ & want to $+/ / /$ posh papers $\backslash=$ \\
\hline$<\# 28: \mathrm{Ma}>$ & /end up like that $\backslash$ \\
\hline$<\# 29: G>$ & $=/$ like that you know? i don't want to $\backslash \mathbb{I}$ \\
\hline$\langle \# 30: \mathrm{D}\rangle$ & //yeah yeah no no no no no no noll \{leaning back \\
\hline <\#31:> & and smiling \\
\hline$\langle \# 32: \mathrm{R}\rangle$ & /they're published papers yeah i mean they are \\
\hline <\#33:> & actually not $\backslash$ relevant $\mathrm{i}$ mean to the teach- what \\
\hline <\#34:> & they did is not related to language teaching at all \\
\hline$\langle \# 35:\rangle$ & so not relevant so so $+\ldots$ \\
\hline
\end{tabular}

Delia's comment (lines 8-11) is potentially face-threatening to all the participants present in the meeting as she indirectly holds them responsible for the outcomes of the upcoming job changes. With it, she elicits comments from Michelle who makes a successful attempt at the floor (Li et al., 2005) which she signals by overlapping Delia and raising her pitch as she does it to gain the floor. In so doing, Michelle starts to provide feedback about why they (the instructors) have not gained higher positions (line 13). At this point, Delia acknowledges that her comment may have damaged Michelle's face and initiates face repair work by overlapping Michelle in an attempt to rephrase what she has previously said while talking in a warm and very low tone, and smiling possibly to downtone the previous potentially face-threatening comment. However, by raising her pitch again, Michelle signals her intention to continue talking and Delia becomes silent. In clarifying why they have not moved up "the ladder" (line 17), Michelle uses the word ambitious which gives her comment a strong negative connotation in the context of this interaction. Consequently, Michelle's comment can be thought to imply that people who did think 'where they were going with that job' are ambitious. The rather aggressive tone of Michelle's remark, then, provides some evidence to support the claim that Delia's initial comment did, in fact, threaten Michelle's face and so she resorts to justifying their actions to challenge Delia's view and save her own face. 
Moreover, the other interactants recognise Michelle's (and, if also affected by Delia's comment, probably also their own) need to restore her positive face and engage in doing face repair work to attend to Michelle's face needs. Then Greta overlaps Michelle (line19) to add propositional content that supports Michelle's stance and builds solidarity among these co-workers. Following this, an agreement point is reached when Delia overlaps Greta (line 21) to make it clear that she has the same goals everybody in that meeting does, that of teaching rather than doing research. To this clarification Michelle replies approvingly (/othat's right 9 line 25) and is overlapped by Greta who also acknowledges Delia's comment (line 26) and elaborates on it explaining she is not interested in doing $\mathrm{PhD}$ studies to gain a position as a researcher, which, consequently, strengthens Delia's point. Martina, at the same time, possibly recognises a transitional relevance place signalled by Greta's pause (see Furo, 2001) and overlaps Greta in an attempt to express solidarity by completing Greta's sentence. As Greta continues talking and completes her idea, Delia overlaps her by using backchanelling responses (yeah yeah no... line 30) to display listenership and agreement with what Greta is saying. Greta and Delia are, at the same time, overlapped by Rebecca who makes a successful claim at the floor (line 32). By explaining that the kind of research they [the absent lecturers] do is not related to teaching practices, Rebecca uses her turn to put forward ideas that support the consensus the group has reached, namely that they, the instructors, wish to have teaching and not research positions.

A structural analysis of this extract would indicate that most of these instances of overlapping speech (except for lines 26 and 30 which are minimal responses) can be said to be disruptive ${ }^{6}$ in form. A functional analysis, however, reveals the role that overlapping speech has in achieving affective goals in this interactional context. In this way, all the instances of overlapping speech analysed in this extract appear to be motivated by participants' need to attend to Michelle's face which, judging by Michelle's rather defensive reaction, has been threatened by Delia's initial comment. In this regard, $\mathrm{Ng}$ et al. (1995) call these moves rescuers, the overlaps that aim at 'rescuing' or saving the current speaker's face. Meier (1995b: 388) explains that the mechanism of repair work involved here "functions to remedy any damage incurred to an 'actor's' [current

\footnotetext{
${ }^{6}$ See structural point of view of overlapping speech discussed in the previous example.
} 
speaker's] image". So the urgency of the need to repair Michelle's image and restore social harmony prompts interactants to engage in a sequence of overlapping speech that is characterised by other-initiated repair manoeuvres (Egbert, 2004). In line with this view, seeing that Michelle is affected by a potentially face-threatening comment, the other members of the group initiate and do repair work to restore her face while at the same time also working to restore the social harmony that seems to prevail in this group throughout the meetings. Overlaps in this context have an active role in doing repair work by which participants collaboratively construct the idea that they have not gained higher positions because they are not interested in those positions and they are doing what they like doing, namely, teaching. They jointly achieve this by each adding and developing supporting information that feeds into each other's comments and that strengthens their point as it builds a coherent argument to support their choice of having their current positions (cf. Ng et al., 1995).

At the same time it restores the positive face of a participant, other-initiated repair can also have an affiliative effect among the participants (Maheux-Pelletier and Golato, 2008). According to Egbert (2004), participants collaboratively work towards the attainment of an interactional goal through a series of successive repair moves that consequently build affiliation. In the example above, group affiliation is achieved as Greta, Delia, Michelle, Rebecca and Martina engage themselves in a succession of overlapping repair turns that express agreement with and confirm what they are all saying (lines 19, 25, 26 and 3), that elaborate on each other's ideas (line 32), and that clarify possible misunderstandings (lines 14 and 21) (see Sheldon, 1993). By providing such supportive comments participants dialogically create a shared understanding of why they are satisfied with their current positions, which brings them together as their group membership is confirmed and strengthened.

\subsubsection{The role of pragmatic particles}

Supportive comments in the form of overlapping speech have also been observed to be elicited by the use of pragmatic particles. The overlaps elicited by the use of pragmatic particles have been observed to play an active role in the conversation as the current 
speaker seeks support from the group and sometimes collaborative comments that offer clarification of what he/she is saying.

In the following example, it is interesting to note Greta's use of you know as a potentially important communicative strategy in that it not only engages people in the conversation but also seems to motivate participants to display overlapping behaviour. In both cases of overlapping speech considered here (lines 2-4 and 13-16), Delia overlaps Greta immediately after she says you know?

Although pragmatic particles are not believed to contribute to the propositional meaning of an utterance, they do express affective meaning (Terraschke, 2005, 2007). In other words, the information conveyed in a conversation is 'modulated' by pragmatic devices (Gardner et al., 1989). Thus, as a negative politeness strategy, it serves to attenuate the force of negatively affective speech (Terraschke, 2005, 2007), while as a positive politeness strategy, it is used to, for instance, convey solidarity, establish shared knowledge and understanding, and check out comprehension of information with the addressee (Stubbe and Holmes, 1995; Bell, 1984).

\section{Example 5.3 [10: 1-16]}

Context: Greta is discussing the quality of the work of instructors in the institution.

People involved: Greta and Delia

\begin{tabular}{|c|c|}
\hline$\langle \# 1: G>$ & ...if you if you if you if you if you're employing \\
\hline$\langle \# 2:>$ & a $\uparrow[$ position] you're getting what you're you know? \\
\hline$\langle \# 3:>$ & /if youl= \\
\hline$\langle \# 4: D>$ & /yeah\} $\\
{\hline\langle \# 5: G>} &{=/ \text { if you'rel paying a [position] you're employing a }} \\
{\hline\langle \# 6:>} &{\text { [position] you're getting [position's] work } /+\backslash \text { yeah?= }} \\
{\hline\langle \# 7: \mathrm{D}\rangle} &{\text { /yeah\/yeah\ }} \\
{\hline\langle \# 8: G>} &{\text { if you want something } \uparrow \text { different }+/ \text { then you have to }} \\
{\hline\langle \# 9:>} &{\text { employ somebody different but } \mathrm{i} \text { think sometimes } \backslash=} \\
{\hline\langle \# 10: D>} &{\text { /then you want all you have to ( ) and you have tol }} \\
{\hline\langle \# 11: G>} &{=\text { it's you know like with dogs or you know cats you }} \\
{\hline<\# 12:>} &{\text { know very sort of animalistic type of stuff you need }} \\
{\hline\langle \# 13:>} &{\text { to show them otherwise you know? /and they have to }} \\
{\hline\langle \# 14:>} &{\text { feel it on their skin you have to pinch them and }} \\
{\hline\langle \# 15:>} &{\text { say hey! you know? }{ }^{\circ} \text { kind of thing }{ }^{\circ}=} \\
{\hline\langle \# 16: D>} &{\text { /yeah, yeah, yeah, yeah, yeah〉 }} \\
$\hline
\end{tabular}


Example 5.3 illustrates the use of you know potentially as both negative and positive politeness strategies. As a negative politeness strategy, Greta introduces the phrase you know at the end of those statements that can convey negative connotations on the topic they are discussing or that express Greta's blunt opinions. The generic you and they in lines 1, 2, 5, 6 and 13, for instance, show that the propositional content of those utterances is not directed to those participants present in the meeting but rather refer to a participant that is not present. However, anticipating any negative effects her comments may bring about among the instructors present, Greta attenuates them employing you know as a mitigation device. At the same time, the pragmatic device may function as a positive politeness strategy since it helps establish interactional empathy. Interestingly, Greta's use of you know elicits backchanelling responses mostly from Delia, who seems to be very actively engaged in the conversation at this point and who responds to the stimulus by providing some input in the form of minimal responses (yeah lines 4 and 16). Although minimal responses do constitute a case of overlapping speech, as argued in chapter 3, they are not considered to be disruptive as the speaker is not claiming a turn but merely displaying listenership (Coates, 1990). As a consequence, Delia's linguistic behaviour could be interpreted as a positive politeness strategy since it serves the purpose of showing support towards Greta's statements and of building solidarity, which, in turn, also builds rapport among the participants (Ouafeu, 2006).

More often than not, pragmatic devices elicit minimal responses ${ }^{7}$ from the listener as interactional feedback with the aim of building a sense of co-participation in the interaction (Coates, 1990; Allan, 1990). However, given their potential to fulfil different functions in an interaction, pragmatic devices should also be able to elicit different kinds of responses (Meyerhoff, 1994). Consider the following example:

\section{Example 5.4 [6: 8-13]}

Context: the instructors are discussing possible changes to their role description.

People involved: Greta, Delia, Rebecca

$\langle \# 8: \mathrm{G}\rangle \quad=$ =if you have umm if you have a a staff member going

$\langle \# 9:>\quad$ on leave and they ask us you know? then we probably

$<\# 10:>\quad$ would get a:: you know? an- another contract for+

\footnotetext{
${ }^{7}$ See Appendix B, extracts 12, 14, and 16 for more examples.
} 
$\left\langle \# 11:>\quad\right.$ you /know? like ${ }^{\circ \circ}$ [position] $\quad$ or something like

$<\# 12:>\quad / /$ that $^{\circ}{ }^{\circ} \mid \backslash$ pretty much or ${ }^{\circ}$ something like that ${ }^{\circ} \mathrm{mmm}$

$\langle \# 13: D, R\rangle \quad /$ for ${ }^{\circ}$ for a couple of months $(. . .)^{\circ} \backslash$

In this example, Greta uses the pragmatic particle you know? repeatedly. In the first two cases she seems to be confirming what she is saying with the listener establishing the grounds for discussing shared knowledge. The third instance, on the other hand, is preceded by a pause that may be interpreted by participants as a turn completion move (cf. Tannen, 1994). However, because the pause is made at the beginning of a prepositional phrase, indicating that Greta intends to keep talking (Furo, 2001), the participants could have interpreted the following you know? as Greta's need for help to finish her idea. As a result, she successfully elicits comments from two of her colleagues when Delia and Rebecca make a simultaneous move to complete Greta's idea echoing the last word (for) before the pause and, in so doing, overlap Greta who has already started completing her idea. As discussed in example 5.1, for instance, the resulting overlapping turn can be looked at from two different perspectives: a mechanical and an interactional one (Furo, 2001). According to the mechanical definition, this overlapping turn would be considered a disruptive overlap, thus an interruption, since the overlap occurs more than two syllables prior to the end of the current speaker's turn and has the potential of seizing the floor from its current speaker (Zimmerman and West, 1975; Edelsky, 1993). In this way, the overlap may be regarded as a threat to the current speaker's completion of her turn (Liddicoat, 2007).

But again, in this case, the interactional view of turns challenges the mechanical definition significantly to capture the interactional essence of conversation. According to the interactional view (Tannen, 1994; Furo, 2001), this instance of overlapping speech would not be regarded disruptive since, functionally speaking, Delia and Rebecca are collaborating in the completion of Greta's thought. In this regard, Clancy et al. (1996) ${ }^{8}$ maintain that some non-floor-taking turns are realised in the form of collaborative finishes and explain that participants judge these turns on the basis of audible evidence. Consequently, judging by the very low pitch of the overlap, Delia and Rebecca do not seem to be making a claim for the floor. In this regard, Couper-Kuhlen (2001) explains

\footnotetext{
${ }^{8}$ In Furo, 2001.
} 
that prosodic features such as pitch help interactants make inferences about turn-taking and floor-management. It logically follows that an utterance said in low pitch is not likely to be interpreted as a move to seize the floor ${ }^{9}$. In other words, this instance of simultaneous speech can be seen as a cooperative overlap as Delia and Rebecca wanted to help Greta but seem to have no intention of taking the floor. This appears to promote in-group solidarity and indexes participants' high involvement in the conversation (cf. Tannen, 1996; Ouafeu, 2006).

Similarly, in example 5.5, Greta dominates the conversation while she is discussing possible applicants for the following year's positions.

\section{Example 5.5 [12: 6-13]}

Context: the instructors discuss possible people to fill future positions. People involved: Greta, Delia, Michelle, Rebecca

$\langle \# 6: G\rangle \quad$ =because $i$ mean if i see + i'm sure there are some

$\langle \# 7:>\quad$ phd students o:r you know? even some master students

$\langle \# 8:>\quad$ or some honour students that will be that will be

$<\# 9:>\quad \uparrow$ great but ++ you know? /like $\backslash++$ they might be they=

$<\# 10: \mathrm{M}>\quad / \mathrm{hmmml}$

$<\# 11: \mathrm{G}\rangle \quad=$ =might be doing it for a ye:ar and then $\uparrow$ you $/$ know?+

$<\# 12:>\quad{ }^{\circ}$ you know? and umm then the next year ${ }^{\circ \circ} \mid=$

$<\# 13: D>\quad$ /yeah to get a bit of money to to ehhh yeah yeah।

In the instance of overlap highlighted here Greta's you know? once again elicits backchanelling responses (yeah line 13) from Delia. But this time Greta makes a pause after you know? Delia identifies a possible turn completion point signalled by the pause and takes the opportunity to add new information which, by being meaningfully connected with what Greta is saying, is relevant to the development of the conversation. Greta, at the same time she is being overlapped, gazes at Delia and acknowledges Delia's contribution by repeating you know?, only this time she does it to show agreement and confirmation with what Delia has said. But Greta has the intention of continuing speaking after this acknowledgement and so her pitch rises in order to keep the floor. This appears to give Delia the indication that Greta's turn has not finished yet and so she switches back to minimal responses (yeah, yeah line 13) as her way of participating in the conversation. The fact that Greta responded to this overlap approvingly seems to be an indication that

\footnotetext{
${ }^{9}$ See overlap resolution devices in Liddicoat, 2007.
} 
she welcomes it as part of the flow of the conversation. In addition to this, the fact that Delia identifies Greta's expectations and acts accordingly presupposes a tacit understanding of operationalisation rules that govern their interactions (cf. Locher, 2006).

\subsubsection{The role of rising intonation in eliciting overlaps}

As discussed above, all those instances analysed of the pragmatic particle you know? that were shown to elicit overlaps were uttered with rising intonation ${ }^{10}$, as the question mark ${ }^{11}$ indicates. The data collected provide additional evidence to suggest that rising intonation, not exclusively used with pragmatic particles, is commonly used in its capacity to elicit responses that are realised as overlaps (Allan, 1990).

Rising intonation, or high rising terminal (henceforth $\mathrm{HRT}^{12}$ ), is a pragmatic device (Bell, 1999) that is associated with "salient rises in pitch at the ends of non-interrogative intonational phrases" (Warren and Britain, 1999: 153). In recent research, this device has been described as a positive politeness strategy used by interactants in order to fulfil a number of interactional goals (Britain and Newman, 1992). Among them, Britain and Newman (1992) distinguish between instrumental goals, that is to say those which help repair miscommunication and do effective negotiation, and affective goals, those which help establish "common ground and solidarity between the interlocutors" (1992: 9). Moreover, it is argued that the use of HRT seems to demand a response from the addressee, which is usually realised in the form of minimal responses (Allan, 1990). Examples 5.6 and 5.7 illustrate this point.

\section{Example 5.6 [8: 1-7]}

Context: Greta is sharing details of her current work conditions with the other participants.

People involved: Greta, Delia, Rebecca

$\langle \# 1: \mathrm{G}\rangle \quad$...now i'm doing [name]s classes because we arranged

$\langle \# 2:\rangle \quad$ that the summer course is not going to $\uparrow$ happen and

<\#3:> i'm i'm being paid for the summer $\uparrow \underline{\text { course } / o f f i c i a l l y l}$

\footnotetext{
${ }^{10}$ Compare you know with falling intonation in extracts 10, and 11. Also see Furo (2001) for intonational completion points.

${ }^{11}$ Arrows $(\uparrow)$ also indicate rising intonation.

12 Also referred to as 'uptalk' (Fletcher et al., 2006).
} 
$<\# 4: \quad$ in $\uparrow$ that $=$

$<\# 5: \mathrm{R}>\quad$ /ohhh $\backslash$

$\langle \# 6: \mathrm{D}\rangle \quad$ /okl

$\langle \# 7: G>\quad=$ so i'm not teaching the summer course and umm +

Example 5.7 also serves to illustrate the point that the use of an HRT seems to demand a response from the addressee.

\section{Example 5.7 [16: 4-9]}

Context: At this point in the meeting Linda comes in the room and joins the other instructors. In this extract the instructors are discussing how they design their classes in their programmes.

People involved: Greta and Delia

$\langle \# 4: G\rangle \quad \quad$... it's more uh like Frida

$\langle \# 5:>\quad$ focuses on ahh speaking a:nd listening in the a $\mathrm{v}$

$\langle \# 6:\rangle \quad$ classes for second $/ \uparrow$ ye:arl and she looks for their mat-

$<\# 7:>\quad$ her own $/ \uparrow$ materiall and you know? deals $/$ you know? $\backslash=$

$<\# 8: \mathrm{D}>\quad / \mathbf{m m} \backslash /$ yeah $\backslash / \mathbf{m m}$ yeah $\backslash$

$<\# 9: G>\quad=$ finds her own materials and puts it in a certain way...

In these examples, Greta's use of rising intonation on verbs (happen), nouns (course, year, material) and demonstratives (that) can be said to have two interrelated interactional functions. On the one hand, it has been found that HRTs have a tendency to occur in a series so that, among other functions, continuity of speaker is ensured. In this regard, Liddicoat explains that "continuing intonation contour effectively overrides a (...) possible transition point" (2007: 59). Thus, Greta's repetitive use of rising intonation secures the floor so she can continue talking (line 4 in example 5.6 and line 7 in example 5.7), which is recognised by Rebecca and Delia who contribute minimally with acknowledging comments.

Allan (1990) argues that the speaker actually intends for these responses to be minimal from which the second interactional function of HRTs in these extracts follows logically. Considering the propositional content of Greta's turns, a HRT may also be used as a strategy to affectively obtain empathy from the other participants (Britain and Newman, 1992). This observation is in line with the evidence found in these meetings that suggest that Greta uses you know with rising intonation in those instances where she is potentially inviting participants to have a say in the conversation, or where she would at least expect participants to respond in some way to what she is saying. In this extract, 
Greta is explaining that she made arrangements to make up for the fact that she is teaching more classes than the institution can afford. By using a HRT, then, Greta elicits minimal responses from Rebecca and Delia that possibly aim at showing understanding and sensitivity towards Greta's comments and ensuring good rapport is maintained.

Moreover, the harmony with which these exchanges flow suggests that there is an implicit understanding between both parties, speaker and addressees, about how HRTs function in interaction. As a consequence of complying with the tacit norms of interaction regarding the use of HRTs, the interactants establish common ground between the listeners and the speaker which, in turn, displays group membership (see Fletcher et al., 2006). Finally, by encouraging some interactional involvement and sharing the floor with other participants, even if it is for a short while, Greta is observing the sociopragmatic principle of association (cf. Scollon and Scollon's (2001) idea of involvement face) by which participants are given "appropriate amounts and types of 'activity' involvement with others" (Spencer-Oatey, 2005: 100).

But not all of those instances of HRTs that elicit overlapping answers do so in the form of minimal responses. There are other instances where HRTs elicit longer turns of collaborative overlapping speech. Consider the following example:

\section{Example 5.8 [14: 4-11]}

Context: the instructors are discussing staff needs and possible scenarios related to these needs.

People involved: Delia and Greta

$\langle \# 4: \mathrm{G}\rangle \quad$ if it was something else like if you wanted to $/$

$\langle \# 5:>\quad$ get a get a umm get another lecturer /you know? $\quad=$

$\langle \# 6: \mathrm{D}\rangle \quad / \mathrm{hmm} \backslash /$ yeah $\backslash /$ yeah $\backslash$

$\langle \# 7:>\quad$ =you would be $\uparrow$ pushing it or /if you wanted more money

$<\# 8:>\quad$ for your bloody research, you know? ${ }^{\circ}$ you would be

$\left\langle \# 9:>\quad\right.$ pushing it $^{\circ} \ldots$

$<\# 10: D>\quad / \uparrow$ yeah ${ }^{\circ}$ that's what they've been doing for the

<\#11:> [name] department yeah ${ }^{\circ}$ 
This example of overlapping speech is preceded by six more lines of Greta's speech in which HRTs are used six more times ${ }^{13}$ before the instance in line 7 ( $\uparrow$ pushing $i t$ ). Following $\uparrow$ pushing it (line 7), Greta introduces a new clause preceded by the connector or, at which point Delia overlaps Greta to provide additional information, resulting in a rather long exchange of overlapping speech.

From a structural point of view (Edelsky, 1993), Delia's move could be interpreted as a 'disruptive' interruption as she makes what seems to be an attempt at the floor when Greta is possibly signalling her intention to continue talking. The high frequency with which HRT occurs, coupled with the high rate of speech delivery of Greta's comment, again suggests Greta uses it as a strategy to keep the floor as she explains what would hypothetically happen if you (the absent lecturers) needed more research funding. Moreover, or (line 7) grammatically functions as a coordinator between sentences or clauses for which it is to be expected that Greta will continue to develop a new idea, as she does in the following utterance. In other words, Greta has not indexed a grammatical, or syntactic, completion point to let her listeners know that a speaker transition was appropriate at that point (cf. Furo, 2001).

From a functional standpoint, however, when looking at Delia's exchange more closely it can be noted that her comment provides additional information to support what Greta has said in lines 4 and 5 about hiring new lecturers. Furthermore, she sounds unobtrusive since she adds this piece of new information in a very low volume which may suggest she is just participating in the conversation with some of her thoughts but not actually having the intention of seizing the floor. In addition to this, the very fact that Greta's intonational patterns and pitch level are maintained throughout the overlapping exchange suggests she does not think it necessary to make a move to maintain the floor (Liddicoat, 2007), which can indicate that she herself does not regard Delia's exchange as a floor-taking move. Delia's overlap then can be said to have a supportive function in the interaction as the content of her comment is highly relevant to the co-construction of the dialogue and which, given its relevance, also signals Delia's high involvement in the conversation.

\footnotetext{
${ }^{13}$ See extract 14 in Appendix B.
} 


\subsection{Discussion}

Several points of discussion stem from the analysis of the previous examples. The first point to be made is that while there is always the possibility that interactants have interpreted these overlaps as disruptive of their right to continue speaking, the opposite may also be true. On the one hand, these overlaps can be looked at from a structural perspective (Furo, 2001) under which they would be considered disruptive as the overlapping turn starts more than two syllables before the completion of the current turn (Zimmerman and West, 1975). This type of overlap is usually called 'interruption' for it constitutes an infringement on the current speaker's right to continue speaking (Tannen, 1996).

On the other hand, as explored in chapter 2, researchers have recognised the functionality of overlapping speech in actual interaction and have put forward an interactional dimension of analysis (Furo, 2001). Thus, from an interactional point of view, the overlaps described here could be interpreted as collaborative moves for two reasons. First, from the evidence discussed in the analysis, the interrupters' affective aim seems to be that of showing affiliation with what the current speaker says to, potentially, ensure the enhancement of good rapport. Second, overlaps may play a key role in the achievement of the meeting's instrumental goals. The transactional goal of the second meeting, from which the examples analysed were taken ${ }^{14}$, is to agree on a common course of action given the fact that the institution has announced that permanent positions will be open for the following year. Following a meeting with their manager in which he outlined the conditions under which the new contracts would operate, the instructors met with the aim of discussing those conditions and reaching an agreement about which of those would favour them and which of those needed to be reconsidered by the management. Negotiating a shared understanding of these conditions then becomes paramount in reaching a consensus upon which to act as a team. Logically, a salient aspect of the process of team negotiation is participation in the co-construction of meaning (Goldberg, 1990). This co-construction of meaning may raise interruptive behaviour "as a direct consequence of the interactants" respective participatory rights and

\footnotetext{
${ }^{14}$ See chapter 4.
} 
obligations" (Goldberg, 1990: 885; Spencer-Oatey, 2008). Thus, because the overlapping behaviour occurs within the context of the negotiation and co-construction of meaning, when, for instance, deciding what kind of responsibilities are implied by the terms 'teaching' and 'course design' (in example 5.1), overlaps are likely to be considered collaborative (Goldberg, 1990). In other words, the instructors are working together towards a common goal, that of deciding on a unified course of action, for which overlaps are likely to be perceived as collaborative and a means of operationalising participation.

What is more, Goldberg (1990) reconciles the structural and the functional dimensions of analysis of overlapping speech and contends that those overlaps that are structurally disruptive but functionally collaborative should be called 'rapport-oriented interruptions'. This view on overlapping speech captures two of the views that can be put forward regarding the overlaps exemplified here.

A second point of discussion that should be raised regarding the analysis of the examples above is that the evidence on the active participation in the construction of overlapping sequences of speech (see examples 5.1, 5.2, 5.5 and 5.8, for instance) calls for three additional interactional points to be noted. Firstly, the interactants participate in a similar fashion, namely, overlapping each other to make a claim at the floor to express their opinion on the matter. Secondly, they also usually yield the floor when another participant has expressed their wish to say something, as is the case with Michelle and Greta in line 11 and with Greta and Rebecca in lines 29 and 32 in example 5.2, for instance. In other words, participants usually overlap the current speaker as a first move to express their opinions and/or add information which is topically relevant to the development of the issue in question and which supports the current speaker's opinion through explicit agreement (consider example 5.8). This, in turn, is identified by the current speaker and sometimes acknowledged by her when the interrupter is allowed to seize the floor to express their opinion. By allowing everybody to speak up, participants can be said to be managing interactional rights and obligations by observing each other's right to maintain their positive face as they are valued as members of the group whose participation in the interaction is deemed important (see Spencer-Oatey, 2008; Paltridge, 2006). Finally, the overlaps considered in this chapter seem to contribute to the unfolding 
conversation and there is no evidence to suggest that participants felt uncomfortable when overlapping and/or being overlapped. On the contrary, given their high rates of occurrence and the overall uniformity with which they are used, overlaps seem to be used by these participants as a tool to index high interactional involvement (Spencer-Oatey, 2008). Indeed, if overlapping speech has the potential to signal active listenership (Furo, 2001), it can also naturally be used as an interactional strategy to display involvement. Tannen (1994; also Ng et al., 1995; Li, 2001) claims that overlaps which make constructive contributions, such as the ones discussed in this chapter, support and facilitate the ongoing development of the conversation by way of expressing high involvement. As a consequence, she contends that those overlaps that arise from the flow of the conversation, in which it is clear that participants are highly involved, are not likely to be considered disruptive but supportive. Indeed, according to James (1993: 240), collaborative interruptions are very frequent since they "serve to carry a metamessage of interpersonal rapport" and thus "failure to interrupt [may be] interpreted as indicating lack of interest." In other words, since the overlapping instances considered here are used as an interactional strategy that enhances and restores participants' face, as well as it provides support, among other functions analysed here, it would not be surprising if participants did not perceive these overlaps as disruptive but as collaborative and a vital aspect of their communication dynamics.

Reflecting upon these points, then, it can be concluded that given interactants' convergence in their way of using overlaps, this group of instructors employs overlaps as part of their jointly constructed social norms strongly oriented towards the maintenance and enhancement of social harmony in their workplace interaction. As postulated by Meier (1995b: 389), this convergence also reaffirms these instructors' membership in the group as they know how to act appropriately and are possibly able to predict interactional behaviour "in accordance with the social norms of [this] particular reference group" (also see Schnurr et al., 2007).

Evolving from a social constructionist theoretical framework, Wenger's (1998) notion of 'community of practice' (CofP) can explain how the use of overlaps can be said to have become part of the jointly constructed social norms of this group of instructors. The notion of CofP captures the dynamic process(es) by which a group of people, in this 
case in the workplace, are mutually engaged in jointly negotiated enterprise which usually results in the construction of a shared repertoire (Corder and Meyerhoff, 2007; Marra and Holmes, 2007). Corder and Meyerhoff (2007) assert that for a group of people to belong to a CofP these three constructs of the notion of CofP need to be present in their interaction, as they are in this group of instructors. Then, in the context of this study, these instructors come together as co-workers who are mutually engaged in social interaction, including weekly and sometimes fortnightly meetings and casual gatherings in kitchens and corridors, and who work together towards the achievement of shared institutional objectives as a team of language instructors (this being the jointly negotiated enterprise aspect of a CofP). Furthermore, Wenger (1998) maintains that while the interactants are actively involved in 'social enterprises', that is to say, as interactants actively 'participate' in social interactions with members of a group, social norms of linguistic and non-linguistic behaviour will emerge as a result. These norms form the 'social matrix' of the group and their social meaning is renegotiated and adjusted as they engage in interaction (Corder and Meyerhoff, 2007). In this regard, in addition to the evidence provided on interactants' convergence in the use of overlaps, the fact that, on average $^{15}$, these instructors have been members of this team for 8.5 years and that they interact with each other on a weekly basis is enough to suggest they have indeed developed a shared repertoire of social norms of linguistic and non-linguistic behaviour that govern their interactions (see Meier, 1995b above). And thus the analysis of the use of overlaps in this chapter suggests that overlaps are used as an interactional strategy to display active involvement, listenership, solidarity and affiliation as part of the shared repertoire of this particular CofP.

Finally, the evidence discussed so far supports the suggestion that interactants prioritise a rapport enhancement orientation in naturally-occurring workplace interaction with the goal of "strengthening and enhancing harmonious relations between [them]" (Spencer-Oatey, 2008: 32). As demonstrated above, interactants achieve this aim by using overlaps to index high involvement and listenership as a way of exercising solidarity and achieving interactional objectives. The use of overlaps to display positive politeness has actually been found to "grease the wheels of conversation" rather than to

\footnotetext{
${ }^{15}$ See Table 2 in Appendix A.
} 
disrupt it (see Tannen, 1994). If, then, participants orient their rapport management in this way, it is only logical to expect that interlocutors encourage overlapping behaviour in order to fulfil their interactional goal of promoting positive politeness. Indeed the data analysed also provide evidence to suggest that overlapping speech is encouraged as part of the interactional negotiation of face relationships (Félix-Brasdefer, 2008) and have become part of the dynamics of this group's interaction.

\subsection{Summary}

In this chapter, both structural and functional views on overlapping speech have been put forward in order to outline possible interpretations of its role in this specific context of intercultural workplace communication. The analysis carried out sheds light on the role of overlapping speech in this CofP's dynamics to suggest that overlaps are used cooperatively to oil the wheels of interaction (Kitzinger, 2008). In practice, the members of this work team use and elicit overlapping speech as a strategy to display active listenership, participation and high involvement in the conversation. Overlapping speech then acts as a marker of solidarity and positive politeness (cf. Marra and Holmes, 2007) that enhances group cohesion and promotes positive rapport (Spencer-Oatey, 2008). Furthermore, it has also been shown that overlapping speech can be employed by participants to do face repair work when deemed necessary in order to ensure good rapport is maintained. Establishing good rapport and fostering positive values that enhance group membership become vital aspects of this CofP's communication in working together towards the attainment of a common goal, that of deciding a future course of action following their job changes.

It has also been argued that judging from the interlocutors' apparent intentions to elicit overlaps and their reactions to overlaps described above, speakers show no evidence of discomfort when overlapping or being overlapped. In fact, the appropriateness with which the overlapping instances seem to be regarded and even encouraged by the listeners and the speaker(s) suggests that this kind of behaviour is part of the common practices this multicultural team engages in when managing negotiation in interaction (Marra and Holmes, 2007). In other words, participants' converging 
linguistic behaviour, together with their responses to it, reflects their "shared ways of engaging in doing things together" (Wenger, 1998: 125). Consequently, the fact that interactants come from different ethnic backgrounds has not prevented them from having developed shared institutional practices related to the use of overlapping speech that promote successful communication and build rapport among participants.

Finally, research on the role of overlapping speech in naturally-occurring interaction reveals that, ultimately, appreciations of the functions of overlaps lie in the participants' perceptions of those overlaps (Mott and Petrie, 1995; Meier, 1995a \& b). As argued by Talbot (1992, as cited in Furo, 2001), the value an interruption (or overlap for that matter) is given in any specific interaction depends on the interruptee's perception of the appropriateness of that interruption in that context. As a result, the etic analysis provided in this chapter would be enriched by these instructors' perceptions of the function of overlaps.

The following chapter, then, addresses interruptee's perceptions of overlaps by providing an emic account of the role of overlapping speech in these meetings through a discussion of the data collected in the participants' interviews. This discussion will shed light on participants' perceptions of the operationalisation(s) of overlaps in naturallyoccurring speech in the workplace. 


\section{Chapter 6 - Participants' perceptions of overlaps: An Emic Discussion}

Chapter 6 presents an emic analysis of the data so as to address the second research question posed in this study, namely, how interactants intend and perceive the use of overlapping speech. To provide such an analysis, this chapter offers participants' insights of their intentions and perceptions of the role of overlapping speech in naturallyoccurring workplace interaction.

\subsection{Introduction}

It has been widely contended that politeness is a "social judgement" (also called a contextual and evaluative judgement; see Ruhi and Işik-Güler, 2007) since what constitutes polite, politic and/or impolite behaviour is judged by interactants in relation to the context of interaction (see Spencer-Oatey, 2000 in chapter 3). Locher and Watts (2005: 29) stress the role of habitus explaining that "individuals evaluate certain utterances as polite against the background of their own habitus" and that participants' expectations arise from the actual context of interaction. In this regard, Félix-Brasdefer (2008) explains that in relational work appropriate social behaviour is negotiated and renegotiated in interaction. As a consequence, the set of marked assumptions and shared expectations by which people operate in interaction are context-dependent, that is to say, these assumptions and expectations have been interactionally negotiated (also see Meier, 1995a \& b; Holmes and Schnurr, 2005; Haugh, 2007a). This negotiation of assumptions

and expectations has the potential of creating social norms of interaction which guide the behaviour of a group of interactants. As discussed in chapter 5, if and when a group of interactants engages in the construction of social norms of interaction, the group can be conceptualised as a Community of Practice (Wenger, 1998). Thus, when interactants evaluate utterances, they base their judgement of their degree of politeness on the appropriacy of the behaviour within the norms of their Community of Practice, resulting in their perceptions of the use of overlapping speech (Mills, 2009). 


\subsubsection{Intentions and perceptions}

In line with the view that politeness is a social judgement, when considering interactants' perceptions of the role of overlapping speech, Murray (1988 in Mott and Petrie, 1995: 327) states that an interruption, for instance, is "always an interpretation [=perception]... of the intent of the second speaker." Following this argument, overlapping speech can be thought to be disruptive if its perceived intention is that of not contributing to the current speakers' claim or if it is regarded as a topic control mechanism exerting power and dominance (see Karakowsky, 2004). However, overlapping speech can also act as a means for interactants to achieve a "conversational duet" ( $\mathrm{Li}, 2001)$ in which the two (or more) interactants contribute thoughts and ideas to jointly construct a conversation. In this case, overlapping speech is likely to be positively perceived as a constructive contribution to the conversation ( $\mathrm{Ng}$ et al., 1995; Furo, 2001).

Recognising the importance of obtaining participants' intentions when overlapping and perceptions of overlaps to uncover the role of overlapping speech in actual interaction, the following discussion draws its data from the individual interviews conducted with four of the instructors. In these interviews participants watched an average of 10 extracts containing instances in which the interviewee overlapped or was overlapped. Upon watching the extracts, participants were asked to reflect on and report their intentions when using overlaps and their perceptions when being overlapped (see chapter 4 for more details). The following discussion, then, focuses on participants' intentions and perceptions of the use of overlapping speech in two workplace meetings. This is followed by a discussion of participants' insights as to what kind of overlap they consider interactionally disruptive.

\subsection{Speakers' intentions when using overlapping speech}

Upon watching several extracts in which participants overlapped the current speaker, interviewees commented on their intentions behind the use of these overlaps. 


\subsubsection{Informative overlaps}

Very often participants reported that they overlapped the current speaker to provide new information with the purpose of displaying involvement. The comments arising from watching example 6.1 serve to illustrate this point.

The exchange in example 6.1 occurred within the first two minutes of the second meeting. Delia opens the meeting by debriefing the participants as a starting point for this meeting's discussion, focusing on the development of the negotiations with the management of future job conditions.

\section{Example 6.1 [5: 1-9]}

Context: Delia is debriefing her colleagues on the previous meeting.

People involved: Delia and Greta

$\langle \# 1: D\rangle \quad$...the second argument he's going to have to have

$\langle \# 2:>\quad$ fixed term $/[$ position] $] \backslash+$ of one three or two years=

$<\# 3: R>\quad /$ yeahl

$<\# 4: D>\quad$ i mean depending now $/{ }^{\circ}$ whatever $^{\circ} \backslash++$ happens $=$

$<\# 5: G>\quad$ /fixed term (...) could be six months $\backslash$ [smiling]

$<\# 6: D>\quad=$ whether it's going to be permanent uh let's say

$\left\langle \# 7:>\quad\right.$ they say ${ }^{\circ \circ}$ yes $^{\circ \circ}$ for the permanent [position] the nature

$\langle \# 8:\rangle \quad$ of it is quite unclear and he's been putting the

<\#9:> emphasis on that twice and $\mathrm{i}$ know this is it...

In the second instance of overlapping speech (lines 4 and 5) Greta overlaps Delia to make a comment that seems to clarify what could also be meant by fixed term position (line 2). This overlap causes Delia to raise her voice $\left(/^{\circ \circ}\right.$ whatever $^{\circ \circ}$ line 4$)$ in order to keep the floor and subsequently pauses to allow Greta to finish her overlapping turn before continuing speaking.

When watching this example Greta explained the following:

Greta I think it [the overlap] was informing (...). I think she took on the role as explaining it [contents of previous meeting] to Martina and I think what we were doing was just sort of giving extra information when we wanted to. But I also always find, I think, I mean I was also finishing you know? one of her sentences you know? or sort of you know? like being involved in the conversation for me was that I was listening to her and then I sort of finish her sentence while she was finishing her sentence (...). For me that was pretty normal, I mean I would do that in a sort of conversation that 
I'm interested in that I want to take part in and then I finish people's sentences or you know? sort of say words. (emphasis added)

According to Greta her comment was informative and she overlapped as a way of displaying involvement and listenership in the conversation. Similar strategies might include finishing the current speaker's sentences, for instance, or adding words to what the current speaker is saying. Greta reports intending the overlap in line 5 to be collaborative rather than disruptive and to index involvement in the conversation (see Liddicoat, 2007). By adding a comment that is relevant to what Delia is saying, Greta seems to be enhancing Delia's positive face and building a sense of affiliation among participants (see Goldberg, 1990). The fact that Greta considers using overlaps in this way as "pretty normal" provides evidence to claim that overlapping speech has become part of the 'norm' for taking part in a conversation. Greta also explained that her intention was not to seize the floor but that she only intended to show engagement with what Delia was saying and to contribute to "the negotiation of information". From what Greta says in the interview it could be concluded that, in her view, in order to show interest in a conversation, interactants need to give their opinion.

Greta made similar comments when watching example 6.2. In this exchange Delia is explaining how she designs the material for her courses.

\section{Example 6.2 [17: 1-8]}

Context: instructors are discussing issues related to material design.

People involved: Greta and Delia

\begin{tabular}{|c|c|}
\hline \#1:D & ere's a there's a i mean that's what i do i \\
\hline$\langle \# 2:\rangle$ & ) each it’s got a folder every $\uparrow$ week and \\
\hline$\langle \# 3:\rangle$ & tells uh exactly what to do there's the transparencies \\
\hline$<\# 4:>$ & /there's all sorts of material $\backslash$ uh $=$ \\
\hline$\langle \# 5: G\rangle$ & /yeah yeah $\mathrm{mmm}^{\circ}{ }^{\circ}$ exactly ${ }^{\circ}$ yeah \\
\hline 6:1 & tell her where to find the /sound files bla bla \\
\hline 7:: & ${ }^{\circ}{ }^{\circ} b l a^{\circ \circ}+$ that's what a $[$ position] $\backslash=$ \\
\hline$\langle \# 8: G\rangle$ & n] $\downarrow$ does i t \\
\hline
\end{tabular}

Greta overlaps Delia in line 8 to make a comment that supports what Delia is saying, even explicitly stating I totally agree (line 8). When considering this extract, Greta said she intended to show her agreement with what Delia was saying. Greta also 
acknowledged she took quite long overlapping turns but said she did not intend to take the floor of the conversation, and commented the following:

Greta I was just trying to take part in the conversation in a more lively way.

This comment provides evidence to support the claim that Greta is making an implicit assumption about the role of overlapping speech in conversation, namely that a conversation is lively when people overlap each other to display agreement with the current speaker's ideas.

Delia supports Greta's views on the intentions of using overlapping speech. While watching extract 14 (see Appendix B), for example, Delia explained that the instance in which she overlaps Greta (lines 10-11) was not intended to be disruptive. She said she "saw it as a way to illustrate and give a backup idea to support what Greta was saying." She also explained that by exemplifying the point Greta made about what the departments in their institution do to obtain money for research she was collaborating in the development of the conversation.

\subsubsection{Overlaps as rescuers}

In addition to using overlaps to provide new information with the aim of displaying involvement, support and listenership, participants reported using overlaps as rescuers. In line with Greta's and Delia's comments on the same extract, Michelle claims to use overlapping speech in an attempt to assist the current speaker when she thinks the current speaker needs help to complete an idea (cf. rescuers by $\mathrm{Ng}$ et al., 1995 in chapter 5). Consider example 6.3:

\section{Example 6.3 [3: 1-10]}

Context: the participants are discussing possible job scenarios for the following year. People involved: Paul, Delia and Michelle

$\langle \# 1: P\rangle \quad$ a::nd well before hopefully before the end of the

$\langle \# 2:\rangle \quad$ second trimester you would know what was going to

$<\# 3:>\quad$ be happening next year

$<\# 4: D>\quad{ }^{\circ \circ}$ and $^{\circ \circ}$ in the scenario that $\{$ puffing $\}+++$

$<\# 5: M>\quad$ it doesn't go ahead? + sorry \{nervous laughter 
<\#6:> from everybody

$\langle \# 7: D\rangle \quad{ }^{\circ}$ no no no ${ }^{\circ \circ}{ }^{\circ}$ ' $m$ just I'm just just thinking if

$\langle \# 8:>\quad$ that if the conclusion by setting a permanent

$\langle \# 9:>\quad$ position right now didn't seem to be sort of we

$<$ (10:> wouldn't gain ${ }^{\circ} \ldots$

After watching this extract, Michelle explained that she thought Delia seemed to be lost for words to finish expressing her thoughts as Delia first puffed and then made a long pause. Michelle said she overlapped Delia in order to offer a possible way of suggesting what she thought Delia wanted to ask. Moreover, Michelle said that due to the tension caused by Delia's long pause, she thought it important to contribute to release this tension. In doing this, Michelle saved Delia's face from a potentially face-threatening situation in which she had no words to express her thoughts.

All the comments discussed so far offer an insight into how this group of instructors intend to use overlapping speech with the same or similar purposes. Participants' reflections on all the extracts in which they overlapped the current speaker coincide; they intended those overlaps to be a collaborative means of displaying interest and involvement in the conversation and assisting the current speaker when help was deemed necessary. The next section illustrates how the same phenomenon applies to participants' perceptions of overlapping speech, namely that all the participants interviewed have the same or similar perceptions of the instances of overlapping speech watched.

\subsection{Speakers' perceptions of the use of overlaps}

Upon watching several extracts in which participants were overlapped or somebody else overlapped the current speaker, interviewees commented on how they perceived these instances. 


\subsubsection{Informative overlaps}

One of the most salient and widely held comments was an instance of overlapping speech is not perceived as disruptive when the second speaker adds new information relevant to the comment of the current speaker. Example 6.4 illustrates this point.

In this example, Greta talks about how the more senior staff would come to realise the extensive work the instructors do if instructors were not there to do it anymore.

\section{Example 6.4 [9: 7-16]}

Context: Greta is talking about the current work loads under the existing work contract. People involved: Delia and Greta

$\langle \# 7: \mathrm{D}\rangle \quad$... and they come and knock on your door again and again

$\langle \# 8:\rangle \quad$ and again \{ironic laughter\} so it's going to be a

$\langle \# 9:>\quad$ bit of a shock for the: for them but $\uparrow /$ we need to $\backslash=$

$\langle \# 10: \mathrm{G}\rangle \quad$ /but but $\backslash$

$\langle \# 11: D\rangle \quad=$ actually $/{ }^{\circ}$ do that yeah ${ }^{\circ}>$

$\langle \# 12: G\rangle \quad$ /but $\uparrow$ that's $\backslash \mathrm{i}$ think

<\#13:> that's kind of the /thingl=

<\#14:D> /hmml

$\langle \# 15: \mathrm{G}\rangle \quad=$ you know i think it's people

$\langle \# 16:>\quad$ don't realise \{exhaling $\ldots$

In the first instance of overlapping speech Greta echoes the first word of the clause Delia has started to utter but (lines 9, 10 and 12) which Delia uses to introduce a new idea. Since she is starting a new clause, Delia's turn is not grammatically complete at the time of the overlap and Greta's first move at taking the floor could be considered an interruption which is unsuccessful. By raising the pitch of her utterance, Delia manages to keep the floor until she finishes her sentence. However, as she is finishing her turn, her pitch decreases considerably, which may show that she is, in a way, yielding the floor to Greta who takes over from that point.

When watching this extract Delia explained that what she was saying at this point was relevant to the topic of the conversation but that her comment was not adding anything new to the conversation. She explained she did not perceive Greta's overlap as disruptive as she had already communicated what she wanted to say. 
Delia I don't see it [the overlap] as bad because I had actually already had an idea across so I don't feel like I've been brushed off or ignored.

Delia seems to deem it a disruptive overlap when the second speaker overlaps at the time when the current speaker is giving new information and since that was not the case at the point when Greta overlaps her, she did not think she was 'interrupted'. Frida adds to Delia's comment claiming that she did not see it as a disruptive overlap either because the second speaker, Greta, was adding new information that was relevant to the topic of the conversation.

Frida I don't perceive it as negative or anything. I just think it's natural and obviously Greta had something that she wanted to say at this particular moment in time that added to whatever Delia was saying. (emphasis added)

She emphasised this point again when watching extract 12 (see Appendix B).

Frida it's not really interrupting, it's more like affirming what she's saying or confirming what she's saying but also at the same time adding new words, or new ideas that either in their opinion says it better than what Greta is saying or makes it clearer to themselves what we are talking about. (emphasis added)

Frida's comment is representative of the other participants' perception of overlapping speech as a natural interactional phenomenon when participants want to add some new information related to what the current speaker is saying. By contributing new information that is relevant to the topic of the conversation participants build a sense of group solidarity and affiliation showing they are working as a team towards a common goal (see Li et al., 2005). The overlap is then positively perceived as a cooperative means of helping the current speaker coordinate the process of the ongoing conversation to develop her idea further (see Li et al., 2005; Kitzinger, 2008).

Similar comments were made on several occasions in the interviews, particularly when the overlap completes the current speaker's sentence or idea. This kind of overlap seems to have added weight when the overlapping comment displays agreement with what the current speaker is saying, as Frida explains. While watching extract 15 (see Appendix B) Greta explains: 
Greta There was one instance in which she was sort of you know? agreeing with me sort of finishing my sentence which I wasn't finishing, but you know? just saying something along the same lines or just adding a word or something like that.

Greta seems to have interpreted Delia's move as a solidarity one in which Delia shows agreement, which consequently enhances Greta's positive face, and helps her finish her sentences by adding a word or by adding more comments along the same lines. Displaying agreement with the current speaker also builds affiliation and promotes good rapport among interactants (see Goldberg, 1990). The following example further illustrates this point.

In example 6.5 Greta and Delia are discussing how they design their classes and what is expected from them in their programmes.

\section{Example 6.5 [16: 9-22]}

Context: Greta and Delia are talking about class design matters.

People involved: Delia, Greta and Frida

\begin{tabular}{|c|c|}
\hline $\begin{array}{l}\langle \# 9: \mathrm{G}> \\
\langle \# 10:\rangle\end{array}$ & $\begin{array}{l}=\text { finds her own materials and puts it in a certain way } \\
\text { /to do it }{ }^{\circ} \text { and i do the same }{ }^{\circ \circ} /\end{array}$ \\
\hline$\langle \# 11: D\rangle$ & /but you see they're they're quite happy to dol that \\
\hline$\langle \# 12:\rangle$ & and they /would not have called it asl \\
\hline$\langle \# 13:\rangle$ & $/ /[$ course $]$ design $\|=$ \\
\hline 〈\#14:G〉 & /that's the ${ }^{\circ 0}$ thing $^{\circ \circ} \mathrm{mm}^{\circ}{ }^{\circ}$ eah ${ }^{\circ}$ \\
\hline$\langle \# 15: \mathrm{F}\rangle$ & $/ /{ }^{\circ}$ no that's not course design that's part of \\
\hline$\langle \# 16:\rangle$ & the teaching ${ }^{\circ} \|$ \\
\hline$\langle \# 17: D\rangle$ & $=$ they would call it as $/() \backslash$ you know?= \\
\hline 〈\#18:G〉 & ${ }^{10}{ }^{\circ}$ that why ${ }^{\circ 0}{ }^{\circ}$ yeah $^{\circ} \mathrm{I}$ \\
\hline 〈\#19:> & $=$ that when you've got /a [position] a fourth $\backslash$ year \\
\hline$\langle \# 20:\rangle$ & student uhh in /in uhh \... \\
\hline$\langle \# 21: F\rangle$ & ${ }^{\circ}$ that's preparing your class ${ }^{\circ} \backslash$ well that \\
\hline K\#22:> & what they call itl \\
\hline
\end{tabular}

In this exchange it is interesting to see the numerous instances of overlapping speech in which the referential content of both Greta's and Delia's overlaps is supportive (lines $11,14,18)$ as they agree with what the current speaker is saying. In this exchange only Frida seems to be adding new information that serves to clarify the point Delia and Greta are making as to what the institution would consider by 'course design' (see example 5.1 and 5.7). 
In her interview, Delia's comment supports the previous comment made by Greta confirming that those overlapping instances that add new information and show agreement with what the current speaker is saying have a collaborative function in the conversation and are consequently not perceived as disruptive.

Delia We're not moving to a different idea, we're just adding things and we're sort of agreeing with each other (...) we're just adding more arguments to support what the person is saying.

The idea that there is no 'disruption' when the overlapping instance involves new information relevant to the topic under discussion is a recurrent topic mentioned by all participants in the interviews. Participants also argue that this new information helps to show agreement and support with what the current speaker is saying which, judging from the high rates of occurrence of overlapping speech exemplified in 6.2, is a highly valued practice in this CofP. According to Kennedy and Camden (1983, in Li et al., 2005) this kind of overlapping speech constitutes what they call an "agreement interruption" which has the purpose of "showing interest or enthusiasm, and involvement in the ongoing conversation" (2005: 235). The supportive purpose with which overlapping speech is perceived by this team of instructors shows that participants have a strong orientation to enhancing each other's face as an important affective goal of the interaction (see rapport interruptions by Goldberg, 1990, in chapter 5). Overlaps that have such a collaborative function can be called, in Delia's words, 'verbal nods.' According to Delia, all the instances of overlapping speech she watched in the interview, whether she overlapped or was overlapped, are verbal nods which serve to display agreement and also help the current speaker to complete her thoughts when the speaker is short of words. In this way, participants collaboratively construct their conversation and build good in-group rapport.

Delia also repeatedly emphasised that "this way of behaving [using overlaps] shows that you're listening to what the others are saying." She stressed the importance of showing the current speaker that the other interactants are interested in what he/she is saying, to show enthusiasm in order to keep the conversation going (see Mott and Petrie, 1995). Delia reported that this group of interactants may engage in long sequences of overlapping speech to display listenership and interest in the conversation (cf. Li, 2001). 
She recognises that displaying listenership builds affiliation and rapport as "it makes the speaker feel good, [...] listened to." Not surprisingly, Delia is one of the most active members of the team when it comes to displaying overlapping behaviour (see extracts in Appendix B).

\subsubsection{Overlapping to negotiate information}

Moreover, interviewees also stressed the role of overlapping speech as a collaborative means to negotiate information and jointly construct conversation. In regards to example 6.5, the following comment synthesizes Greta's idea of the role of overlapping speech in conversation while it also highlights the recurrent assumptions and interpretations of overlapping speech stemming from the data collected in the interviews.

Greta I think it's just very lively and very kind of sharing in a collaborative kind of way, I think we're totally negotiating meaning I mean we're not negotiating meaning but we're negotiating information you know? Like we're building with information kind of idea, we're totally working together I think that's a collaborative thing. (emphasis added)

Greta made a similar comment when watching extract 7 (see Appendix B) only this time she also adds that engaging in overlapping speech indexes interactants' willingness/eagerness to participate actively in the conversation.

Greta I don't think I feel any 'interrupting' going on. I think that maybe it's the sort of background of negotiating things like just you know? I think I prefer something like that than not having a conversation and talking about things. (emphasis added)

In these two comments Greta expresses her assumptions of what "having a conversation" entails. For her 'having a conversation' implies that interactants share and negotiate ideas to collaboratively build conversation and overlapping speech is part of the dynamics of how this is achieved. Overlaps are not perceived as disruptive because this group of interactants use them to negotiate and build ideas collaboratively. She mentioned that everybody in the meeting had the same goal and they were all interested 
in what they all had to say and they were giving each other a chance to speak. Greta explained that in a different kind of meeting where people do not care about what others have to say, there would be a different kind of interaction, one in which people participated less and "interrupted" less. This shows then that Greta's judgement of overlapping behaviour is positive and that it may serve as a communicative strategy to show interest in what others have to say, which also builds rapport. Furthermore, according to Greta, taking part in a conversation entails 'participating' which seems to be directly connected to the idea of using overlapping speech as a way of exercising that participatory right and indexing degrees of participation, which, in turn, displays involvement in the interaction (see Tannen, 1994).

\subsubsection{Perceptions of overlaps as rescuers}

A further point to be made regarding interviewees' comments is that overlaps are, supporting the argument in chapter 5, perceived as rescuers (Ng et al., 1995). Consider what Frida said when watching extract 3 (see Appendix B) in which, in the middle of her turn, Delia pauses to possibly think how to word what she will say next when Michelle 'interrupts' her thought in an attempt to help Delia complete her idea.

Frida

Not, it doesn't really, I mean, it was clear that Delia wasn't finished but I think it wasn't really interruption, I think it was probably more of a help, offering help (...) especially of the way she [Michelle] apologised afterwards. But at the same time it was clear that she [Michelle] said it in a lot more clearer words than Delia was trying to say coz she started very carefully (...) but it was a quiet break [Delia's pause] so anyone could have stepped in and said something. (emphasis added)

Frida explained that in meetings such as these ones where participants have to negotiate a decision, it is often hard to think of the right words to say so as not to offend any participants. Thus, in situations such as the one above, she explained it is normal to think the current speaker does not know how to say something so another participant tries to help. This is supported by Delia's perceptions of the same exchange. 
Delia I actually don't have the words to, I'm looking for words and poor Michelle is helping. I can't find how to formulate the question [...] there is a huge silence when Michelle fills in the gap for me.

Delia acknowledges that she was trying to find the right words to continue talking and that Michelle was trying to help. In this case, the overlap was perceived by at least two participants as a move to rescue the current speaker, Delia, and to possibly save her face in front of the group for not having the right words to express her thoughts (see $\mathrm{Ng}$ et al., 1995). Thus, the use of overlapping speech is also perceived as a repair mechanism that serves to restore participants' image in potentially face-threatening situations (see Meier, 1995; see discussion in chapter 5).

\subsection{Summary}

Of the 10 extracts that each participant watched in the interview, none of the instances of overlapping speech present was perceived to be disruptive. On the contrary, overlaps are perceived as a communicative strategy that serves to display interest and listenership, to enhance and save participants' positive face and to negotiate ideas collaboratively in the unfolding of the conversation.

\subsection{What constitutes interruptive behaviour}

Considering the fact that participants did not report perceiving any instances of overlapping speech as having a disruptive function in the meetings recorded, participants were asked what, in their opinion, counted as an interruption as a final question of their interviews. To this Greta responded:

Greta I think if you, I think in the meeting in particular if you're trying to work on something together to I mean, in this meeting for example [meeting 1] and also in the other meeting, I think there was not really any points for interruptions just because all of them were going for the same goal. [...] to get information out and to exchange information from different sources and the same one with the other meeting. Whereas I could for example imagine interrupting someone if it was more, you know? if I only had a 
one-on-one with Paul [manager] kind of thing, and he was just saying that was totally wrong and I just felt strongly about it and I you know? would interrupt him and say this is totally wrong. So a lot of the times here it was just negotiating meaning.

She then added that an interruption involves "disturbing someone in what they wanted to say whereas I never felt disturbed and I don't think anyone else kind of felt disturbed." Greta's reflections seem to indicate that, in her opinion, the role of overlapping speech may be judged according to the goal of the interaction and the propositional meaning of the overlap. When the information contained in the overlapping instance supports what the current speaker is saying, the overlap is not likely to be perceived as an interruption. In the context of these meetings, overlaps are also deemed collaborative when the goal of the interaction is that of negotiating information as the use of overlaps can be considered part of the dynamics of the negotiation process. However, if the propositional content of the overlap contradicts that of the current speaker's, the overlap is perceived as an interruption. Thus, this view of overlaps supports the claim made in chapter 5 which contends that overlaps are interactionally judged by their function rather than by their form.

By contrast this norm finds support in Frida's response. In her opinion, overlapping speech becomes disruptive when the second speaker's intention is to take over the conversation preventing the current speaker from finishing his/her idea. In addition, she agrees with Greta in that an overlap is disruptive when it introduces an idea that contradicts what the current speaker is saying.

Frida I think it's an interruption when you are talking so you have taken over as the main speaker in a conversation and you're not necessarily hesitant in what you're saying, you know what you're saying but possibly one of the other speakers either at that moment in time feels that they have something really important and they can't wait, they have to say it now, [...] and then take over from you, or they maybe have something contrary to say and they can't wait until it's their turn coz maybe they know with this particular speaker it will never be their turn or it will be too late by the time they get around to saying it. And they say 'I wanna say this now' and they just interrupt.

Similarly, Michelle claims an overlap is disruptive if the current speaker has not completed an idea. In other words, an overlap is disruptive if the second speaker overlaps 
before the current speaker has fully expressed an idea. However, she believes that using overlapping speech to collaborate with each other is a way of "encouraging everybody to give their opinion."

Frida also emphasised that when the overlap has the aim of helping the current speaker in some way, she does not consider that an interruption. Overlaps are also positively regarded when they serve to display confirmation with what the current speaker is saying. In support of the collaborative views of the use of minimal responses (Coates, 1990; Stubbe, 1991; Mott and Petrie, 1995), Frida explained that confirmation is displayed through the use of minimal responses. Used in this way, Frida contends that overlapping speech has a positive effect on the current speaker as it makes him/her feel regarded and listened to.

Frida I don't see it as interrupting if people sort of confirm another speaker even if that means they do more than just say 'hmm' 'yes, yes' [...] I think that as a speaker you actually feel that people are listening to you and they are thinking along with you and contributing to what they are saying rather than interrupting you. So an interruption would be where someone actually takes over the act of being the main speaker.

Participants seem to agree that overlapping speech has a supportive and collaborative function when it contributes adding new information relevant to what the current speaker is saying and when it helps to oil the wheels of the process of negotiation of information. In terms of the affective goals involved in the use of overlapping speech, overlaps display involvement and listenership in the conversation which enhances the current speaker's positive face and builds team rapport.

\subsection{Conclusion}

The fact that the use of overlapping speech is considered a normal way of displaying solidarity and building rapport in this CofP and that participants agree in their intentions and perceptions of the use of overlapping speech provides evidence to suggest that overlaps are part of this CofP's social norms of behaviour. When considering this CofP's social norms of the use of overlaps, they have been observed to have two distinct goals in the two meetings recorded. From an affective point of view, the participants' interviewed 
explain they used overlapping speech to index high involvement, listenership, engagement and interest. Participants also regarded overlaps as collaborative when they confirm what the current speaker is saying and when they contribute to the development of the conversation by adding relevant information. One of the participants defined overlaps as verbal nods when they have the aim to fulfil the affective goal(s) of the conversation by, for instance, showing the current listener that the other participants are interested in what he/she is saying. Using overlapping speech in this way participants observe each other's positive face needs, building group affiliation and rapport. In addition, also from an affective point of view, overlaps were identified as rescuers that help the current speaker to complete a sentence or an idea when deemed necessary. In this case, overlaps are employed to save the current speaker's face in a potentially facethreatening situation.

From a transactional point of view, overlapping speech can be said to be part of the group's dynamics when they are working together towards the achievement of a common transactional goal. As discussed in previous chapters, the task-based goal of the two meetings recorded was to arrive at a consensus about the work conditions instructors hoped to have in the future work contracts. By making (overlapping) comments that provide new information that builds on the ideas expressed by current speaker, participants are not only displaying high involvement in the conversation but also negotiating information and ideas that would potentially lead them towards the achievement of their shared goal. Participants in this CofP use overlapping speech to collaborate in the development of the conversation in what they understand to be an 'active' style. Motivated by this, overlapping speech seems to be highly prized by this CofP and, judging from participants' comments, failure to overlap can potentially be interpreted as lack of involvement and/or observation of this CofP's norms of social behaviour (see Tannen, 1994). As demonstrated in chapters 5 and 6, overlapping speech plays an important role as a communicative strategy employed by this CofP to negotiate information and build rapport. This turn-taking behaviour, which has been socially constructed (see Liddicoat, 2007), has been observed as being part of this CofP's norms of social behaviour. Thus, given its importance in the development of conversation from 
both an affective and a transactional point of view, failure to use overlapping speech may be interpreted as failure to comply with this CofP's norms of social behaviour.

This chapter focused its discussion on participants' intentions and perceptions of the use of overlapping speech. This discussion supports not only the analysis of the overlaps in chapter 5 but also the view that this group of instructors operate, regardless of their ethnic background, as a CofP. This CofP shares the same assumptions and expectations about how to build collaboration and solidarity through the use of overlaps in conversational interaction.

The following chapter offers some concluding remarks of this study. 


\section{Chapter 7 - Conclusion}

Politeness is an aspect of communication that has been particularly unfairly regarded within the field of intercultural interaction; most studies in this field frame intercultural communication in terms of miscommunication. This study, however, took a positive stance on the interplay of interactional norms of politeness in intercultural face-to-face workplace interaction and investigated how people from different ethnic backgrounds do relational work in naturally-occurring workplace exchanges. The present study focused its analysis on the role of overlapping speech in this context of interaction guided by two research questions: 1) how does overlapping speech function in workplace interactions in New Zealand? and 2) how are these overlaps intended and 'perceived' by culturally different interactants?

With the aim of advancing a comprehensive understanding of the role of overlapping speech as an interactional phenomenon long neglected in the field of intercultural communication, this study drew on research both on politeness theory (Brown and Levinson, 1978, 1987, 1994) and rapport management (Spencer-Oatey, 2000, 2008) to explore the interplay of contextual factors and social norms of interaction to the study of overlapping speech in intercultural workplace communication. These frameworks of analysis provided the tools to consider how relational work is done through the use of overlapping speech as an interactional strategy used to achieve a given communicational goal (Furo, 2001; Liddicoat, 2007).

In order to investigate the role of overlapping speech in intercultural workplace interaction, the data for the present study were drawn from two meetings in a large educational institution in New Zealand. The participants in these meetings were six female language instructors and one male manager. The two meetings studied took place in April-May 2009 and had the aim of discussing imminent job adjustments to take place the following year. For practical reasons, the data collection process was divided into two phases. In the first phase, the two meetings were video and audio recorded. From this data, eighteen extracts were selected for their ability to illustrate common linguistic behaviour regarding the use of overlaps observed in the two meetings. Following the selection of extracts, the researcher analysed these instances of overlaps employing 
rapport management as an analysis framework so as to answer the first research question, namely the role played by overlaps in intercultural workplace communication. Moreover, adopting the stance that overlapping speech is dialogically constructed and an interpretative category that depends on the participants' perceptions of overlaps (Furo, 2001), phase two of the data collection process involved individual stimulated recall interviews with the participants. The purpose of these interviews was to elicit participants' intentions and perceptions regarding the use of overlaps. During these interviews participants watched extracts of instances of overlaps and reported on their intentions when overlapping the current speaker and their perceptions when they were overlapped. Thus, the aim of the second phase of data collection was to answer the second research question.

Overall, the analysis and discussions presented in chapters 5 and 6 demonstrate that this group of instructors operate as a CofP rather than as ethnic individualities who have shared assumptions and expectations regarding the appropriate use of overlaps to collaboratively construct meaning in interaction. In the analysis of chapter 5, the aim was to address the first research question, that is to say, the role of overlaps in intercultural workplace interaction. In this regard, the analysis revealed that, considering their interactional function, those instances of overlaps analysed in this study are likely to be interpreted as collaborative rather than disruptive. Overlaps have been observed to be used to achieve both affective and transactional goals. From an affective point of view, the interactants have used overlaps as an interactional strategy to show affiliation with what the current speaker was saying to, potentially, ensure the enhancement of good rapport (Spencer-Oatey, 2008). Overlapping speech has also potentially been used to signal active listenership and to display involvement (Furo, 2001). By overlapping, the interactants facilitated the development of the topic of the conversation. In addition to enhancing participants' positive face, overlaps have also been used to restore interactants' face in potentially face-threatening situations when, for instance, the current speaker seemed not to be able to find the right words to express an idea.

From a transactional point of view, overlaps were used to negotiate a shared understanding of the job adjustments to take place the following year, which was vital for the instructors to reach a consensus upon which to act as a team. In working together 
towards the achievement of a common goal, that of deciding on a unified course of action, participants can be said to have used overlaps as a communicative strategy in the process of team negotiation in which these overlaps also indexed interactants' degree of participation in the co-construction of meaning (Goldberg, 1990). In this way, it has been argued, participants managed interactional rights and obligations by observing each other's right to maintain their positive face as valued members of the group whose participation in the interaction was deemed important (see Goldberg, 1990; SpencerOatey, 2008). Thus, because the overlapping instances occurred within the context of the negotiation and co-construction of meaning, overlaps are likely to be perceived as collaborative and a means of operationalising participation.

It was also noted that the interactants converged in the way they participated as they engaged in, sometimes long, sequences of overlapping speech to either express their opinions or add information that was relevant to what they current speaker was saying, for instance. The high rates of occurrence of the overlaps and the overall uniformity with which they were used support the claim that this group of instructors belong to a Community of Practice (Wenger, 1998) employing overlaps as part of their jointly constructed social norms strongly oriented towards the maintenance and enhancement of social harmony in their workplace interaction. These jointly constructed social norms result in the construction of a shared repertoire under which the CofP operates in interaction (Corder and Meyerhoff, 2007; Marra and Holmes, 2007). In addition, the convergence in the use of overlaps also reaffirms these instructors' membership in the work team as they know how to act appropriately in accordance with the social norms of this group (Meier, 1995b; Schnurr et al., 2007; Holmes and Meyerhoff, 1999). From the discussion in chapter 5 it can be concluded that overlaps seem to be deeply rooted in the dynamics of the development of conversation in this CofP.

In relation to the second research question, chapter 6 was devoted to participants' insights into how they intended to use overlaps and how they perceived others who overlapped them. Coming from different ethnic backgrounds participants are supposedly expected to use and judge overlapping speech differently (see Hickey and Stewart, 2005; Félix-Brasdefer, 2008). However, in support of the claims made in chapter 5, the assumptions and expectations relating to the functions of overlapping speech in a 
conversation were found to be shared by all participants interviewed and can be said to have become part of their social norms of behaviour in their own community of practice. These instructors, then, come together as a CofP since they are mutually engaged in social interaction and cooperatively work towards the achievement of shared institutional objectives as a team of language instructors. Furthermore, participants' comments revealed that the use of overlapping speech was considered a normal and appropriate way of displaying solidarity and maintaining and enhancing participants' positive face. Defined by participants as verbal nods, overlaps are regarded a collaborative means through which to construct conversation and positive team rapport. Participants' reflections show that this is achieved by using overlaps as an interactional strategy to display active involvement, listenership, solidarity and affiliation as part of the shared repertoire of this CofP. The degree of participation in a conversation has also been found to be strongly associated with the use of overlaps. This CofP highly prizes the use of overlapping speech as a way of participating in the negotiation of meaning and failure to overlap was regarded as lack of interest and engagement in the conversation.

This study demonstrated that considering intercultural communication from the perspective of rapport management can provide valuable and positive insights into how people from different ethnic backgrounds do relational work as they construct meaning in interaction. The significance of this study, then, lies in the importance of a change of focus when investigating intercultural communication. Traditionally regarded as a site where to investigate instances of miscommunication, this study demonstrates that intercultural communication can be investigated as a site for the collaborative construction of social norms of behaviour that potentially lead to successful communication. 


\section{References}

Allan, S. 1990. "The rise of New Zealand intonation." in Bell, A. \& Holmes, J. (Eds.) New Zealand ways of speaking English. Clevedon: Multilingual Matters: 115-128.

Arundale, R. 2006. "Face as relational and interactional: A communication framework for research on face, facework, and politeness." Journal of Politeness Research 2: 193216.

Bargiela-Chiappini, F. \& Harris, S. 2006. "Politeness at work: Issues and challenges." Journal of Politeness Research 2: 7-33.

Bargiela-Chiappini, F. \& Nickerson, C. 2003. "Intercultural business communication: a rich field of studies.” Journal of Intercultural Studies 24.1: 3-15.

Bell, A. 1999. "Maori \& Pakeha English: a case study.” In Bell, A. \& Kuiper, K. (Eds.) New Zealand English. Amsterdam: John Benjamins Publishing Company: 221-248.

Boxer, D. 2002. Applying Sociolinguistics: Domains and face-to-face interaction. Amsterdam: John Benjamins Publishing Company.

Britain, D. \& Newman, J. 1992. "High rising terminals in New Zealand English.” Journal of the International Phonetic Association 22: 1-11.

Brown, P. \& Levinson, S. 1978. Politeness: Some universals in language usage. Cambridge: Cambridge University Press.

Brown, P. \& Levinson, S. 1987. Politeness: Some universals in language usage. $2^{\text {nd }}$ ed. Cambridge: Cambridge University Press.

Brown, P. \& Levinson, S. 1994. Politeness: Some universals in language usage. $13^{\text {th }}$ ed. Cambridge: Cambridge University Press.

Christie, C. 2007. "Relevance theory and politeness." Journal of Politeness Research 3: 269-294.

Clyne, M. 1996. Inter-cultural communication at work: Cultural values in discourse. Cambridge: Cambridge University Press.

Coates, J. 1990. Women, men and language: A sociolinguistic account of sex differences in language. London: Longman.

Coates, J. 1993. Women, men and language: A sociolinguistic account of sex differences in language $2^{\text {nd }}$ ed. London: Longman.

Coates, J. 1996. Women talk: conversation between women friends. Oxford: Blackwell. 
Corder, S. \& Meyerhoff, M. 2007. "Communities of practice in the analysis of intercultural communication." In Kotthoff, H. \& Spencer-Oatey, H. (Eds.) Handbook of intercultural communication. Berlin: Mounton de Gruyter: 443-461.

Couper-Kuhlen, E. 2001. "Interactional prosody: High onsets in reason-for-the-call turns." Language in Society 30/1:29-53.

Eckert, P. \& McConnell-Ginet, S. 2003. Language and Gender. Cambridge: Cambridge University Press.

Edelsky, C. 1981. "Who’s got the floor?” Language in Society 10: 383-421.

Edelsky, C. 1993. "Who's got the floor?” In Tannen, D. (Ed.) Gender and conversational interaction. New York: Oxford University Press: 189-227.

Edwards-Leis, C. 2006 "Variations to stimulated recall protocols to enhance student reflection: I did, I saw, I remembered.” http://www.aare.edu.au/06pap/edw06717.pdf

Eelen, G. 2001. A critique of politeness theories.” Manchester: St. Jerome Publishing.

Egbert, M. 2004. "Other-initiated repair and membership categorization - some conversational events that trigger linguistic and regional membership categorization." Journal of Pragmatics 36: 1467-1498.

Félix-Brasdefer, J.C. 2008. Politeness in Mexico and the United States. Amsterdam: John Benjamins Publishing Company.

Fletcher, J. and Loakes, D. 2006. "Patterns of rising and falling in Australian English." In Warren, P. \& Watson, C.I. (Eds.) Proceedings of the 11th Australian International Conference on Speech Science and Technology 2006: 42-7.

Furo, H. 2001. Turn-taking in English and Japanese. New York: Routledge.

Gardner, R., Gardner, B. \& Van Cantfort, T. 1989. Teaching sign language to chimpanzees. Albany: State University of New York Press.

Gass, S. \& Mackey, A. 2000. Stimulated recall methodology in second language research. Mahwah: Lawrence Erlbaum Associates, Publishers.

Goffman, E. 2006. On face-work: An analysis of ritual elements in social interaction. In Jaworski, A. \& Coupland, N. (eds.) The Discourse Reader. London: Routledge.

Goldberg, J. A. 1990. "Interrupting the discourse on interruptions: an analysis in terms of relationally neutral, power- and rapport-oriented acts." Journal of Pragmatics 14: 883903. 
Günthner, S. 2007. "Intercultural communication and the relevance of cultural specific repertoires of communicative genres." In Kotthoff, H. \& Spencer-Oatey, H. (Eds.) Handbook of intercultural communication. Berlin: Mouton de Gruyter.

Günthner, S. 2008. "Negotiating Rapport in German-Chinese Conversation.” In SpencerOatey (ed.) Culturally Speaking. London: Continuum: 207-226.

Hannah, A. \& Murachver, T. 1999. "Gender and conversational style as predictors of conversational behavior." Journal of Language and Social Psychology 18: 153-174.

Harris, P.; Moran, R. and Moran, S. 2004. Managing cultural differences. Amsterdam: Elsevier Butterworth Heinemann.

Haugh, M. 2007a. "The discursive challenge to politeness research: An interactional alternative." Journal of Politeness Research 3: 295-317.

Haugh, M. 2007b. "Emic conceptualisations of im(politeness) and face in Japanese: Implications for the discursive negotiation of second language learner identities." Journal of Pragmatics 39: 657-680.

Henderson, L. \& Tallman, J. 2006. Stimulated recall and mental models. Maryland: The Scarecrow Press, Inc.

Heritage, J. 2005. "Conversation analysis and institutional talk." In Fitch, K. \& Sanders, $\mathrm{R}$ (Eds.) Handbook of language and social interaction. Mahwah: Lawrence Erlbaum Associates, Publishers: 103-148.

Hickey, L and Stewart, M. (eds.) 2005. Politeness in Europe. Clevedon: Multilingual Matters, Ltd.

Holmes, J. 1995. Women, men and politeness. London: Longman.

Holmes, J. and Meyerhoff, M. 1999. "The community of practice: theories and methodologies in language and gender research." Language and Society 28: 173-183.

Holmes, J. and Stubbe, M. 2003. Power and Politeness in the Workplace: A sociolinguistic analysis of talk at work. London: Pearson Education.

Holmes, J. and Stubbe, M. 2003. Power and politeness in the workplace. London: Longman.

Holmes, J. and Marra, M. 2004. "Relational practice in the workplace: women's talk or gendered discourse." Language in Society 33: 377-398. 
Holmes, J. and Schnurr, S. 2005. "Politeness, humor and gender in the workplace: negotiating norms and identifying contestation." Journal of Politeness Research 1: 121149.

Holmes, J.; Marra, M. and Schnurr, S. 2008. Impoliteness and ethnicity: Māori and Pākehā discourse in New Zealand workplaces. Journal of Politeness Research 4/2: 193219.

Holtgraves, T. 2005. "Social psychology, cognitive psychology, and linguistic politeness." Journal of Politeness Research 1: 73-93.

James, D. and Clarke, S. 1993. "Women, men and interruptions: A critical review." In Tannen, D. (Ed.) Gender and conversational interaction. New York: Oxford University Press: 231-280.

Karakowsky, L., McBey, K. and Miller, D. 2004. "Gender, perceived competence, and power displays: examining verbal interruptions in a group context." Small Group Research 35: 407-439.

Kennedy, C. and Camden, C. 1983. "Interruptions and non-verbal gender differences." Journal of Nonverbal Behavior 8/2: 91-108.

Kerbrat-Orecchioni, C. 2005. "Politeness in France: How to buy bread politely." In Hickey, L. \& Stewart M. Politeness in Europe. Clevedon: Multilingual Matters Ltd: 2944.

Kitzinger, C. 2008. "Conversation analysis: technical matters for gender research." In Harrington, K., Litosseliti, L., Sauntson, H. \& Sunderland, J. (Eds.) Gender and language research methodologies. Hampshire: Palgrave Macmillan: 119-138.

Laplante, D. and Ambady, N. 2003. "On how things are said: voice tone, voice intensity, verbal content, and perceptions of politeness." Journal of Language and Social Psychology 22: 434-441.

Lett, J. 1990. "Emics and etics: notes on the epistemology of anthropology." In Headland, T., Pike, K. \& Harris, M. (Eds.) Emics and etics. The insider/outsider debate. Newbury Park: Sage: 127-142.

Li, H. 2001. "Cooperative and intrusive interruptions in inter- and intracultural dyadic discourse.” Journal of Language and Social Psychology 20/3: 259-284.

Li, H. Krysko, M., Desroches, N. \& Deagle, G. 2004. "Reconceptualizing interruptions in physician-patient interviews: cooperative and intrusive." Communication and Medicine 1/2: $145-157$. 
Li, H., Yum, Y., Yates, R., Aguilera. L., Mao, Y. \& Zheng, Y. 2005. "Interruption and involvement in discourse: can intercultural interlocutors be trained?" Journal of Intercultural Communication Research 34/4: 233-254.

Li, H. Z.; Zhang, Z.; Yum, O. K.; Lundgren, J.; \& Pahal, J. 2008. "Interruption and patient satisfaction in resident-patient consultations." Health Education: An International Journal 108/5: 411-427.

Liddicoat, A. 2007. An introduction to Conversation Analysis. London: Continuum.

Locher, M.A. 2006. "Polite behaviour within relational work: The discursive approach to politeness." Multilingua 25: 249-267.

Locher, M.A. \& Watts, R.J. 2005. "Politeness theory and relational work." Journal of Politeness Research 1: 9-33.

Locher, M.A. \& Langlotz, A. 2008. "Relational work: at the intersection of cognition, interaction and emotion." Bulletin Suisse de Linguistique Appliquée 88: 165-191.

Lyle, J. 2003. "Stimulated recall: a report on its use in naturalistic research." British Educational Research Journal 29/6: 861-878.

Mackey, A. \& Gass, S. (2005). Second Language Research: Methodology and Design. New Jersey: Lawrence Erlbaum Associates, Publishers.

Maheux-Pelletier, G. \& Golato, A. 2008. "Repair in membership categorization in French.” Language in Society 37: 689-712.

Marra, M. 2008. "Recording and analysing talk across cultures." In Spencer-Oatey (ed.) $2^{\text {nd }}$ ed. Culturally Speaking. London: Continuum: 304-321.

Marra, M. \& Holmes, J. 2007. "Humour across cultures: joking in the intercultural workplace." In Kotthoff, H. \& Spencer-Oatey, H. (Eds.) Handbook of intercultural communication. Berlin: Mounton de Gruyter: 153-172.

Meier, A. J. 1995a. "Defining politeness: Universality in appropriateness." Language Sciences 17/4: 345-356.

Meier, A.J. 1995b. "Passages of politeness." Journal of Pragmatics 24: 381-392.

Meyerhoff, M. 1994. "Sound pretty ethnic, eh?: A pragmatic particle in New Zealand English." Language in Society 23/3: 367-388.

Mills, S. 1995. "Language, gender and career." In Mills, S. (Ed.) Language and gender: Interdisciplinary perspectives. London: Longman. 
Mills, S. 2009. "Impoliteness in a cultural context." Journal of Pragmatics 41: 10471060 .

Morgan, A. 2007. 'Using video-stimulated recall to understand young children's perceptions of learning in classroom settings." European Early Childhood Education Research Journal 15/2: 213-226.

Mott, H. \& Petrie, H. 1995. "Workplace interactions: women's linguistic behaviour." Journal of Language and Social Psychology 14: 324-336.

Murata, K. 1994. "Intrusive or co-operative? A cross-cultural study of interruption." Journal of Pragmatics 21: 385-400.

Murray, S. 1985. "Towards a model of member's methods for recognizing interruptions." Language in Society 14: 31-40.

Ng, S., Brooke, M. \& Dunne, M. 1995. "Interruption and influence in discussion groups." Journal of Language and Social Psychology 14: 369-381.

Ouafeu, Y. 2006. "Politeness strategies in colloquial Cameroon English: Focus on three pragmatic particles: na, ya and eihn.” Nordic Journal of African Studies 15/4: 536-544.

Paltridge, B. 2006. Discourse Analysis: An introduction. London: Continuum.

Paterson, D. \& Graham, L. 2000. "Inclusive teaching from the inside: What teachers think." International Special Education Congress 2000: Including the excluded. www.isec2000.org.uk/papers_p/paterson_1.htm

Ruhi, S. \& Işik-Güler, H. 2007. "Conceptualizing face and relational work in (im)politeness: Revelations from politeness lexemes and idioms in Turkish." Journal of Pragmatics 39: 681-711.

Schnurr, S.; Marra, M. \& Holmes, J. 2007. "Being (im)polite in New Zealand workplaces: Māori and Pākehā leaders.” Journal of Pragmatics 39.4: 712-729.

Scollon, R. \& Scollon, S. 1995. Intercultural Communication: A discourse Approach. Cambridge: Blackwell.

Scollon, R. \& Scollon, S. 2001. Intercultural Communication: A Discourse Approach. Massachusetts: Blackwell Publishers.

Sheldon, A. 1993. "Pickle fights: gendered talk in preschool disputes." In Tannen, D. (Ed.) Gender and conversational interaction. New York: Oxford University Press: 83109. 
Spencer-Oatey, H. 2000. "Rapport Management: A framework for analysis." In SpencerOatey (ed.) Culturally Speaking. London: Continuum.

Spencer-Oatey, H. 2005. "(Im)politeness, face and perceptions of rapport: Unpacking their bases and interrelationships." Journal of Politeness Research 1: 95-119.

Spencer-Oatey, H. 2008a. "Introduction." In Spencer-Oatey, H. (ed.) $2^{\text {nd }}$ ed. Culturally Speaking. London: Continuum: 1-8.

Spencer-Oatey, H. 2008b. "Face, (im)politeness and rapport." In Spencer-Oatey (ed.) $2^{\text {nd }}$ ed. Culturally Speaking. London: Continuum: 11-47.

Spencer-Oatey, H. \& Xing, J. 2003. "Managing rapport in intercultural business interactions: a comparison of two Chinese-British business meetings." Journal of Intercultural Studies 24.1: 33-46.

Spencer-Oatey, H. \& Xing, J. 2008. "Issues of face in Chinese business visit in Britain." In Spencer-Oatey, H. (ed.) $2^{\text {nd }}$ ed. Culturally Speaking. London: Continuum: 258-273.

Steel, C. 2003. "Investigating concept mapping and stimulated recall to reveal academic teacher beliefs and how they are enacted through learning designs for the web." Association for the Advancement of Computing in Education.

Stubbe, M. 1991. "Talking at cross-purposes?: the effect of gender on New Zealand primary school children's interaction strategies in pair discussions." Diss. Victoria University of Wellington.

Stubbe, M. \& Holmes, J. 1995. "You know, eh and other 'exasperating expressions': an analysis of social and stylistic variation in the use of pragmatic devices in a sample of New Zealand English.” Language and Communication 15: 63-88.

Talbot, M. 1998. Language and gender. Cambridge: Polity Press.

Tanaka, N., Spencer-Oatey, H. \& Cray, E. 2008. “Apologies in Japanese and English.” In Spencer-Oatey (ed.) $2^{\text {nd }}$ ed. Culturally Speaking. London: Continuum: 73-94.

Tannen, D. 1993. "The relativity of linguistic strategies: Rethinking power and solidarity in gender and dominance." In Tannen, D. (Ed.) Gender and conversational interaction. New York: Oxford University Press: 165-188.

Tannen, D. 1994. Gender \& Discourse. New York: Oxford University Press.

Terraschke, A. 2005. "On Being Polite in a Second Language: An Analysis of NonNative use of English Pragmatic Devices in English-German Interactions." 9th International Pragmatics Conference. 
Terraschke, A. 2007. "Use of general extenders by German non-native speakers of English.” IRAL 45: 141-160.

Tzanne, A. 2001. "'What you're saying sounds very nice and I'm delighted to hear it' Some considerations of the functions of presenter-initiated simultaneous speech in Greek panel discussions." In Bayraktaroğlu, A. \& Sifianou, M. (Eds.) Linguistic politeness across boundaries: the case of Greek and Turkish. Amsterdam: John Benjamins Publishing Company: 271-306.

Warren, P. \& Britain, D. 1999. "Intonation and prosody in New Zealand English." In Bell, A. \& Kuiper, K. (Eds.) New Zealand English. Amsterdam: John Benjamins Publishing Company: 146-172.

Watts, R. 1992. "Linguistic politeness and politic verbal behaviour: Reconsidering claims for universality." In Watts, R., Ide, S. \& Ehlich, K. (Eds.) Politeness in language: Studies in its history, theory and practice. Berlin: Mounton de Gruyter: 43-49.

Watts, R. 2003. Politeness. Cambridge: Cambridge University Press.

Watts, R., Ide, S. \& Ehlich, K. 2005. "Introduction.” In Watts, R., Ide, S. \& Ehlich, K. (Eds.) $2^{\text {nd }}$ ed. Politeness in Language. Berlin: Mouton de Gruyter: 1-17.

Wenger, E. 1998. Communities of Practice: learning, meaning and identity. Cambridge: Cambridge University Press.

Www.stats.govt.nz

Zimmerman, D. \& West, C. 1975. "Sex roles, interruptions and silences in conversation." In Thorne, B. \& Henley, N. (Eds) Language and Sex: difference and dominance. Massachusetts: Newbury House Publishers, Inc.: 105- 129. 


\section{Appendix A}

Table 2 - Participants' background information

\begin{tabular}{|c|c|c|c|c|c|c|c|}
\hline Participant & Paul & Michelle & Rebecca & Linda & Delia & Greta & Frida \\
\hline Place of birth & New Zealand & Spain & China & Argentina & France & Germany & Germany \\
\hline $\begin{array}{l}\text { Totaling time } \\
\text { overseas }\end{array}$ & 8 years & 24 years & 20 years & 8 years & 23 years & $\begin{array}{c}9 \text { years, } 6 \\
\text { months }\end{array}$ & 11 years \\
\hline $\begin{array}{l}\text { Language spoken } \\
\text { at home }\end{array}$ & English & Spanish & Chinese & Spanish & $\begin{array}{l}\text { French and } \\
\text { regional dialect } \\
\text { (Morvandiau) }\end{array}$ & German & German \\
\hline Gender & Male & Female & Female & Female & Female & Female & Female \\
\hline Age group & $50-54$ & $50-54$ & $50-54$ & $45-49$ & $45-49$ & $30-34$ & $30-34$ \\
\hline Ethnic group & Pākehā & European & Chinese & Latin American & $\begin{array}{l}\text { French (not } \\
\text { European!) }\end{array}$ & European & German \\
\hline $\begin{array}{l}\text { Years working in } \\
\text { the institution }\end{array}$ & 2.5 years & 15 years & 18 years & 7 years & 15 years & 8 years & 3 years \\
\hline $\begin{array}{l}\text { Years as a } \\
\text { member of this } \\
\text { team }\end{array}$ & 2.5 years & 3 years & 18 years & 7 years & 15 years & 5 years & 3 years \\
\hline Proficiency level & Good & - & Fluent & Fluent & Fluent & Fluent & Fluent \\
\hline
\end{tabular}




\section{Appendix B - Transcriptions conventions and extracts}

\section{Transcription conventions}

\begin{tabular}{|c|c|}
\hline$\underline{\text { me }}$ & underlined words to indicate emphatic stress \\
\hline \{laughter\} & Paralinguistic features and clarifications in square brackets \\
\hline+ & Pause up to one second \\
\hline$=$ & Continuing speech / latching \\
\hline 11 & Simultaneous speech \\
\hline$/ / \quad 11$ & Simultaneous speech among three people \\
\hline (ok) & Transcriber's best guess at an unclear utterance \\
\hline$?$ & Question intonation \\
\hline- & Incomplete or cut-off utterance \\
\hline Hello & Italics used to highlight points in the analysis \\
\hline [laughter] & Deleted words to protect participants' identities \\
\hline .. & Indicates that there are preceding or following utterances \\
\hline$\uparrow \downarrow$ & Arrows indicate upward or downward intonation of the word they precede \\
\hline${ }^{\circ} \mathrm{me} \mathrm{o}^{\circ}$ & Degree marks indicate decreased volume of materials between them \\
\hline${ }^{\circ \circ} \mathrm{me} \mathrm{m}^{\circ \circ}$ & Two degree marks indicate increased volume of materials between them \\
\hline me: & Colon indicates stretching of sound it follows \\
\hline
\end{tabular}

All names used in the excerpts are pseudonyms.

\section{Participants' pseudonyms:}

D: Delia

G: Greta

F: Frida

Ma: Martina

M: Michelle

P: Paul

R: Rebecca

L: Linda

Transcriptions of extracts

\section{MEETING 1}

Extract 1: minute 00:42 - 1:07

\begin{tabular}{|c|c|}
\hline$\langle \# 1: \mathrm{P}\rangle$ & ${ }^{\circ \circ} \mathrm{So}^{\circ \circ} \mathrm{i}$ 've read this but maybe you want to + \\
\hline$\langle \# 2:>$ & ta:lk ++ about it ++++ and then we can go from there \\
\hline$\langle \# 3: M>$ & ${ }^{\circ} \mathrm{well}^{\circ} \backslash$ \\
\hline$<\# 4: G>$ & $/ \uparrow^{\circ \circ}$ well ${ }^{\circ} \backslash$ no no you go $\{$ laughs nervously $\} / \mathrm{i}$ \\
\hline$\langle \# 5:>$ & thought $\backslash$ you weren't going to that's why $i$ always so \\
\hline$\langle \# 6:>$ & /if you want to then you gol \\
\hline $\begin{array}{l}\langle \# 7: M> \\
\langle \# 8 \cdot\rangle\end{array}$ & $\begin{array}{l}/(\ldots) \backslash / \text { no no no no } \backslash \text { mainly just sort of stating the } \\
\text { same what it savs here }\end{array}$ \\
\hline
\end{tabular}


Extract 2: minute 16:57 - 17:20

\begin{tabular}{|c|c|}
\hline $\begin{array}{l}<\# 1: \mathrm{G}> \\
<\# 2:> \\
<\# 3:>\end{array}$ & $\begin{array}{l}\text { so what you're saying is that there are people in } \\
\text { the+ [name] programme that are on a [type] contract } \\
\text { that are in a very similar position like we are that }\end{array}$ \\
\hline$\langle \# 4:>$ & have worked here for several years ${ }^{\circ}$ you know \\
\hline$\langle \# 5:>$ & degrees and experience stuff like that ${ }^{\circ}++$ \\
\hline$<\# 6: \mathrm{P}>$ & {$[\text { nodding }]^{\circ}$ exactly $^{\circ}$} \\
\hline$<\# 7: G>$ & ${ }^{\circ}$ ok $\underline{i}$ didn't know that ${ }^{\circ \circ}$ like we've never $\mathrm{i}$ \\
\hline$<\# 8:>$ & mean /we've sort of we've we'vel= \\
\hline$\langle \# 9: \mathrm{D}\rangle$ & /no we've never nol \\
\hline$<\# 10: \mathrm{Ma}>$ & /nol \\
\hline$<\# 11: G>$ & we've always had big discussions and for years \\
\hline$<\# 12:>$ & i'm+ sure at least for three or four years+ there's \\
\hline$\langle \# 13:>$ & been discussions about this sort of thing... \\
\hline
\end{tabular}

Extract 3: minute 21:16-21:45

$\begin{array}{ll}<\# 1: P> & \text { a::nd well before hopefully before the end of the } \\ \text { <\#2:> } & \text { second trimester you would know what was going to } \\ \text { <\#3:> } & \text { be happening next year } \\ \text { <\#4:D> } & { }^{\circ \circ} \text { and }{ }^{\circ \circ} \text { in the scenario that }\{\text { puffing }\}+++ \\ \text { <\#5:M> } & \text { it doesn't go ahead? }+ \text { sorry }\{\text { nervous laughter } \\ \text { <\#6:> } & \text { from everybody } \\ \text { <\#7:D> } & { }^{\circ \circ} \text { no no no }{ }^{\circ \circ}{ }^{\circ} \text { '' } \text { just I'm just just thinking if } \\ \text { <\#8:> } & \text { that if the conclusion by setting a permanent } \\ \text { <\#9:> } & \text { position right now didn't seem to be sort of we } \\ \text { <\#10:> } & \text { wouldn't gain }{ }^{\circ} \ldots\end{array}$

Extract 4: minute 37:47 - 39:11

\begin{tabular}{|c|c|}
\hline$\langle \# 1: G>$ & ...this regular salary review thing for + is that is \\
\hline$\langle \# 2:>$ & that normal for permanent positions?+ that you \\
\hline$\langle \# 3:>$ & have regular salary reviews?++ because i mean + \\
\hline$\langle \# 4: \mathrm{P}\rangle$ & it's an ongoing process but it occurs with the \\
\hline$\langle \# 5:\rangle$ & with the [position] collective as well \\
\hline$\langle \# 6: G>$ & oh \\
\hline$\langle \# 7: \mathrm{P}\rangle$ & yes \\
\hline$\langle \# 8: G>$ & does it? \\
\hline$\langle \# 9: \mathrm{P}\rangle$ & yeah mm \\
\hline$\langle \# 10: G>$ & ok i've never had to do the salary review \\
\hline$\langle \# 11: \mathrm{P}\rangle$ & no // /it's donel $/{ }^{\circ \circ}$ it's done ${ }^{\circ \circ}{ }^{\circ}$ yeah between the \\
\hline <\#12:> & university /and the union ${ }^{\circ} \backslash$ \\
\hline$\langle \# 13: M>$ & /neither have il \\
\hline$\langle \# 14: G>$ & $/ /$ they do the salary review ${ }^{\circ} \backslash I$ \\
\hline$<\# 15: F>$ & /oh okl \\
\hline
\end{tabular}




\begin{tabular}{|c|c|}
\hline$\langle \# 16: G\rangle$ & ${ }^{\circ \circ} \mathrm{so}^{\circ \circ}$ maybe we mean something different /herel \\
\hline$\langle \# 17: D>$ & /yesl \\
\hline$\langle \# 18: G>$ & /you know $\backslash$ maybe because- \\
\hline$\langle \# 19: \mathrm{D}>$ & /we did-I \\
\hline$<\# 20: M>$ & /we:1l ${ }^{\circ \circ} \mathrm{ah}^{\circ \circ}$ no because usually in at least in \\
\hline$\langle \# 21:\rangle$ & the new collective they have different you have \\
\hline$\langle \# 22:>$ & different bars /so $\backslash \mathrm{i}$ suppose you can go higher i \\
\hline$\langle \# 23:>$ & don't know um++ /after-I \\
\hline$<\# 24: G>$ & $/ \mathrm{mm} \backslash /$ yeah yeah $\backslash \mathrm{i}$ think i mean basically \\
\hline$\langle \# 25:>$ & what+ we would be after would be to be \\
\hline$\langle \# 26:>$ & able to you know? increase our $\uparrow$ salary if \\
\hline <\#27:> & we have had a good you know?+ /like-। \\
\hline$\langle \# 28: D>$ & /assessment \\
\hline$<\# 29: G>$ & assessment /likel \\
\hline$\langle \# 30: \mathrm{F}\rangle$ & /performance review $\mathrm{mm} \backslash$ \\
\hline$<\# 31: G>$ & ${ }^{\circ}$ performance review ${ }^{\circ \circ} /$ that's the word $\backslash$ thank you \\
\hline$\langle \# 32: \mathrm{P}\rangle$ & /yeah okl \\
\hline$<\# 33: D>$ & /yes $\backslash$ \\
\hline$<\# 34: G>$ & so you know? like you would do performance \\
\hline$\langle \# 35:>$ & reviews and then according to that you \\
\hline <\#36:> & know? you would be put up a level with your \\
\hline <\#37:> & salary kind of thing i think+ is that /part- 1 \\
\hline$\langle \# 38: F\rangle$ & /or \i guess if it's was a permanent position \\
\hline <\#39:> & $i$ guess maybe the number of years that \\
\hline <\#40:> & would accumulate in the position... \\
\hline
\end{tabular}

\section{MEETING 2}

Extract 5: minute 1:40 - 1:59

$<\# 1: D>\quad$..the second argument he's going to have to have $\langle \# 2:>\quad$ fixed term $/[$ position] $\backslash+$ of one three or two years= $\langle \# 3: \mathrm{R}>\quad$ /yeahl

$\left\langle \# 4: D>\quad\right.$ i mean depending now $/{ }^{\circ \circ}$ whatever ${ }^{\circ} \backslash++$ happens=

$<\# 5: G>\quad$ /fixed term (...) could be six months

$\langle \# 6: D>\quad=$ whether it's going to be permanent uh let's say

$\left\langle \# 7:>\quad\right.$ they say ${ }^{\circ \circ}$ yes $^{\circ \circ}$ for the permanent [position] the nature

$\langle \# 8:\rangle \quad$ of it is quite unclear and he's been putting the

$<\# 9:>\quad$ emphasis on that twice and $\mathrm{i}$ know this is it...

Extract 6: minute 3:20 - 3:56

$<\# 1: G>\quad$ i mean i'm i'm sure we'd be happy the point with $\langle \# 2:\rangle \quad$ the with the ummm ++ that i forgot to ask which $\mathrm{i}$

$\langle \# 3:>\quad$ just wrote down now is that umm what actually

$\langle \# 4$ : $\quad$ happens if you know? /if $\backslash$ we're going back to the you

<\#5:> know to the $/ /^{\circ \circ}\left[\right.$ position] ${ }^{\circ} \| /$ what happens= 


\begin{tabular}{|c|c|}
\hline$\langle \# 6: F\rangle$ & ${ }^{\circ}{ }^{\circ}$ hh yeah ${ }^{\circ}$ \\
\hline$\langle \# 7: D>$ & $/ /[$ position $]{ }^{\circ \circ}$ yeah $^{\circ \circ} \mid I$ \\
\hline$\langle \# 8: G>$ & $=$ if you have umm if you have a a staff member going \\
\hline$<\# 9:>$ & on leave and they ask us you know? then we probably \\
\hline$\langle \# 10:>$ & would get a:: you know? an- another contract for+ \\
\hline$\langle \# 11:>$ & you /know? like ${ }^{\circ}[$ position] $\backslash$ or something like \\
\hline$\langle \# 12:>$ & $/ /$ that $^{\circ \circ} \|$ pretty much or ${ }^{\circ}$ something like that ${ }^{\circ} \mathrm{mmm}$ \\
\hline$\langle \# 13: \mathrm{D}, \mathrm{R}\rangle$ & $/$ for ${ }^{\circ}$ for a couple of months $(\ldots)^{\circ} \backslash$ \\
\hline$\langle \# 14: D>$ & $/ /$ exactly $\mid$ so to a certain extent to ensure if \\
\hline$\langle \# 15:>$ & there was a push from the [position] and say all \\
\hline <\#16:> & we want those [position] to do is the coordination \\
\hline$<\# 9:>$ & of ( ) classes or whatever... \\
\hline
\end{tabular}

Extract 7: minute 5:30 - 5:50

\begin{tabular}{|c|c|}
\hline$\langle \# 1: D>$ & .the second scenario would be to do is fixed it \\
\hline$\langle \# 2:>$ & would still be argue they're low so i'm pretty sure \\
\hline$\langle \# 3:>$ & they're all just going to be zero point three or \\
\hline$<\# 4:>$ & zero point five but not all point seven not all \\
\hline$\langle \# 5:>$ & ${ }^{\circ \circ}$ would you agree ${ }^{\circ \circ}() ?$ \\
\hline <\#6:G> & no they'll low i reckon they'll be low $/{ }^{\circ}$ zero point \\
\hline$\langle \# 7:>$ & three or whatever ${ }^{\circ}$ \\
\hline$\langle \# 8: \mathrm{R}>$ & /you know what i'm paid? i'm i'm at the $/ /$ moment +||$=$ \\
\hline$\langle \# 9: D>$ & //zero point three yes yeah yeahlI \\
\hline$\langle \# 10: R>$ & $=$ down point to two two two but to usually you know \\
\hline$\langle \# 11:>$ & they are just (...) i can usually can (...) like a point \\
\hline$\langle \# 12:>$ & seven sevenish but this year because my contract is \\
\hline$\langle \# 13:>$ & three years one so... \\
\hline
\end{tabular}

Extract 8: minute 7:30 - 7:48!!

\begin{tabular}{|c|c|}
\hline$\langle \# 1: G\rangle$ & ...now i'm doing [name]s classes because we arranged \\
\hline$\langle \# 2:>$ & that the summer course is not going to $\uparrow$ happen and \\
\hline$\langle \# 3:>$ & i'm i'm being paid for the summer $\uparrow$ course /officially \\
\hline$\langle \# 4:>$ & in $\uparrow$ that $=$ \\
\hline$\langle \# 5: R>$ & /ohhh\ \\
\hline$\langle \# 6: D\rangle$ & /okl \\
\hline$<\# 7: G>$ & $=$ so i'm not teaching the summer course and umm + \\
\hline$\langle \# 8: \mathrm{R}\rangle$ & why you're not teaching the summer course anymore? \\
\hline$\langle \# 9: G>$ & because there's no money /because because ifl= \\
\hline$\langle \# 10: R>$ & /oh i see no money yeah $\backslash$ \\
\hline$\langle \# 11: \mathrm{G}\rangle$ & $=$ because if because if if if i'm taking [name]s \\
\hline$\langle \# 12:>$ & classes i'm doing extra hours and the extra hours \\
\hline <\#13:> & are just being taken away from the summer course \\
\hline$\langle \# 14:>$ & because the summer course is a non compulsory cou \\
\hline
\end{tabular}

Extract 9: minute 11:38 - 12:05!

$<\# 1: D>\quad$...then uhh in that way + fit everybody except your $<\# 2:>\quad$ own uhh colleagues and the permanent [position] staff 
$\langle \# 3:\rangle \quad$ who all of a sudden will have to realise \{changing

$\langle \# 4:\rangle \quad$ intonation as if doing direct speech\} oh gee you've

$\langle \# 5:\rangle \quad$ got a hundred and twenty students in a course ironic

$\langle \# 6:>\quad$ laughter $\}$ and you got-course coordination means that?

$\langle \# 7:>\quad$ and they come and knock on your door again and again

<\#8:> and again \{ironic laughter\} so it's going to be a

$<\# 9:>\quad$ bit of a shock for the: for them but $\uparrow /$ we need tol=

$<\# 10: G>\quad$ /but butl

$\langle \# 11: \mathrm{D}\rangle \quad=$ actually $\downarrow /{ }^{\circ}$ do that yeah ${ }^{\circ}$

$<\# 12: G>\quad$ /but $\uparrow$ that's $\backslash$ i think

$<\# 13:>\quad$ that's kind of the /thingl=

$<\# 14: \mathrm{D}\rangle \quad / \mathrm{hmml}$

$\langle \# 15: \mathrm{G}\rangle \quad=$ you know i think it's people

$<\# 16:>\quad$ don't realise $\{$ exhaling $\ldots$

Extract 10: minute 12:55 - 13:35

\begin{tabular}{|c|c|}
\hline$\langle \# 1: G>$ & ...if you if you if you if you if you're employing \\
\hline$<\# 2:>$ & a $\uparrow[$ position] you're getting what you're you know? \\
\hline$\langle \# 3:>$ & /if youl= \\
\hline$\langle \# 4: D>$ & /yeahl \\
\hline$\langle \# 5: G>$ & $=/$ if you'rel paying a [position] you're employing a \\
\hline$\langle \# 6:>$ & [position] you're getting [position's] work $/+\backslash$ yeah?= \\
\hline$\langle \# 7: \mathrm{D}\rangle$ & /yeah\/yeah $\backslash$ \\
\hline$\langle \# 8: G>$ & if you want something $\uparrow$ different $+/$ then you have to \\
\hline$<\# 9:>$ & employ somebody different but $\mathrm{i}$ think sometimes $\mid=$ \\
\hline$\langle \# 10: \mathrm{D}\rangle$ & /then you want all you have to ( ) and you have tol \\
\hline$\langle \# 11: G>$ & $=$ it's you know like with dogs or you know cats you \\
\hline$\langle \# 12:>$ & know very sort of animalistic type of stuff you need \\
\hline$\langle \# 13:\rangle$ & to show them otherwise you know? /and they have to \\
\hline$\langle \# 14:>$ & feel it on their skin you have to pinch them and \\
\hline$\langle \# 15:>$ & say hey! you know? ${ }^{\circ}$ kind of thing ${ }^{\circ}=$ \\
\hline$\langle \# 16: \mathrm{D}\rangle$ & /yeah, yeah, yeah, yeah, yeah\ \\
\hline$\langle \# 17: G>$ & $=$ so that's the only way $+{ }^{\circ} \mathrm{i}$ know like i don't ${ }^{\circ \circ}$ \\
\hline$\langle \# 18:>$ & /i don't wanna put [name] or [name] or [name] \\
\hline$\langle \# 19:>$ & through the $\backslash$ situation of of not doing what i've \\
\hline$<\# 20:>$ & always been $\uparrow$ doing $=$ \\
\hline$\langle \# 21: \mathrm{D}\rangle$ & /but it's it's very tricky + yeah no yeah yeah yeah $\backslash$ \\
\hline$\langle \# 22: G>$ & $=$ because $\mathrm{i}$ think you know if they know what we're \\
\hline$<\# 23:>$ & $\uparrow$ doing \{complaining tone $\}$ but it's just above but \\
\hline$\langle \# 24:\rangle$ & you know if like we can't seem to get to above. \\
\hline
\end{tabular}

Extract 11: minute 14:13 to $15: 21$

$\langle \# 1: D\rangle \quad$...but in language teaching i found i mean i've got you

$\langle \# 2:>$

$<\# 3: \mathrm{G}>$ know [name] who was a /[position] $\backslash=$

$<\# 4: D>$

/hmml

$<\# 5: G>$

$=\mathrm{i}$ a few time i've said you're not /paid for that $=$

$<\# 6: D>\quad=/$ reminding her $\backslash$ you are not paid $/=$ 


\begin{tabular}{|c|c|}
\hline$\langle \# 7: G>$ & /yeah totally $\backslash / \mathrm{hmmmm \}$ \\
\hline$\langle \# 8: \mathrm{D}\rangle$ & $=$ you don't have to be /here on that dayl you \\
\hline$<\# 9:>$ & don't have to come to that /meeting $\mid=$ \\
\hline$\langle \# 10: \mathrm{G}\rangle$ & /exactly $\backslash / \mathrm{hmmm} \backslash$ \\
\hline$\langle \# 11: \mathrm{D}\rangle$ & $=$ you can just read the minutes $/ \backslash / \wedge \backslash$ you're \\
\hline$\langle \# 12:>$ & not paid for that i mean $=$ \\
\hline$\langle \# 13: G>$ & /hmmml \\
\hline$\langle \# 14: M>$ & //yeah》I \\
\hline$\langle \# 15: D>$ & $=$ and and and that $/ /+\|=$ \\
\hline$\langle \# 16: M>$ & //but peoplell \\
\hline$\langle \# 17: \mathrm{D}\rangle$ & $\{$ gazing at Michelle $\}={ }^{\circ}$ but $^{\circ \circ}$ people ${ }^{\circ \circ} \underline{\mathrm{do}}^{\circ \circ}$ that \\
\hline$<\# 18:>$ & because in language teaching you see the students \\
\hline <\#19:> & you know four times a week and and you get uhhh \\
\hline$<\# 20:>$ & you know $/ / /+\|||=$ \\
\hline$\langle \# 21: G>$ & /of course you do $\uparrow$ yes you ${ }^{\circ \circ} \underline{\mathrm{do}}^{\circ \circ} \backslash$ \\
\hline$\langle \# 22: M>$ & //but thenII \\
\hline$\langle \# 23: D>$ & $=()$ with them and that's why then you end up doing \\
\hline$<\# 24:>$ & more you know as $\mathrm{a}^{\circ}[\text { position }]^{\circ}=$ \\
\hline$\langle \# 25: M>$ & $=$ and at the same time probably what we all did \\
\hline$<\# 26:>$ & you said $\{$ changing tone of voice as if narrating $\}$ oh! \\
\hline$<\# 27:>$ & $\mathrm{i}$ have- $\mathrm{i}$ got my foot at $\uparrow$ university it's going to \\
\hline$<\# 28:>$ & be easier is but you know here is no future unless \\
\hline$<\# 29:>$ & you become an $\uparrow[$ position $]=$ \\
\hline$\langle \# 30: \mathrm{D}\rangle$ & $=$ yeah $/$ unless yes yes yes of ${ }^{\circ}$ course $^{\circ} \backslash$ \\
\hline$\langle \# 31: M>$ & lat the moment + so $\backslash$ people think \{ changing tone \\
\hline$<\# 32:>$ & of voice as if narrating $\}$ ok! i got i managed to get \\
\hline$<\# 33:>$ & into university that's the good s- the first step \\
\hline$<\# 34:>$ & that's great and schange of tone of voice, from \\
\hline$<\# 35:>$ & excited as if telling a story to pessimistic tone $\}$ \\
\hline$<\# 36:>$ & bu::t you know they'll have maybe they'll have to \\
\hline$\langle \# 37:>$ & find by themselves find out by themselves that $\mathrm{mmmm}$ \\
\hline$<\# 38:>$ & you know? they are going to do a lot of work and at \\
\hline$<\# 39:>$ & the end you know? it's not going to be valued $\uparrow o: r+i$ \\
\hline$<\# 40:>$ & don't know unfortunately i am very pessimistic but \\
\hline$<\# 41:>$ & mmmm... \\
\hline
\end{tabular}

Extract 12: minute 16:30 to $17: 23$

\begin{tabular}{|c|c|}
\hline$\langle \# 1: G>$ & the question is how well does it function and how \\
\hline$\langle \# 2:>$ & how is the standard going /to stay up the way \\
\hline$\langle \# 3:\rangle$ & it $\underline{\text { is } \backslash / /+}+\|=$ \\
\hline$\langle \# 4: D>$ & /is going to stay up yeah\ \\
\hline$\langle \# 5: R>$ & $/ / \mathrm{hmmll}$ \\
\hline$\langle \# 6: G>$ & $=$ because i mean if i see + i'm sure there are some \\
\hline$\langle \# 7:\rangle$ & phd students o:r you know? even some master students \\
\hline$\langle \# 8:>$ & or some honour students that will be that will be \\
\hline$\langle \# 9:>$ & $\uparrow$ great but ++ you know? $/$ like $\backslash++$ they might be they $=$ \\
\hline$<\# 10: M>$ & $/ \mathrm{hmmml}$ \\
\hline$\langle \# 11: G>$ & $=$ might be doing it for a ye:ar and then $\uparrow$ you $/$ know? \\
\hline$\langle \# 12:>$ & ${ }^{\circ \circ}$ you know? and umm then the next year ${ }^{\circ} \backslash=$ \\
\hline
\end{tabular}


$<\# 13: D>\quad$ /yeah to get a bit of money to to ehhh yeah yeah〉

$<\# 14: G>\quad=$ you get a really $\uparrow$ crappy one who you know? doesn't

$<\# 15:>\quad \uparrow \mathrm{know}$ what they are doing /o:r the other thing $\backslash++=$

$<\# 16: F, D>\quad /$ consistencyl $/{ }^{\circ}$ consistency ${ }^{\circ} \backslash$

$\langle \# 17:\rangle \quad=$ yeah $/{ }^{\circ \circ}$ and ${ }^{\circ \circ} \mid=$

$<\# 18: \mathrm{M}>\quad$ /and $+\mathrm{hmmml}$

$<\# 19: \mathrm{G}\rangle \quad=$ the other thing is that you know it

$<$ 20:> $\quad$ changes all the $\uparrow$ time

$\langle \# 21: M>\quad$ /and the problem is that if the want $\backslash$ more

$\langle \# 22:>\quad$ post graduate $=$

$<\# 23: D>\quad{ }^{\circ}$ ehh Frida what do you want to $\left.{ }^{\circ}\right) \backslash$

$<\# 24: M>\quad=$ students they are not going to get them like that

$<\# 25: G>\quad$ hmmm but maybe they'll just have to find- find it

$<\# 26:>\quad$ out the hard way that's the /i think that's the $\mid=$

$<\# 27: M>\quad /$ yeah that's right $l=$ and I think that's the-

$<\# 28: D>\quad /{ }^{\circ}$ and Frida do you say ${ }^{\circ}$

$\langle \# 29: \mathrm{R}>\quad /(\mathrm{)})$

$<\# 30: D>\quad{ }^{\circ} e^{\circ} h_{h h h}^{\circ \circ}$ i want to hear Frida, Frida you

<\#31:> don't say anything...

Extract 13: minute 21:20 to 21:58

$\langle \# 1: \mathrm{M}>\quad$...a:nd well maybe now it's time to move $\uparrow$ on and do

$\langle \# 2:>\quad$ something $\uparrow$ else you know yes i haven't $+\mathrm{i}$ haven't

$\langle \# 3:>\quad$ really been thinking when i was teaching here where am

<\#4:> $\quad$ igoing $/ / /$ no? $\backslash 1=$

$<\# 5: \mathrm{G}\rangle \quad / \mathrm{hmml}$

$<\# 6: D>\quad / / y e s$ yeahll \{general 'yes' echoes

$<\# 7: M>\quad$ well you know? bu::t=

$\langle \# 8: D\rangle \quad \quad={ }^{\circ} \mathrm{i}$ suppose ${ }^{\circ \circ}$ that yes $\mathrm{i}$ mean in a in a way when you

$\langle \# 9:>\quad$ are in this position you have ample opportunity to

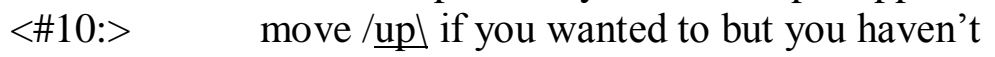

$\left\langle \# 11:>\quad\right.$ because there ${ }^{\circ}$ is ${ }^{\circ}=$

$<\# 12: \mathrm{G}>\quad / \mathrm{hmmml}$

$<\# 13: \mathrm{M}>\quad=/{ }^{\circ}$ or maybe because ${ }^{\circ} \backslash /$ or because $l=$

$\langle \# 14: D\rangle \quad \quad \quad{ }^{\circ}$ if there were i mean i'm i'm ${ }^{\circ} \backslash\{$ in a very high

$\langle \# 15:>\quad$ pitch, leaning back

$<\# 16: M>\quad=$ we our our character we're no ambitious people in

$\langle \# 17:\rangle \quad$ the sense of ambitious to climb //a ladder $\backslash$ \{Martina

$<\# 18:>\quad$ laughs nervously\}

$\langle \# 19: \mathrm{G}\rangle \quad / /{ }^{\circ}$ but the thing is that we're $\uparrow$ doing what we like

$<\# 20$ : $\quad$ doing ${ }^{\circ} \|=$

$<\# 21: D>\quad / /$ no no but $\mathrm{i}$ want to teach yeahll \{whispering

$<\# 22:>\quad$ that's right $\mathrm{i}$ want teaching positions

$<\# 23:>\quad$ idon't want a research

$<\# 24:>\quad$ position \{smiling, her palms up pointing at Greta

$<\# 25: \mathrm{M}>\quad /{ }^{\circ}$ that's right ${ }^{\circ} \backslash$

$\left\langle \# 26: G>\quad=/^{\circ \circ}\right.$ exactly $^{\circ} \backslash$ i mean $\mathrm{i}$ can do a phd but i don't

$<\# 27:>\quad$ want to $+/ / /$ posh papers $l=$

$<\# 28: \mathrm{Ma}>\quad$ /end up like that 
$<\# 29: \mathrm{G}\rangle \quad=$ =/like that you know? i don't want to $\backslash \mathrm{II}$

<\#30:D> //yeah yeah no no no no no no noll \{leaning back

$<\# 31:>\quad$ and smiling

$<\# 32: \mathrm{R}>\quad$ they're published papers yeah i mean they are

$<\# 33:>\quad$ actually not $\backslash$ relevant $i$ mean to the teach- what

$<\# 34:>\quad$ they did is not related to language teaching at all

$\langle \# 35$ :> $\quad$ so not relevant so so + ...

Extract 14: minute 24:30 - 24:50

\begin{tabular}{|c|c|}
\hline$\langle \# 1: G>$ & ...yes but you know? they're they're exactly like \\
\hline$<\# 2:>$ & $\uparrow$ you / \you know? not passionate enough about the fact \\
\hline$\langle \# 3:>$ & to actually push it $\uparrow$ through because you know? if it \\
\hline$\langle \# 4:>$ & was something else like if you wanted to $/ \backslash$ get a get a \\
\hline$\langle \# 5:>$ & umm get another lecturer /you know? $=$ \\
\hline$\langle \# 6: D>$ & $/ \mathrm{hmm} \backslash /$ yeah $\backslash /$ yeah $\backslash$ \\
\hline$\langle \# 7:\rangle$ & you would be $\uparrow$ pushing it or /if you wanted more money \\
\hline$\langle \# 8:>$ & for your bloody research, you know? ${ }^{\circ}$ you would be \\
\hline$\langle \# 9:>$ & pushing it $^{\circ}$.. \\
\hline$<\# 10: D$ & / yeah 'that's what they’ve been doing for the \\
\hline \#11 & [name] department yeahำ \\
\hline
\end{tabular}

Extract 15: minute 29:07 - 29:25
$\langle \# 1: \mathrm{G}\rangle \quad$...because $\mathrm{i}$ think we discussed this because i said you
$\langle \# 2:>\quad$ know? like + we've got more students than /you know?=
$\langle \# 3: D>\quad$ leverl
$\langle \# 4: G\rangle \quad=$ =from years before and we /had to you kno:w? sort
$\langle \# 5:>\quad$ of uhhh $\quad$ have extra tutorials and /stuff like that
<\#6:> $\quad{ }^{\circ}$ but apparently ${ }^{\circ} \backslash=$
$<\# 7: D>\quad$ /yeah yeah $\backslash /$ but it it could have been yeahl
$\langle \# 8: G\rangle \quad=$ that's the the the cap still because it was they they
$<\# 9:>\quad$ set this cap when it was a really high $/+\backslash /$ high
<\#10:> $\quad{ }^{\circ}$ enrolment but ${ }^{\circ}-1$
$<\# 11: D>\quad /$ level $\backslash /$ but you see $\backslash$ are we talking about maybe
$<\# 12:>\quad$ it could be the case because I do have the feeling
<\#13:> that we have more students...

Extract 16: minute 38:00 - 38:35
$\langle \# 1: \mathrm{G}\rangle$
...i mean for second year for example is umm that ++
$\langle \# 2:>$
the [position] doesn't say you're doing this in you
$\langle \# 3:>$
class and you're doing this in your class and you're
$\langle \# 4:>$
doing this in your class yeah? it's more uh like Frida
$\langle \# 5:>$
focuses on ahh speaking a:nd listening in the av
$\langle \# 6:>$
classes for second $/ \uparrow$ ye:ar $\backslash$ and she looks for their mat-
$\langle \# 7:\rangle$
her own $/ \uparrow$ material $\backslash$ and you know? deals /you know? $=$
$\langle \# 8: D>$
$/ \mathrm{mm} \backslash /$ yeah $\backslash / \mathrm{mm}$ yeah
$\langle \# 9: G\rangle$
=finds her own materials and puts it in a certain way
$\langle \# 10:>$
/to do it ${ }^{\circ \circ}$ and i do the same ${ }^{\circ \circ}$ 
$<\# 11: G>\quad$ /but you see they're they're quite happy to do $\backslash$ that

$\langle \# 12:>\quad$ and they /would not have called it as।

<\#13:> $\quad / /[$ course] design $\|=$

$<\# 14: \mathrm{G}>\quad /$ that's the ${ }^{\circ \circ}$ thing ${ }^{\circ \circ} \mathrm{mm}^{\circ}$ yeah $^{\circ}$

$<\# 15: \mathrm{F}\rangle \quad \quad \quad /{ }^{\circ}$ no that's not course design that's part of

$\langle \# 16:\rangle \quad$ the teaching ${ }^{\circ} 11$

$<\# 17: D>\quad=$ they would call it as $/() \backslash$ you know?=

$<\# 18: G>\quad{ }^{\circ \circ}$ that why ${ }^{\circ \circ}{ }^{\circ}$ yeah ${ }^{\circ}$

$<\# 19:>\quad=$ that when you've got $/$ a [position] a fourth $\backslash$ year

<\#20:> student uhh in /in uhhl...

$<\# 21: \mathrm{F}\rangle \quad /{ }^{\circ}$ that's preparing your class ${ }^{\circ} \backslash /$ well that's

$<\# 22:>\quad$ what they call it $\backslash$

Extract 17: minute 40:27 - 41:00

$\langle \# 1: D>\quad$...but there's a there's a i mean that's what i do $\mathrm{i}$

$\langle \# 2:>\quad$ mean $(. .$.$) each it's got a folder every \uparrow$ week and

$\langle \# 3:>\quad$ tells uh exactly what to do there's the transparencies

<\#4:> /there's all sorts of material $\mathrm{uh}=$

$<\# 5: G>\quad$ /yeah yeah mmm ${ }^{\circ}$ exactly ${ }^{\circ}$ yeahl

$<\# 6: D>\quad$ tell her where to find the /sound files bla bla

$\left\langle \# 7:>\quad{ }^{\circ}\right.$ bla ${ }^{\circ \circ}+$ that's what a [position] $l=$

$\langle \# 8: G\rangle \quad \quad \quad{ }^{\circ \circ}$ and that's what a [position] $\downarrow \underline{\text { does }}$ i totally $\downarrow$ agree $^{\circ \circ} \backslash$

$<\# 9: D>\quad=$ if they have to /

<\#10:> to /find $\backslash$ flexibility obviously /because $\backslash$ the: $(\ldots)=$

$<\# 11: \mathrm{G}\rangle \quad / \mathrm{mm} \backslash / \mathrm{mm} \backslash /{ }^{\circ}$ true ${ }^{\circ}$

$\langle \# 12:>\quad=$ but they don't have to design what's the session

$\langle \# 13:>\quad$ if you say you the objective is the future $/ \uparrow$ tensel

$\langle \# 14:>\quad$ they do not have to design a series of cre-

<\#15:> /activities $\backslash$ to do ${ }^{\circ 0}$ that $^{\circ \circ}=$

$<\# 16: \mathrm{G}>\quad / \mathrm{mmm} \mathrm{mmm} \backslash$ /exactlyl

$<\# 17: D>\quad=$ it's already done eh: done for them...

Extract 18: minute 42:05 - 43:08

$\langle \# 1: \mathrm{G}\rangle \quad$...and ${ }^{\circ \circ} \underline{\underline{j}}^{\circ \circ}$ would you know? $\underline{\mathrm{i}}$ would read up on the

$\langle \# 2:>\quad \uparrow$ grammar that you know? when it says future $\uparrow$ tense

$\langle \# 3:>\quad$ i $\quad$ would read $\uparrow$ up or you know? i'll go to the $\uparrow$ lecture

$\langle \# 4:>\quad$ where they $\uparrow$ explain you know how that works and you

$\langle \# 5:>\quad$ know? / i'll read-l

$<\# 6: D>\quad$ /but you got to $\backslash$ design so activities that they uh:

$\langle \# 7:>\quad$ /you know? in groups or-।

$<\# 8: G>\quad$ /no that's what myl ${ }^{\circ}$ lecturer ${ }^{\circ \circ}$ will be doing because

$<\# 9:>\quad / / a s$ a $\uparrow[$ position]-II $\{$ laughs nervously $\}$

$<\# 10: D>\quad / /$ but but $1 \backslash$ in $\mathrm{f}$ - in the [name] programme as a

<\#11:> $\quad \uparrow[$ position] they will they will not give it to you

$\langle \# 12:>\quad$ they will tell you the objective /is you can talk

$\left\langle \# 13:>\quad\right.$ about + the future ${ }^{\circ \circ} \underline{\text { life }}^{\circ \circ}$ and then you have $\downarrow$ to $\backslash$

$\langle \# 14: G\rangle \quad$ /yeah but $i$ think + but $i$ think there is there is $(. .$.

$\langle \# 15:>\quad$ hmm $\backslash$ that's then that's where the negotiation

<\#16:> has to $\uparrow$ happen because i mean i don't want [name] 
$\langle \# 17:>\quad$ to tell me what $\mathrm{i}$ do in my class $\mathrm{i}$ think this /is

<\#18:> you know i do you know? like i'm-

$<\# 19: D>\quad$ you know what to $\uparrow \underline{d o} \backslash$ but don't you think that

<\#20:> because you actually knew and you prepared the work

$\langle \# 21:>\quad$ you should be $\uparrow$ rewarded

$\langle \# 22: \mathrm{F}\rangle \quad{ }^{\circ}$ yeah $^{\circ}$

$<\# 23: G>\quad$ that's my $\uparrow$ point that's what i'm saying you know?

$<\# 24:>\quad$ if $\mathrm{i}$ mean $\mathrm{i}{ }^{\circ}{ }^{\circ}$ prefer $^{\circ \circ}$ the way it goes... 


\title{
Appendix C
}

\section{Interviews Information Sheet}

\author{
VICTORIA UNIVERSITY \\ OF WELLINGTON \\ Te Whare Wananga o te Upoko \\ o te Ika a Maui

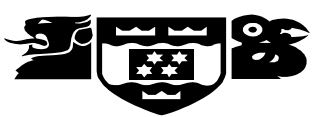 \\ MA Project: LALS 584 \\ Mariana Lazzaro
}

\section{Information}

In this interview you will watch a video replay of extracts from the two meetings you recently attended. The videotape will provide a visual and aural stimulus for you to answer the researcher's questions. (For details about the project please see Project Information Sheet, which will be provided to participants in this instance as well.)

\section{Your task}

3. You will watch a series of extracts of the meeting containing simultaneous speech events. For each extract you will be asked to comment on how you felt when you were overlapped by another participant, or why you overlapped other participants. It is very important that you comment on what you recall you felt or thought at the time of the event.

4. There are no wrong answers in this interview. If you cannot remember what you felt at a given moment of the meeting or why you overlapped, why there was simultaneous speech, that is okay. I would rather you were honest and say little or nothing, in case you do not remember anything about an event, rather than create an explanation.

5. You can answer the questions orally or by writing them down. If you decide to answer the questions orally, your voice will be recorded. If you decide to do write them down, the researcher will provide you with an answer sheet.

Please pause the video at any point you think convenient to elaborate/comment on the question. The researcher may also stop the tape at times to ask questions. You can also replay the extracts as many times as you think necessary. 


\title{
Appendix D
}

\section{Project Information}

\author{
VICTORIA UNIVERSITY \\ OF WELLINGTON \\ Te Whare Wananga te Upoko \\ o te Ika a Maui

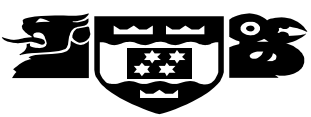

MA Project: LALS 584

Mariana Lazzaro

\begin{abstract}
About the project
Traditionally, the literature on intercultural communication has focused its analysis on instances of miscommunication. However, the goal of this research project is to describe how people of different cultures communicate effectively with each other.
\end{abstract}

\section{What will the researcher do?}

To achieve this aim, three meetings will be video and audio recorded. Following this, selected participants will be asked to take part in an interview the day after the meeting. In this instance, participants will be invited to comment on extracts from the meetings in order to facilitate and/or triangulate the researcher's understanding of what is going on. In other words, participants will be asked to recall and comment on certain sequences in the meetings. Thus, if participants agree to be videotaped, the videotapes will facilitate the recall process providing visual and aural stimulus for participants. Moreover, relevant sections of those meetings will be transcribed to analyse communication patterns. In the analysis the focus will be on intercultural communication strategies rather than the content of the interaction. Real names will be replaced with pseudonyms to protect your identity.

\section{What will the data be used for?}

The recordings and other information I collect from you will be used only for the purposes of this MA research, and publications and presentations based on this research.

\section{Who will have access to the data?}

All recordings and other information collected as part of this project will be stored securely at Victoria University. Only my supervisor, Dr Meredith Marra, and I will have access to this material. We will not play any recordings to other staff or managers in your organisation. Nothing will be reported back to management after the meeting or discussed with anybody inside or outside the School. All the data collected is completely confidential and will be destroyed two years after collection. You are free to withdraw your consent until the end of the data collection process.

Thank you for taking the time read this information sheet. Should you have any queries regarding this project please feel free to contact me or my supervisor. 


\section{Appendix E}

\section{Background information and consent form}

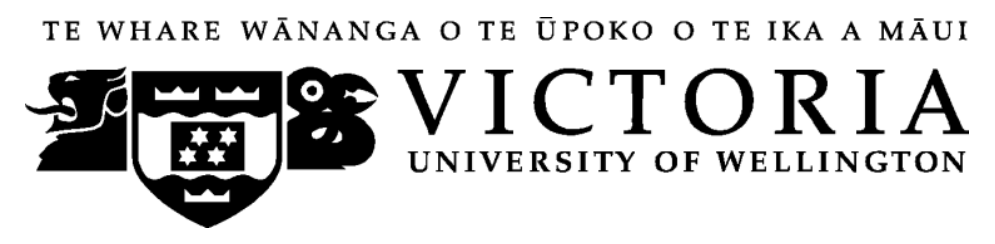

MA Project: LALS 584

\section{Mariana Lazzaro}

Q Were you born in New Zealand?

Yes

No

2. If no, (a) where were you born?

(b) at what age did you come to New Zealand?

c) (a)

Have you been overseas in the last 3 years?

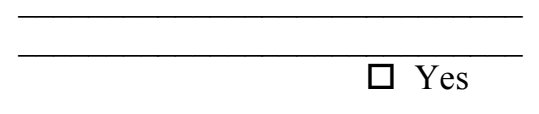

No

(b) If yes, for how long were you overseas in the last 3 years?

4. How long in total have you spent overseas during your life?

5. Which language(s) did you speak in your home before starting school?

6. Gender:

7. Circle your age group:

under $20 \quad 20-24$

$35-39 \quad 40-44$

$55-59 \quad 60-64$

8. Which ethnic group(s) do you identify with? (e.g. Maori)

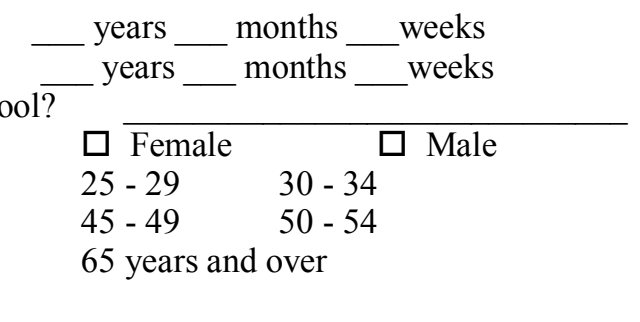

9. How long have you been working in this institution?

10. How long have you been a member of your particular team?

11. Do you use another language at work? If yes, which language(s)?

(Please describe proficiency e.g. fluent, good, fair, minimal)

I give permission for video recording $\square$ and audio recording $\square$ two meetings I will attend, and associated transcription to be used for research purposes and I understand that my identity will not be disclosed.

Signed: Print Full Name: Date:

In case I am asked to participate in a follow-up interview, I give permission for audio recording the interview and associated transcription to be used for research purposes and I understand that my identity will not be disclosed.

Signed: Print Full Name: Date: 